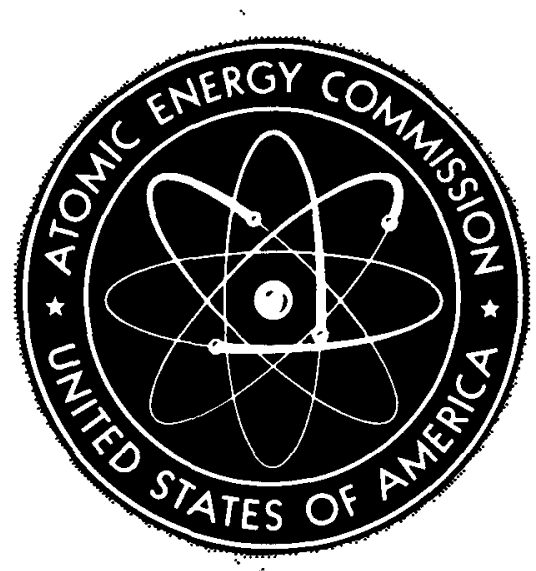

SAN-679-1

ELECTRICAL COMPONENT TECHNOLOGY

FOR 0.25 TO 10.0 MEGAWATT SPACE

POWER SYSTEMS

DESIGN STUDY

Quarterly Technical Progress Report No. 1

September 1 - November 30, 1966

Edited by

A. E. King

August 1967

[DTIE Issuance Date]

Aerospace Electrical Division

Westinghouse Electric Corporation

Lima, Ohio 


\section{DISCLAIMER}

This report was prepared as an account of work sponsored by an agency of the United States Government. Neither the United States Government nor any agency Thereof, nor any of their employees, makes any warranty, express or implied, or assumes any legal liability or responsibility for the accuracy, completeness, or usefulness of any information, apparatus, product, or process disclosed, or represents that its use would not infringe privately owned rights. Reference herein to any specific commercial product, process, or service by trade name, trademark, manufacturer, or otherwise does not necessarily constitute or imply its endorsement, recommendation, or favoring by the United States Government or any agency thereof. The views and opinions of authors expressed herein do not necessarily state or reflect those of the United States Government or any agency thereof. 


\section{DISCLAIMER}

Portions of this document may be illegible in electronic image products. Images are produced from the best available original document. 


\section{LEGAL NOTICE}

This report was prepared as an account of Government sponsored work. Neither the United States, nor the Commission, nor any person acting on behalf of the Commisslon:

A. Makes any warranty or representation, expressed or implied, with respect to the accuracy, completeness, or usefulness of the information contained in this report, or that the use of any information, apparatus, method, or process disclosed in this report may not infringe privately owned rights; or

B. Assumes any liabllities with respect to the use of, or for damages resulting from the use of any information, apparatus, method, or process disclosed in this report.

As used in the above, "person acting on behalf of the Commission" includes any employee or contractor of the Commission, or employee of such contractor, to the extent that such employee or contractor of the Commission, or employee of such contractor prepares, disseminates, or provides access to, any information pursuant to his employment or contract with the Commission, or his employment with such contractor.

This report has been reproduced directly from the best available copy.

Printed in USA. Price $\$ 3.00$. Available from the Clearinghouse for Federal Scientific and Technical Information, National Bureau of Standards, U. S. Department of Commerce, Springfield, Virginia 22151. 
Quarterly Technical Progress Report No. 1

DESIGN STUDY
ELECTRICAL COMPONENT TECHNOLOGY FOR 0.25 TO 10.0 MEGAWATT
SPACE POWER SYSTEMS

November 30, 1966

Edited by:

a.

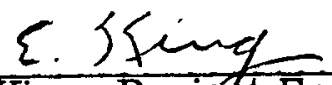

A. E. King, Project Engineer Liquid Metal Development Section

Approved by:

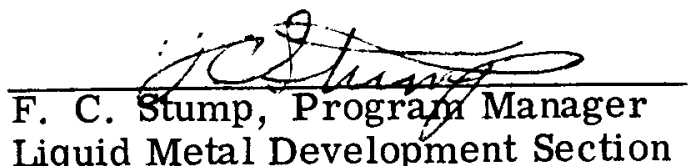

Liquid Metal Development Section

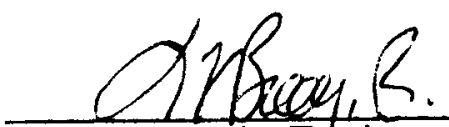

N. W. Bucci, Engineering Manager Systems R \& D Department Aerospace Electrical Division Westinghouse Electric Corporation

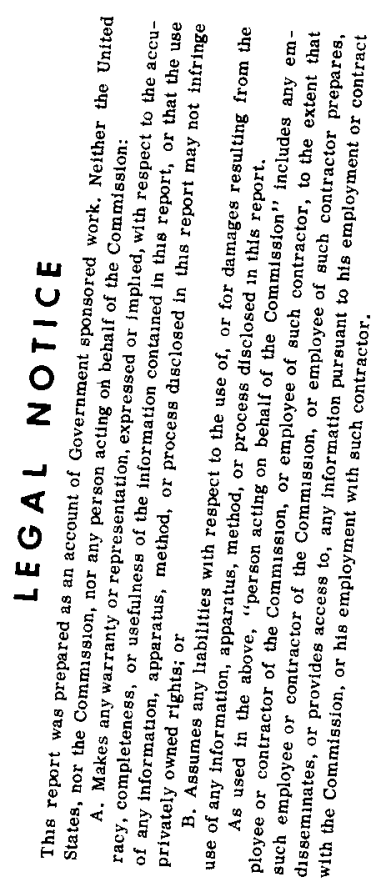

Prepared Under

Contract A T(04-3)-679

for the

San Francisco Operations Office

U. S. Atomic Energy Commission 


\section{FOREWORD}

This Quarterly Technical Progress Report describes work under contract to the United States Atomic Energy Commission from September 1, 1966 to November 30, 1966, on a Design Study of Electrical Component Technology for 0.25 to 10 Megawatt Space Power Systems.

The work is directed toward defining representative Rankine nuclear space power electrical systems, the electrical components therein and their development problems. The work was conducted by the Westinghouse Electric Corporation, Aerospace Electrical Division under contract AT(043) -679 administered by the USAEC San Francisco Operations Office. Technical liaison is maintained with the USAEC Division of Space Nuclear Systems, Washington, D. C., Mr. G. S. Leighton, Liaison Officer, and with the Reactor Division of the San Francisco Operations Office, Mr. F. W. Hunton, Liaison Officer.

Members of the Westinghouse Systems Research and Development Department assisting in the preparation of this report include A. E. King, J. B. Fanger, T. C. Allen, D. R. Basel, R. C. Fear, R. D. Jessee, C. C. Kouba, J. L. McCabria, and E. F. Swiderski. 


\begin{abstract}
Background technology, design philosophies, and parametric screening study plans are presented on a-c generators, a-c motors, power conditioning and power distribution equipment for 0.25 to 10.0 megawatt space nuclear electric power plants utilizing the Rankine conversion cycle. The power conditioning and distribution equipment includes transformers, rectifiers, frequency changers, contactors and transmission lines. Radiation degradation of electrical components is considered. Progress on experiments to verify analytical techniques for inductor generator designs typical of high-power, high-speed, high-frequency, high-temperature applications is included.
\end{abstract}


CONTENTS

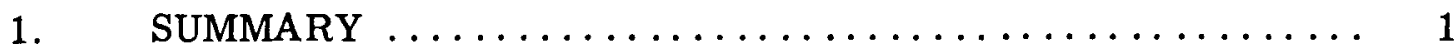

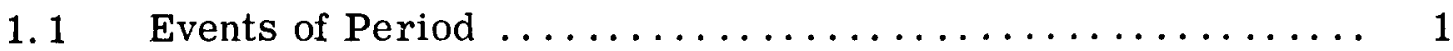

1.2 Forecast for Coming Period $\ldots \ldots \ldots \ldots \ldots \ldots$

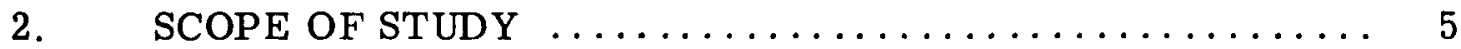

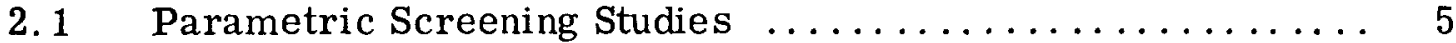

2.2 Conceptual Design Analyses $\ldots \ldots \ldots \ldots \ldots \ldots \ldots$

2.3 Experimental Verification $\ldots \ldots \ldots \ldots \ldots \ldots \ldots$

3. PARAMETRIC SCREENING STUDIES $\ldots \ldots \ldots \ldots \ldots \ldots \ldots$

3.1 Generator Parametric Study $\ldots \ldots \ldots \ldots \ldots \ldots \ldots \ldots \ldots \ldots$

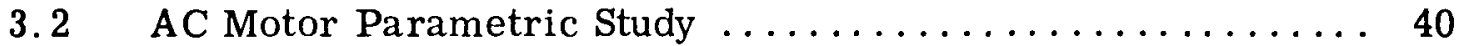

3.3 Power Conditioning Parametric Study ............. 79

4. SYSTEM DE FINITIONS $\ldots \ldots \ldots \ldots \ldots \ldots \ldots \ldots \ldots \ldots$

$4.1 \quad$ Electrical Load ........................ 111

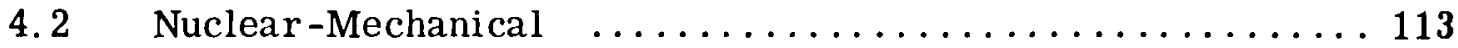

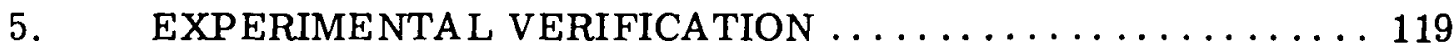

5.1 Magnetic Unbalance and Flux Distribution $\ldots \ldots \ldots \ldots \ldots \ldots 121$

5.2 Magnetic No-Load Loss Tests ................... 130

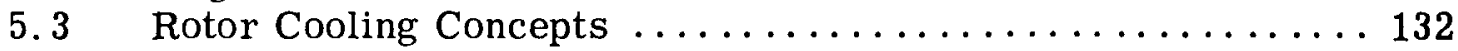

REFERENCES . . . . . . . . . . . . . . . . . . . . 139

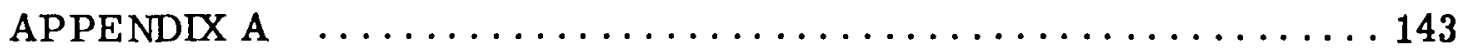

APPENDIX B $\ldots \ldots \ldots \ldots \ldots \ldots \ldots \ldots \ldots \ldots \ldots \ldots \ldots \ldots$ 
page blank 


\section{FIGURES}

3.1 Inductor Generator $\ldots \ldots \ldots \ldots \ldots \ldots \ldots \ldots \ldots \ldots \ldots \ldots \ldots$

3.2 Axial Gap Inductor Generator Configuration ........... 16

3. 3 Axial Gap Inductor $467 \mathrm{KVA}$ - 3040 CPS, 22, 800 RPM $\ldots . .17$

3.4 Radial Gap Inductor Generator $467 \mathrm{KVA}$ - $3040 \mathrm{CPS}$,

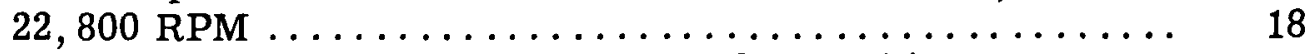

3.5 DC Magnetization Curves for Hiperco 27, 0.004 Inch

3.6 DC Magnetization Curves for Hiperco 27 Frame Forgings ... 24

3.7 Inductor Generator Hiperco 27 Stator Tooth Loss at $60 \mathrm{KL} / \mathrm{in}^{2}$,

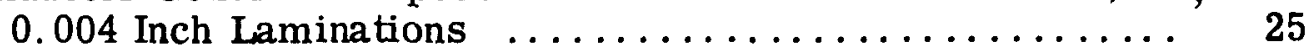

3.8 Inductor Generator Hiperco 27 Core Loss at $70 \mathrm{KL} / \mathrm{in}^{2}$, 0.004 Inch Laminations $\ldots \ldots \ldots \ldots \ldots \ldots \ldots \ldots . \ldots \ldots$

3.9 DC Magnetization Curves for $\mathrm{H}-11$ and Nivco Rotor Forgings ........................... 27

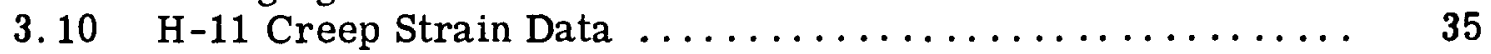

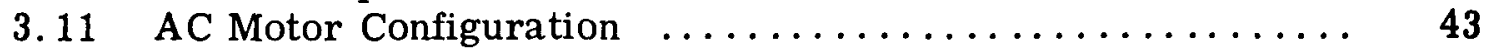

3.12 Stator Heat Transfer Paths $\ldots \ldots \ldots \ldots \ldots \ldots \ldots \ldots . . \ldots$

3.13 Thermal Conductance Across Metal Interfaces ........ 52

3.14 Rotor Heat Transfer Paths .................. 56

3.15 Simplified Flow Chart Strap Wound Induction Motor Design Computer Program ........................ 74

3.16 Per Phase Equivalent Circuit $\ldots \ldots \ldots \ldots \ldots \ldots \ldots \ldots . \ldots \ldots$

3.17 Power Circuit for a Typical Cycloconverter .......... 81

3.18 Through-The-Coil Cooling $\ldots \ldots \ldots \ldots \ldots \ldots \ldots \ldots \ldots . \ldots 2$

3.19 Between-The-Coils Cooling .................. 93

3.20 Three-Phase Rectifier-Bridge Assembly with Series Diodes in the Rectifier Legs . .................... 97

5.1467 KVA Experimental Generator ............... 120

5.2 Stator Test Fixture .......................... 123

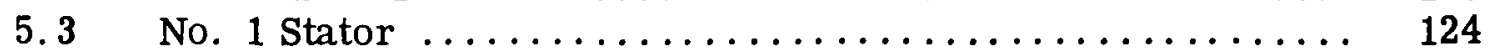

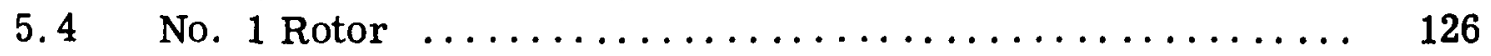

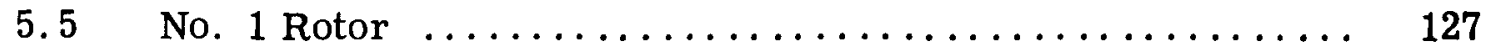

5.6 Stator Test Set-Up ....................... 128

$5.7 \quad$ Stator Test Assembly and Instrumentation $\ldots \ldots \ldots \ldots \ldots \ldots . \ldots \ldots$

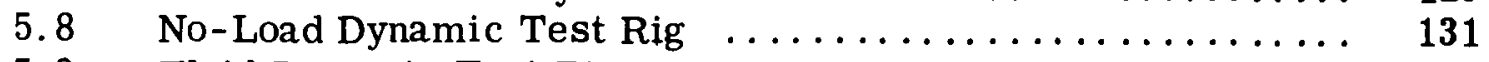

$5.9 \quad$ Fluid Dynamic Test Rig $\ldots \ldots \ldots \ldots \ldots \ldots \ldots \ldots \ldots \ldots \ldots$ 


\section{TABLES}

2.1 Summary of Design Study Tasks $\ldots \ldots \ldots \ldots \ldots \ldots \ldots \ldots$

3.1 Comparative Can Loss Data ................. 38

3.2 Materials Selection, AC Motors ................. 59

3.3 Parameter Ranges and Data Points for Frequency Changer

Parameter Evaluations .................... 83

3.4 Parameter Ranges and Data Points for Transformer Parameter Evaluations ....................... 87

3.5 Data Points for Evaluation of Three-Phase Rectifiers ...... 95

3.6 5 Kilovolt DC Silicon Diode Rectifier Assembly Systems . .. 99

3.7 Parameter Ranges and Data Points for Transmission and Distribution Evaluation $\ldots \ldots \ldots \ldots \ldots \ldots \ldots \ldots \ldots \ldots \ldots$

4.1 Summary of Estimated Electrical System Losses ....... 115

4.2 Summary of Estimated Electrical System Coolant Flows ..... 116

B. 1 Rectifier Circuit Configurations and Characteristics ...... 150 


\section{SUMMARY}

The Aerospace Electrical Division of the Westinghouse Electric Corporation has been under contract to the United States Atomic Energy Commission since September 1, 1966 to define conceptual designs of complete electrical power systems and the electrical components therein which are suitable for Rankine nuclear space power systems in the 0.25 to 10.0 megawatt range. Three representative missions - interplanetary, planetary, and orbital - have been specified in order that the conceptual defi nitions consider dependent design parameters typical of actual flight conditions. Work is being carried on in design studies and in associated analytical verification experiments.

The design studies are being carried out in two successive stages: (1) analytical screening studies to establish parametric data, optimum designs and design limitations for four power levels, and (2) detailed studies of selected configurations to determine the best conceptual design at each power level and the development problems associated with them. The electrical system componenents being studied are a-c generators, a-c motors, frequency changers, power conditioning equipment, power transmission and control equipment, and electrical system control and protection equipment. The results of the studies will be applicable to: (1) defining the component development effort required to realize mission capabilities and (2) aiding the electrical system designer and nuclear system planner in specifying the optimum electrical configuration for specific missions.

The analytical verification experiments are being carried out to evaluate the adequacy of certain analytical techniques for a-c generator design. The experiments are specifically directed toward evaluating magnetic unbalance forces, magnetic flux distributions, generator losses at no-load conditions, and rotor coolant flow concepts.

\subsection{EVENTS OF THE PERIOD}

Because of the undefined nature of space electrical systems and the desirability of selecting and analyzing parametric data for the most realistic systems possible, the majority of effort this first quarter has been the preparatory work to define necessary approaches, limitations and guidelines for the parametric screening studies. The importance of this information can not be slighted since the standards, definitions and 
assumptions arrived at can influence the parametric data and conclusions of the study. As a result of the attention given to review of design techniques, the emphasis of this particular quarterly progress report is on discussion and presentation of parametric information and the resulting standards (both constant and variable) to be used in the design programs. Plans outlining the selective screening procedures to be used in actually executing the parametric studies next quarter are also presented.

In most cases, the selection of design standards required verifying the applicability of previously developed values over the ranges to be studied. However, new materials developments, materials data and basic design improvement suggestions coming out of past liquid metal machinery development programs required additional evaluations.

Included in the work this quarter was the updating, expanding and improving of generator, motor and transformer design calculation techniques to include recent developments. These latest design calculations were added to the design programs wherever possible so that they will be a routine part of the parametric output.

The present status of the parametric studies is summarized below:

1. The parametric standards, ranges, etc., other than those to be specified during the actual execution of the parametric studies, have been selected.

2. Preliminary generator and motor computer designs have been completed to verify the design calculations, the selection of ranges, parameters, etc., and to determine and eliminate any unforeseen problem areas prior to running the parametric designs.

3. An approach was defined for power conditioning analysis that eliminates the complex interdependence of parameters by means of separate evaluations. Transformer computer design techniques are being modified to include high tem perature cooling configurations and 5000 volt rectifier preliminary designs have also been made.

4. Basic system definitions have been completed relative to selection of specific values of parameters to be studied; system definition studies are continuing now to determine detailed electrical and mechanical configuration information for the conceptual design comparisons.

5. Materials selections are being finalized and pertinent data are being tabulated.

6. Approaches were defined to adequately evaluate frequency changers and transmission and distribution components. Parameter ranges and basic design approaches have been determined. Design comparisons are continuing. 
In the analytical verification test programs, work is progressing either on or ahead of schedule in all areas. The static test components for the magnetic force and flux distribution tests were completed, assembled and checked out; static tests were initiated late in November and are proceeding according to plan. The design modifications necessary to convert the static test components to the no-load dynamic tests were completed and drawings are presently being prepared. Design modifications to convert the fluid dynamic test rig for the rotor flow experiments were completed and well over half of the actual hardware changes have already been made.

\subsection{FORECAST FOR COMING PERIOD}

Parametric screening studies will be completed on the generators, a-c motors, frequency changers and power transmission and distribution equipment. The electrical load systems and prime-mover configurations will be defined. Parametric screening studies on power conditioning will be nearly completed. This data will be compiled into topical reports and utilized in the Conceptual Design Analyses during the following quarter.

The magnetic force and flux distribution tests will be completed and the hardware modifications to no-load dynamic tests will be started. The rotor coolant flow experiments will be in progress. 
page blank 


\title{
2. SCOPE OF STUDY
}

The scope of the Design Study is summarized in the following section in order for the reader to better understand the extent of the work to be carried out and the relationships of the various work described in the following sections. There are three major tasks which contain a total of twelve separate but closely interrelated sub-tasks as listed below.

Table 2.1 Summary of Design Study Tasks

\author{
Parametric and Screening Studies \\ Power Uses and Missions Definition \\ Nuclear-Mechanical System Definition \\ Generator Parametric Study \\ AC Motor Parametric Study \\ Frequency Changer Parametric Study \\ Power Conditioning Parametric Study \\ Power Transmission and Distribution Study \\ Conceptual Design Analyses \\ Electrical System Definition \\ Conceptual Design Analysis and Layout \\ Experimental Verification (generator only) \\ Experimental Evaluation of Magnetic Unbalance \\ Forces and Flux Distribution \\ Experimental Evaluation of No-Load Losses \\ Experiments Associated with Rotor Cooling Concepts
}

Summary descriptions of the sub-tasks are presented below:

\subsection{PARAMETRIC AND SCREENING STUDIES}

\subsubsection{Power Uses and Missions}

The mission requirements and environmental conditions that affect electrical component designs are included in the selection of the design conditions for three classes of missions: 
1. interplanetary mission (electrical propulsion)

2. manned earth orbital, and

3. lunar or planetary base.

Basic specifications for each class of mission are being provided by the Contracting Office from which Westinghouse Aerospace Electrical Division will determine the relative magnitudes of a-c and d-c power, voltage levels, bus configurations etc. to be selected for the Conceptual Designs.

\subsubsection{Nuclear-Mechanical System Definition}

The requirements and limitations imposed on the electrical components by the prime mover system and associated equipment are included in the selection of the design conditions. Particular emphasis is being placed on determining the electrical component requirements relative to system considerations such as:

1. system/component weight penalty per kilowatt of loss,

2. turbine limiting speed,

3. turbine-generator integration,

4. load transients and prime mover response rate,

5. system pumping requirements,

6. radiation levels,

7. radiator penalties and low temperature cooling limitations, and

8. weight and volume limitations.

\subsubsection{Generator Parametric Study}

The five major system parameters to be evaluated relative to generator weight, efficiency, versatility and technology available a re generator rating, speed, frequency, output voltage, and coolant temperature. The optimum (lightest, most efficient and practical) combination of frequency, speed and voltage will be determined for four MVA ratings. Rather than arbitrarily examining all possible combinations, an interative (recycling) process is being applied whereby the specific parameters will be determined in as few combinations as possible. The selection of designs for study in later tasks will be based on the ability of the generator design configurations to fulfill recognized design limitations. Two designs which are representative of the best designs above and which have hot spot temperatures in excess of $1100^{\circ} \mathrm{F}$ will be analyzed using advanced $\left(1500^{\circ} \mathrm{F}\right)$ materials to evaluate possible weight and efficiency benefits. One design which is representative of the best designs above will be analyzed using $1400^{\circ} \mathrm{F}$ coolant to evaluate possible weight and efficiency benefits. 


\subsubsection{AC Motor Parametric Study}

Parametric studies will be conducted for 3-phase induction motor electromagnetic components over a specified range of approximately 5-250 horsepower. These motors are expected to be used primarily for driving liquid metal circulating pumps. Secondary use considerations include fulfilling the Power Uses and Mission requirements. Motor parameters of particular interest include weight, efficiency and power factor as affected by operating voltage, frequency, speed and cooling temperature. The selected operating frequencies are those obtainable from a static frequency changer as evaluated in the sub-task below and those coincident with the generator output frequencies.

The resulting parametric data will be in a form that it can be easily combined with centrifugal-pump data in order to assess the relative applicability and technological problems of these pump packages when compared to static electromagnetic pumps.

\subsubsection{Frequency Changer Parametric Study}

Parametric studies will be conducted on three-phase frequency changers to operate primarily with the a-c induction motors and electromagnetic pumps. Secondary consideration will be given to configurations capable of supplying the requirements defined for the Power Uses and Missions. Frequency changer characteristic data includes weight, efficiency, and maximum cooling temperature limitations based on existing state-of-the-art semiconductors and other static components. Design analyses will be performed on operating multiple low-power frequency changers in parallel to obtain higher power levels and will include evaluations of parallel operations, real-power load division, and reactive-power load division.

Three frequency changer designs will be evaluated using high-temperature gas and/or vapor tubes and other advanced high-temperature components such that direct comparisons can be made between low-temperature and high-temperature frequency changers.

\subsubsection{Power Conditioning Parametric Study}

Parametric studies will be conducted on power conditioning components for use in power systems rated in the range of 0.25 to 10 mega watts with primary emphasis placed on single-phase and three-phase transformers as well as three-phase rectifiers. Expectations are that transformer ratings up to several megawatts will be required for three-phase transformers and up to one megawatt for single-phase transformers. Three-phase rectifier systems will be evaluated for d-c voltage levels up to approximately 30,000 volts in anticipation of the Power Uses and Mission requirements. 
Parametric data includes weight, efficiencies and cooling temperature limitations for various power and voltage levels and for both semiconductor and gastube rectifiers.

A compilation and evaluation of existing data on radiation effects to power conditioning components will be performed for the purposes of summarizing the applicability of this data to megawatt power conditioning equipment.

\subsubsection{Power Transmission and Distribution Study}

Studies will be performed on electric power transmission lines to define parameiric data on weights, power losses, impedances, operating temperatures and cooling requirements for both $\mathrm{d}-\mathrm{c}$ and a-c power and for conductor geometries and spacing considerations at power levels up to 10 mega watts. Voltages up to 30,000 volts for $d-c$ systems and up to 20,000 volts for a -c systems will be considered unless the definitions from the Power Uses and Missions indicate otherwise.

\subsection{CONCEPTUAL DESIGN ANA LYSES}

\subsubsection{Electrical System Definition}

Electrical system configurations will be analyzed for four power levels in the range of 0.25 to 10 megawatts. Relative magnitude of a $-\mathrm{c}$ and $\mathrm{d}-\mathrm{c}$ power, voltage, bus configurations, etc., will be selected to provide power as required for the Power Uses and Missions. Consideration will also be given to parallel operation of a-c busses, d-c busses, load division, unbalanced loading, electrical faults, etc., in order to provide guidance for electrical system component technology developments.

Design analyses will be performed on possible circuit configurations for supplying inductor generator field power of approximately 3-100 kilowatts. Special attention will be given to selecting generator excitation control systems that are capable of functioning when multiple generators are connected in parallel.

Concepts will be defined for controlling real and reactive load division in parallel systems, for sensing and isolating electrical faults, for transferring essential mission loads to unfaulted electrical busses, for supplying sudden increases or decreases in electrical loads and for supplying high quality electric power at closely-regulated voltages and frequencies.

\subsubsection{Conceptual Design Analyses}

By screening the component configurations studied in the above parametric study, optimum configurations will be selected for generators, a-c motors, frequency changers, power conditioning and power transmission and distribution equipment. At least one of the optimum configurations 
present in each rating will be studied and further evaluated such that a complete conceptual layout design of the configuration can be made of sufficient dimensional detail for a weight-breakdown analysis. The designs of the components in the layouts will be optimized relative to weight, losses, minimum fabrication complexities and state-of-development of the hardware concepts.

\subsection{EXPERIMENTAL VERIFICATION}

\subsubsection{Experimental Evaluation of Magnetic Unbalance Forces and Flux Distribution}

A static magnetic mockup is being prepared using available generator components from the previous $467 \mathrm{kva}$ experimental generator development program.* The mockup is fitted with search coils to measure magnetic flux levels at a minimum of eighteen different locations within and external to the magnetic circuit. The magnetic unbalance forces and torques created by an eccentric and misaligned rotor and stator will also be measured. The measured forces, torques and flux distribution, both useful and leakage, will be compared with design predictions to verify present analytical calculation techniques and indicate where improvements might be appropriate.

\subsubsection{Experimental Evaluation of No-Load Losses}

The static mockup of the above experiments will be modified to permit dynamic operation using water cooling and oil-lubricated bearings. The experiments will be conducted to measure the no-load losses (pole face, magnetic and field coil) and corresponding temperature distributions at constant speed. The measured data will be compared with the analytically calculated predictions and with the available materials data to verify its adequacy and indicate appropriate improvements.

\subsubsection{Experiments Associated with Rotor Cooling Concepts}

The flud dynamic test rig from the same Air Force Contract** is being modified to include a rotor with radial flow pole passages for the rotor coolant. Experiments will be run with "easy-fluids" that simulate a potassium rotor coolant and will determine rotor flows, pressures and temperatures as a function of speed.

*Task 2.4.4, Full Scale Generator, SNAP-50/SPUR Contract

AF33(615)-2326. See Figure 5.1, page 120.

**Task 2.4.3, Rotor Development, SNAP-50/SPUR Contract A F33(615)-2326. 
page blank 


\title{
3. PARAMETRIC SCREENING STUDIES
}

\section{1 GENERATOR PARAMETRIC STUDY}

\begin{abstract}
During the first quarter, all preparatory work necessary for initiation of the generator design studies was completed. Applicable background and reference data was reviewed and the required information extracted. The radial air-gap inductor generator configuration was verified as best suited to space power applications. The inductor generator design calculations were reviewed, updated, and past designs were recalculated to verify the improvements. Electrical, mechanical, and cooling circuit parameters, both variable and constant, were selected for use in the parametric studies. Materials requirements were established and generator materials selected. Plans for completing the parametric studies were reviewed and finalized.
\end{abstract}

\subsubsection{Technical Discussion}

(a) Review of Background Data. A review of the data obtained and the conclusions reached on previous space generator programs and materials programs proved useful in establishing material choices, electrical and mechanical design parameters, and the parametric study approach and procedures. The previous generator programs were the SNAP -50/SPUR Generator Studies (1)* (USA F Program 675A), the NASA Generator Parametric Study (2) (NAS 5-1234), and in-house construction and test of a 50 $\mathrm{KW}$ inductor generator model. The materials programs were Contracts NAS 3-4162(3), (4) and NAS 3-6465 (35).

The SNAP-50/SPUR generator studies dealt in detail with electrical, mechanical, and thermodynamic circuit design, materials, fabrication techniques and anticipated performance of a 467 KVA inductor generator with a $600^{\circ} \mathrm{F}$ liquid-metal coolant. Data utilized from this program included (1) choice of internal electrical parameters, (2) rotor materials, (3) manufacturing tolerances, (4) cooling circuit design techniques, and

(5) calculation of pole face losses.

*Superscript numbers in parentheses refer to references listed at end of report. 
The NASA parametric study involved calculation of some 400 liquid-metal cooled inductor generator designs covering a range of ratings from $250 \mathrm{KW}$ to $10 \mathrm{MW}$. Since this generator parametric study was completed in December 1962 , a number of modifications and refinements have been made to improve the Westinghouse inductor generator design calculation techniques and programs. A more precise flux plotting method has been adopted for use in the computer routine and additional leakage fluxes have been taken into account. Recently verified pole face loss calculation techniques and rotor stress and cooling design calculations were added to improve routines relative to rotor design.

Results of the NAS 5-1234 study provided a basis for choosing internal electrical parameters and for establishing the parametric study approach and procedures for the present program.

The Westinghouse in-house program for construction and test of a $50 \mathrm{KW}$ inductor generator model (5) served to verify the inductor generator design program as well as provide experience in actual inductor generator construction.

The topical reports from NASA Materials Program, NAS 3-4162, provided the required information for selecting generator conductor, insulation, magnetic, and structural materials as discussed in detail in following sections of this report. Information gathered on a current electrical materials program, NAS 3-6465, is also being utilized as it becomes available.

(b) Generator Configuration. The following criteria (1), (2) were used to choose the generator configuration best suited to space power applications:

(1) To reduce system complexity, the generator must be directly coupled to the turbine. This indicates a high speed generator since high speed turbines have suitable operating efficiencies and the weights of both turbine and generator decrease as speed increases.

(2) Means must be provided for removing the power losses developed within the generator. Pure radiation cooling is usually inadequate to maintain operating temperatures below the Curie point of the magnetic material; also, operating temperatures are limited by the allowable material stresses in the high speed rotors. Some fluid must be circulated through the generator to transfer the losses.

(3) Brushes should not be used because of extreme temperature, speed, and environmental conditions.

(4) Rotating windings are not desirable because, at high speeds, rotor stresses will be high. If windings were placed on the rotor, severe problems could result. For example, creep of the metallic conductors could crack the insulating (ceramic) coating, thus exposing the conductors to the potassium vapor present in the generator cavity. The windings and associated wedging would increase mechanical stresses during rotation. Shift of the rotating windings would create rotor unbalance and, hence, severe bearing loading. Containment of the rotor end windings also poses problems. 
(5) Cantilevered, inter-spaced Lundell-type pole configurations should not be used because of the resulting high rotor stresses which occur at high speeds and the high rotor flux leakage between adjacent poles.

(6) Permanent magnet excitation is not desirable for large ratings because of the low mechanical strength and low flux density capabilities of permanent magnets and because of the voltage regulation problems of permanent-magnet generators.

Inductor generators are most suitable based on the above criteria. The following discussion compares axial and radial gap inductor generators and shows why the radial gap machine was chosen as best suited for space power generation.

In the radial gap inductor generator there are two stator stacks, each of which contains a common a-c output winding. There are essentially two, toothed rotors mounted on a common shaft and a toroidal d-c field winding placed between the two stators. The north poles are located at one end of the machine and the south poles at the other end. The three-phase a-c winding is wound into the stator as in a salient pole generator except the iron stack of punchings is effectively separated into two sections. Figure 3.1 shows the configuration of a typical inductor generator. As the rotor turns, each a-c conductor sees alternate north and south flux.

In this generator, the total stack length must be approximately twice the length of the stack on a conventional salient pole generator. The stator leakage reactance and the electromagnetic weight are therefore greater than in a conventional machine. However, the important advantages of the inductor generator may be summarized as follows:

1. The generator is brushless.

2. There are no rotating windings.

3. The rotor leakage flux is small since the north and south poles are widely separated.

4. There are no cantilevered rotor poles. The rotor can be made of simple solid construction resulting in the best mechanical design to meet high rotational stresses.

5. One stationary field coil excites all magnetic poles.

6. The core loss is approximately one-half that of a conventional generator.

Electromagnetically similar axial gap inductor generators can be designed to several different configurations, two of which are shown in Figures 3.2 and 3.3. The axial-gap and radial-gap generators have the same principles of operation; a basic physical difference exists in that the pole faces and stack lengths for the axial-gap generator are perpendicular to the axis of rotation while in the radial-gap machine they are parallel to the axis of rotation. For this reason, the stator and rotor diameters of the axial-gap machine are normally much larger than those of an equivalent radial-gap machine. 


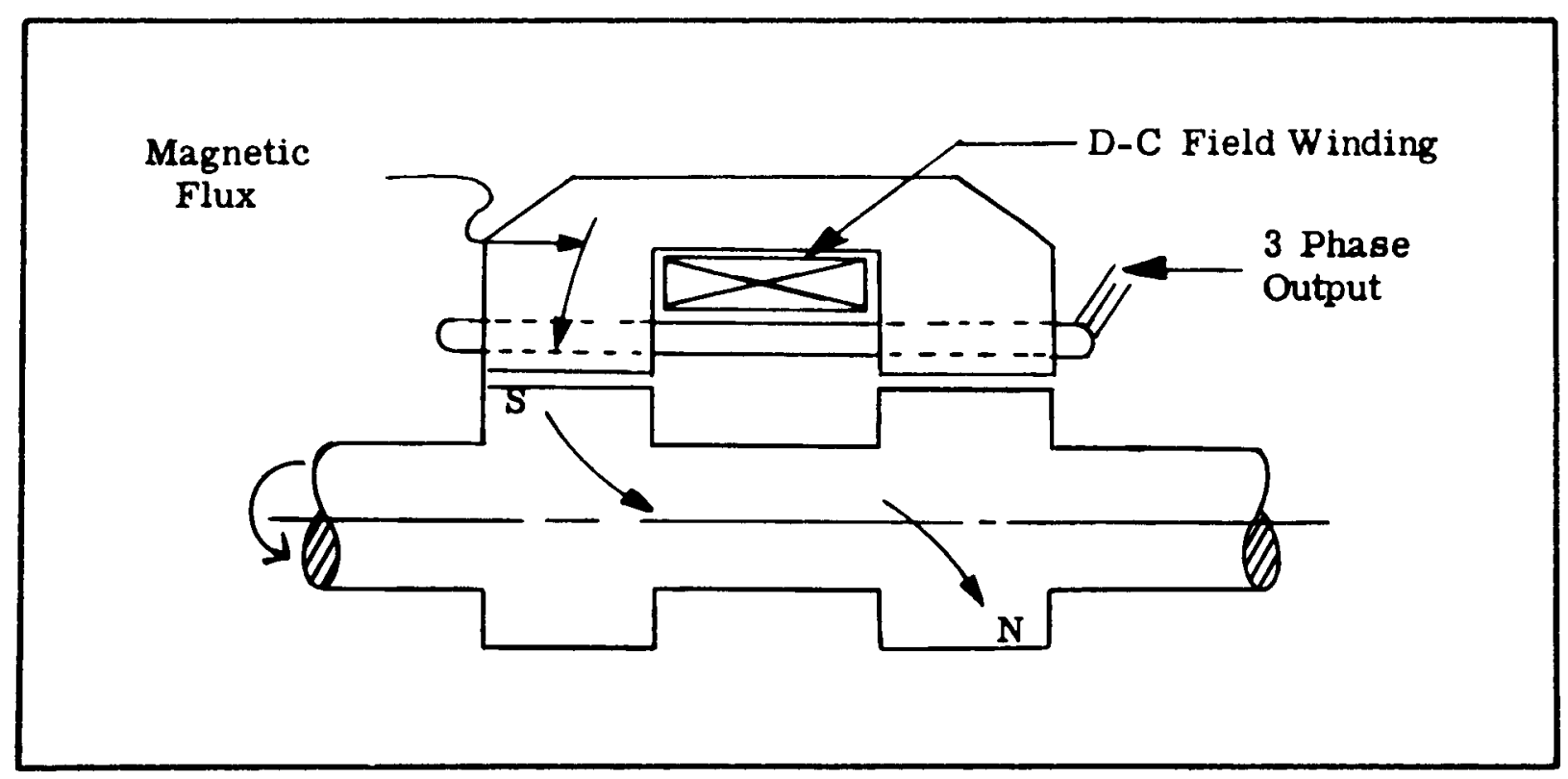

Figure 3.1 Inductor Generator 
An evaluation of the axial-gap designs shown in Figure 3.2 and 3.3 was performed by comparing design features and results against an equivalent radial-gap generator. In this evaluation the same design parameters (e.g., number of slots, gap length, flux and current densities, number and size of conductors, etc.) were used for all machines. The machine ratings were all $467 \mathrm{KVA}, 3040 \mathrm{cps}, 120 / 208$ volts at a power factor of 0.75 lagging; design speed was $22,800 \mathrm{rpm}$.

The electrical weight of the axial gap generator in Figure 3.2 proved to be about 13 percent heavier than the equivalent radial-gap generator shown in Figure 3.4 whereas the axial-gap generator configuration shown in Figure 3.3 was approximately two percent lighter than the radial-gap ma chine. Inspection of Figure 3.3 shows, however, that the frame necessary to support the armature structure was not included in the design (since it is not a part of the electromagnetic path). Including the frame would add considerably more than two percent to the generator weight.

The generators above were compared on the basis of the axial and radial gap machines having equivalent design parameters specified according to optimized radial-gap machines. Since an optimized design of an axial-gap machine may require different design constants and parameters, the above comparison may not be completely conclusive. However, comparing the weight of the SNAP-50/SPUR radial-gap inductor generator against its axial-gap counterpart developed (partially) on another program (6) leads to the conclusion that, even for the optimized machine, the axial-gap machine is still 10 to 28 percent heavier.

Of course, any weight considerations must include the cooling system weight penalties associated with the generator losses. The comparison between the axial and radial gap generators in Figures 3.3 and 3.4 indi cated that they had nearly equal efficiencies; the axial gap machine only had two percent greater losses which is as one might suspect for equivalently designed machines. Comparison of the axial gap generator in Reference (6) with the radial gap generator indicated that a realistic comparison could not be made, the reasons for which are explained below.

The calculation techniques for determining inductor generator losses are based on certain assumptions, approximations, and variances, all of which can lead to fairly divergent results depending on whether the analyst uses an optimistic or conservative approach. The losses calculated by Westinghouse for the radial-gap generator tended to be conservative since calculation techniques have not been verified for large, high-speed, highfrequency, high-temperature machines of several hundred KVA.* However,

*At present, calculation techniques have only been verified on genera tors of $50 \mathrm{~kW}$ or less. The experimental verification, no-load loss dynamic tests which are a part of this study are expected to establish the adequacy of extending the ayalytical techniques and thereby indicate more realistic assumptions and approximations. 


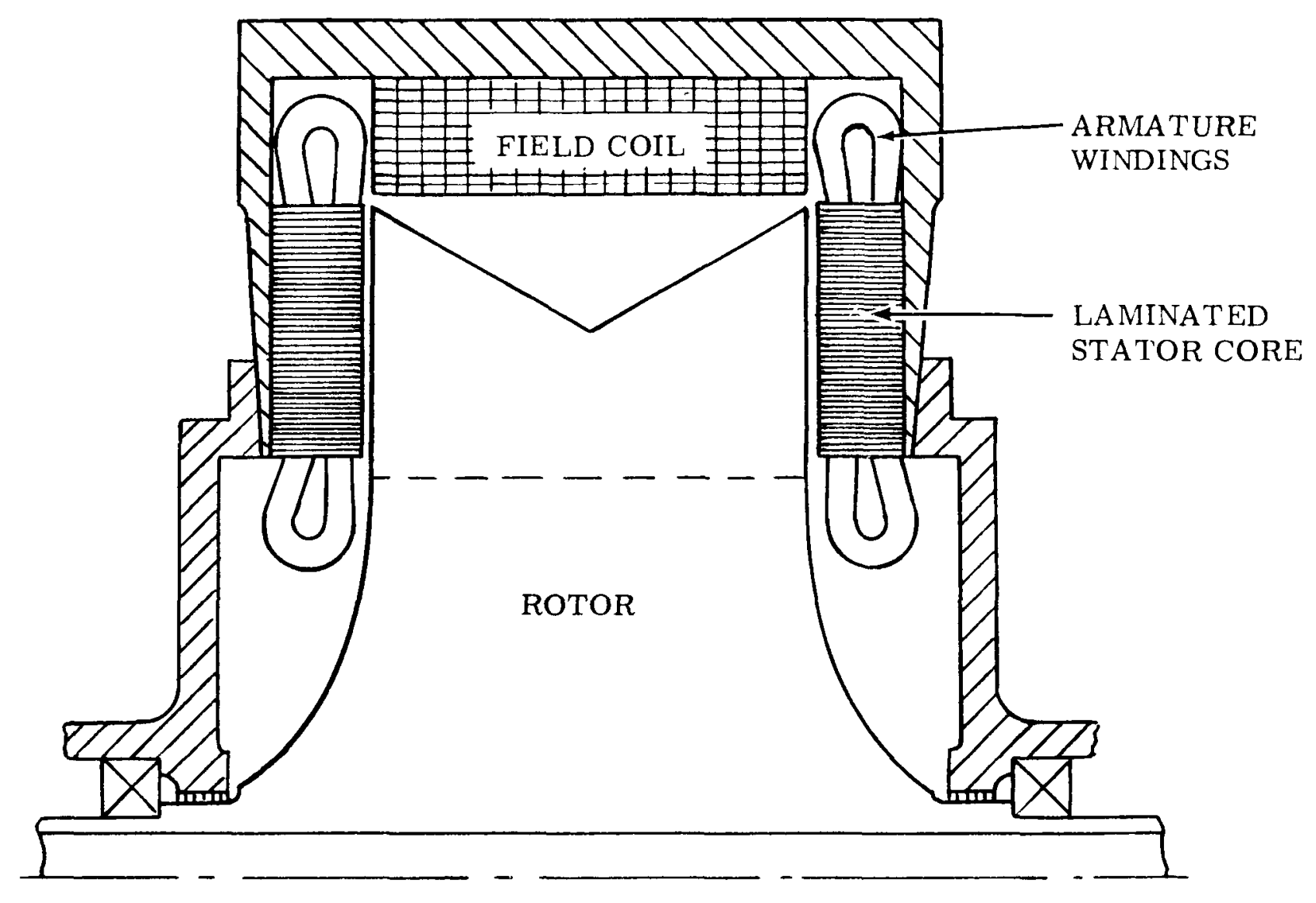

Figure 3.2 Axial Gap Inductor Generator Configuration 


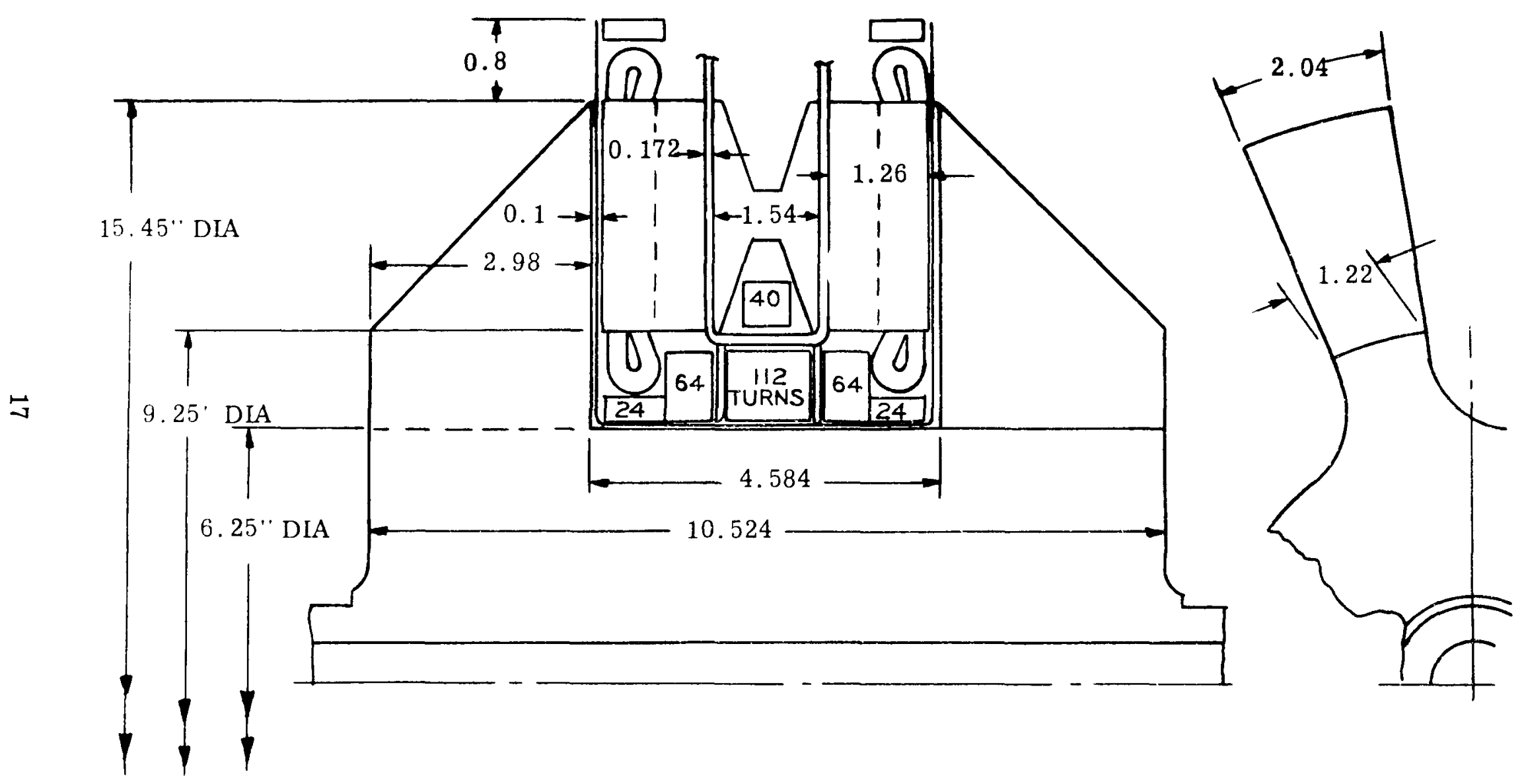

Figure 3.3 Axial Gap Inductor $467 \mathrm{KVA}$ - $3040 \mathrm{CPS}, 22,800 \mathrm{RPM}$ 


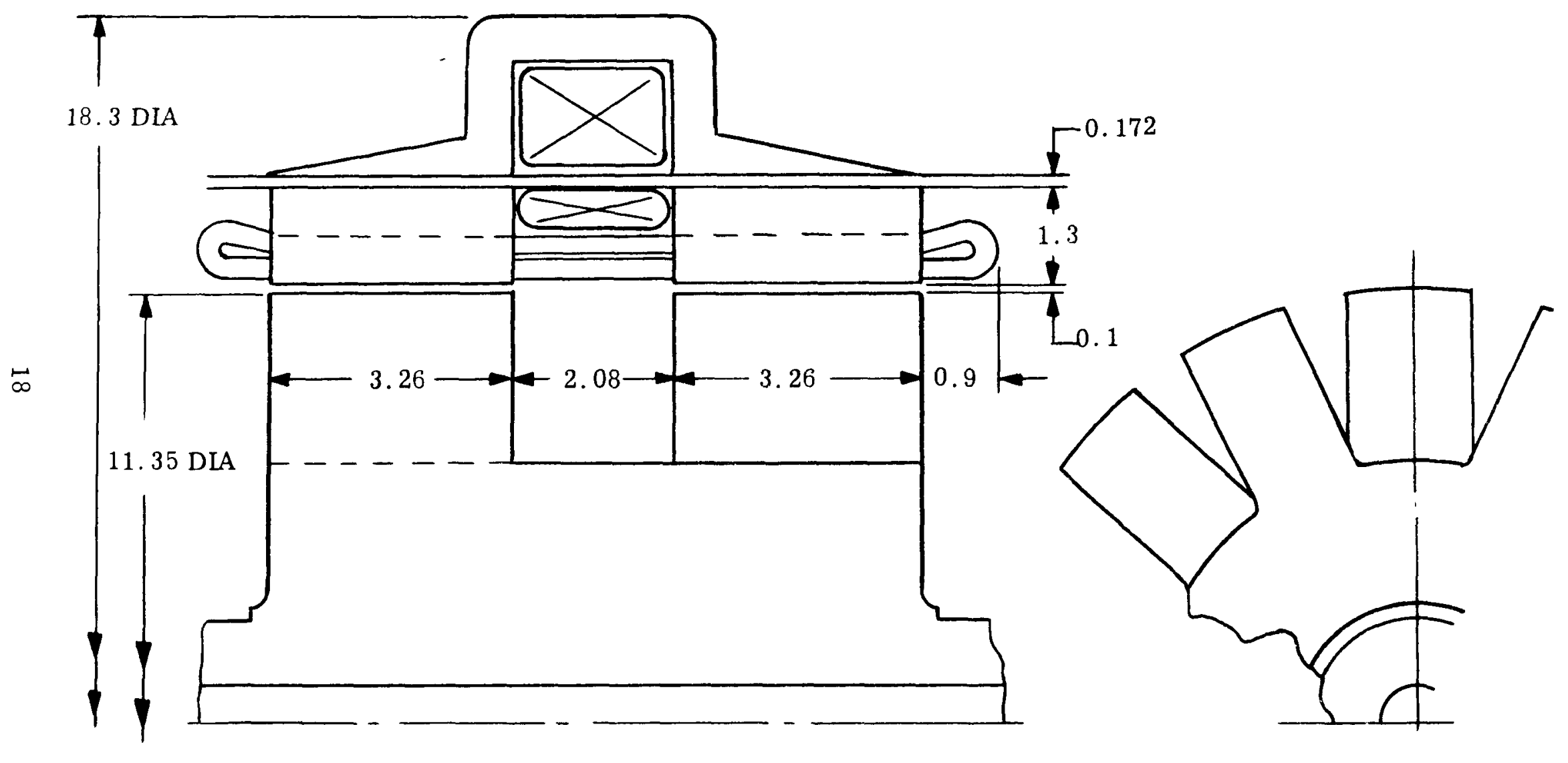

Figure 3.4 Radial Gap Inductor Generator 467 KVA - 3040 CPS, 22, 800 RPM 
the losses reported in Reference (6) appear to be based on more optimistic methods. This point is best illustrated by examining the one single greatest source of losses, the losses in the stator core and teeth. According to the published data on the axial gap generator in Reference (6), there exists the following similarities between it and the SNAP-50/SPUR radial gap generator: (1) the material is the same for both, HIPERCO-27 steel; (2) the flux densities in the teeth and cores of both generators are exactly the same, and (3) the rotor speed, effective number of poles and resulting frequency are the same. The only pertinent differences which do exist are: (1) the volume of steel in the axial-gap laminations is 44 percent greater, and (2) the thickness of the laminations is twice as great, 0.008 inches instead of 0.004 inches. All these factors lead to one conclusion, that the losses should be greater in the axial gap machine, assuming both are analyzed in the same manner. Surprisingly enough, however, the calculated losses (6) are only $14.8 \mathrm{KW}$, or 48 percent less than those calculated by Westinghouse for the radial gap machine. Thus, two fairly divergent calculation approaches are being used and no meaningful comparison could be made.

The somewhat higher weights for the axial-gap machines are insignificant when compared to other considerations for high speed applications. Maximum rotor stress is approximately 1.6 to 2.5 times as high for both axial-gap configurations as compared to the maximum stress for the radialgap generator owing to the larger rotor diameter and required pole configuration for the axial-gap machine. In addition, rotor losses (pole face loss) are considerably higher for the axial-gap generator owing to the higher pole tip speeds. The losses are 36 percent greater for the generator shown in Figure 3.3 than for the generator shown in Figure 3.4. This disadvantage is compounded by the fact that most of these losses are concentrated near the pole tips. The pole face loss is higher near the tips since most of the pole face area is at the larger diameters and also because the gap flux density is highest in this region due to the larger ratio of tooth width to tooth pitch occurring there. In addition, the mechanical strength requirement for the pole face groove lands dictates that the cantilevered lands be thicker at the pole tip, further increasing pole face loss. This makes cooling of the axial-gap generator much more complex than cooling the radial-gap generator. In fact, close examination of the rotor losses, temperature and stress distribution in the axial gap machine of Reference (6) indicates that the rotor would probably have passed into third stage creep sometime during its 10,000-hour life. Admittedly, creep is not a special design problem in axial gap generators; however, third stage creep is a problem to any machine since, in that stage, failure is imminent. The reader is referred to Appendix $A$ for a more detailed discussion of the analysis leading to this conclusion. 
So long as the axial-gap rotor remains absolutely parallel to its stator, there will be no magnetic unbalance between opposite poles. Any deviation, however, will introduce a moment which will tend to tilt the rotor further. The magnitude of this moment will be determined by the clearance of the bearing system. This moment has been reduced in much smaller machines by constructing the rotor core of a non-magnetic material with the rotor poles fabricated to this core. With an axial-gap generator of large rating, the rotor stresses are such that welding the rotor poles to a non-magnetic core is not feasible. The fastening of the rotor poles by a turbine blade root or similar device has not been evaluated but with development should be possible. Stress calculations for a shroud over the pole tips shows the shroud stresses to be too high for consideration.

For applications where the armature windings cannot be exposed to a hostile environment, such as potassium vapor, the windings must be protected (assuming present state-of-the-art materials) with a suitable structure located in the "air" gap. The structure for the radial-gap configuration consists of a uniform cylinder that can be permanently joined to the stator assembly. The structure for the axial-gap configuration must consist of essentially two flat discs with appropriate metal end extensions. This structure is inherently weaker and more sensitive to diaphragming and similar loadings which can be expected in operation.

Whereas the radial location of the stator with respect to the rotor centerline is critical for the radial-gap machine, the axial location of the stator with respect to the rotor is critical in the axial-gap machine because of the respective gap alignments. Differential, axial thermal expansion between the rotor and stator would be difficult to control with the axial gap configuration on an integrated turbo-generator unless separate thrust bearings were used on the turbine and the generator. Otherwise, the axial spacing on the turbine blades must be a function of the generator spacing and the differential expansion between the generator and turbine.

(c) Design Program. A digital computer design program will be used for the generator design portions of the study program. This program uses 123 input items to design the electrical configuration and coolant circuits and to calculate generator electrical performance losses, rotor stresses, and component temperatures. The input items fall into the following groups:

Rating

Materials and materials properties
Power output, voltage output, number of poles, number of phases, coolant temperature, speed, power factor.

Frame, stator punchings, pole faces, rotor, stub shafts, conductors, internal ambient, insulations. 
Internal Dimensions

Performance

Tolerances
Rotor ID, air gap, slot shape, shaft $O D$, bearing bore, conductor placement, field coil shape.

Current densities, direct axis synchronous reactance, winding paths, field voltage and current, pole embrace, phase belts, flux leakage ratios, tooth width to slot pitch ratio, slot skew, coil throw, bearing friction coefficient, pole face configuration, shape of field wire, phase angle for unbalanced voltage conditions, ratio of generated to terminal volts.

Flux densities, winding clearance, slot clearances, frame air gap, coil throw.

The following data is calculated and printed out for each generator design:

Component dimensions and weights

Harmonic analysis

No-load saturation curve

Full-load saturation curve

Component temperatures

Voltage unbalance for unbalanced loads

Losses

Rotor stress and cooling configuration

(d) Materials. The following materials have either been specified or selected for use during the design study.

(1) Stator Steel - Magnetic Materials Report NASA -CR-54091 (3), shows HIPERCO 27 and CUBEX to be suitable for the temperature range to be considered in this study. Since fabrication difficulties have been encountered with CUBEX, HIPERCO 27 was chosen for the stator punchings and the forged frame. Punchings 0.004 -inch thick will be used to minimize iron losses in the stator stacks. Magnetization curves determined from the data on pages 303 and 305 of NASA -CR-54091 will be used, as shown by Figures 3.5 and 3.6

The attached core loss curves, Figures 3.7 and 3.8 , were prepared from data published in Materials Report NASA-CR-54091, pages 318-323. Core loss values from the report were multiplied by three, as past design 
experience has shown this to be necessary to allow for harmonics, stray losses, stacking and other fabrication effects.

A stacking factor of 0.90 will be used for the 0.004 -inch stator punchings* and a stator steel and frame steel density of $0.285 \mathrm{lbs} / \mathrm{in}^{3}$ will be used for size and weight calculations.

(2) Rotor Steel - H-11 steel was chosen for $500^{\circ} \mathrm{F}$ and $800^{\circ} \mathrm{F}$ coolant temperatures and NIVCO was chosen for $800^{\circ} \mathrm{F}$ and $1100^{\circ} \mathrm{F}$ coolant temperatures based on a preliminary rotor materials comparison study which compared the combined magnetic-physical properties and thermo-physical properties of $\mathrm{H}-11$, NIVCO, precipitation hardened martensitic alloys and dispersion hardened cobalt alloys over a $500^{\circ} \mathrm{F}$ to $1600^{\circ} \mathrm{F}$ temperature range. Final choice of the material at $800^{\circ} \mathrm{F}$ will be made after preliminary rotor stress and temperature comparisons can be completed. A materials choice has not been made for a $1400^{\circ} \mathrm{F}$ coolant. Magnetization curves per pages 431 and 482 of NASA-CR-54091, were used to obtain the curves shown in Figures 3.9.

A rotor steel density of 0.281 and $0.312 \mathrm{lb} / \mathrm{in}^{3}$ will be used for weight calculations for $\mathrm{H}-11$ and NIVCO respectively.

(3) AC Windings - Rectangular Inconel 600-clad silver wire with Anadur insulation will be used for coolant temperatures of $500^{\circ} \mathrm{F}$ and $800^{\circ} \mathrm{F}$. This insulation is composed of fiber glass, fusible glass frit, and refractory oxide powders retained on the conductor during winding by a resin binder. Subsequent firing after winding fuses the glass frit to serve as a rigid binder. An insulation thickness of 0.011 -inch per conductor side will be used for all $500^{\circ} \mathrm{F}$ and $800^{\circ} \mathrm{F}$ coolant temperature designs. Report NASA-CR-54092, page 279 showed the following electric strengths for 0.0068-inch Anadur insulation at $3200 \mathrm{cps}$ :

$\begin{array}{rc}{ }^{\circ} \mathrm{F} & \begin{array}{r}\text { Total } \\ \text { Volts }\end{array} \\ 500 & 430 \\ 932 & 420 \\ 1112 & 410\end{array}$

A more recent work has shown that an Anadur thickness of 0.011 -inch is better than 0.0068 -inch from the standpoints of application and damage resistance. A conservative value of 400 volts electric strength will be assured for all generator designs where Anadur insulation is used.

Rectangular dispersion-strengthened copper conductors with alumina insulation plasma-arc-sprayed on preformed coils will be used for coolant temperatures of $1100^{\circ} \mathrm{F}$ and above. Report NASA-CR-54092, page 469, shows high purity alumina electric strengths as follows:

*This is in accordance with past experience with the 0.004 -inch thick stator punchings used on the SNAP-50/SPUR experimental generator. 


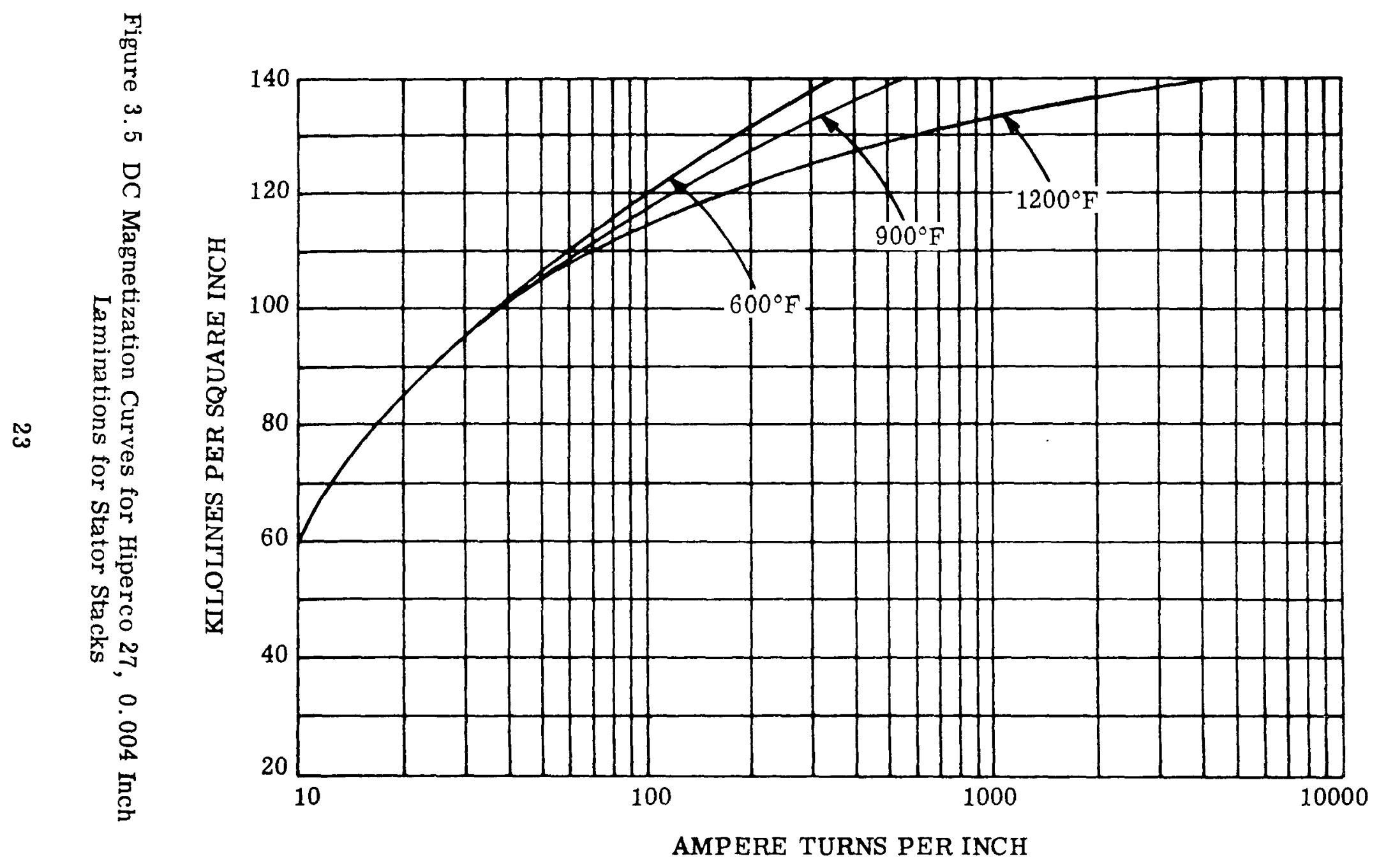




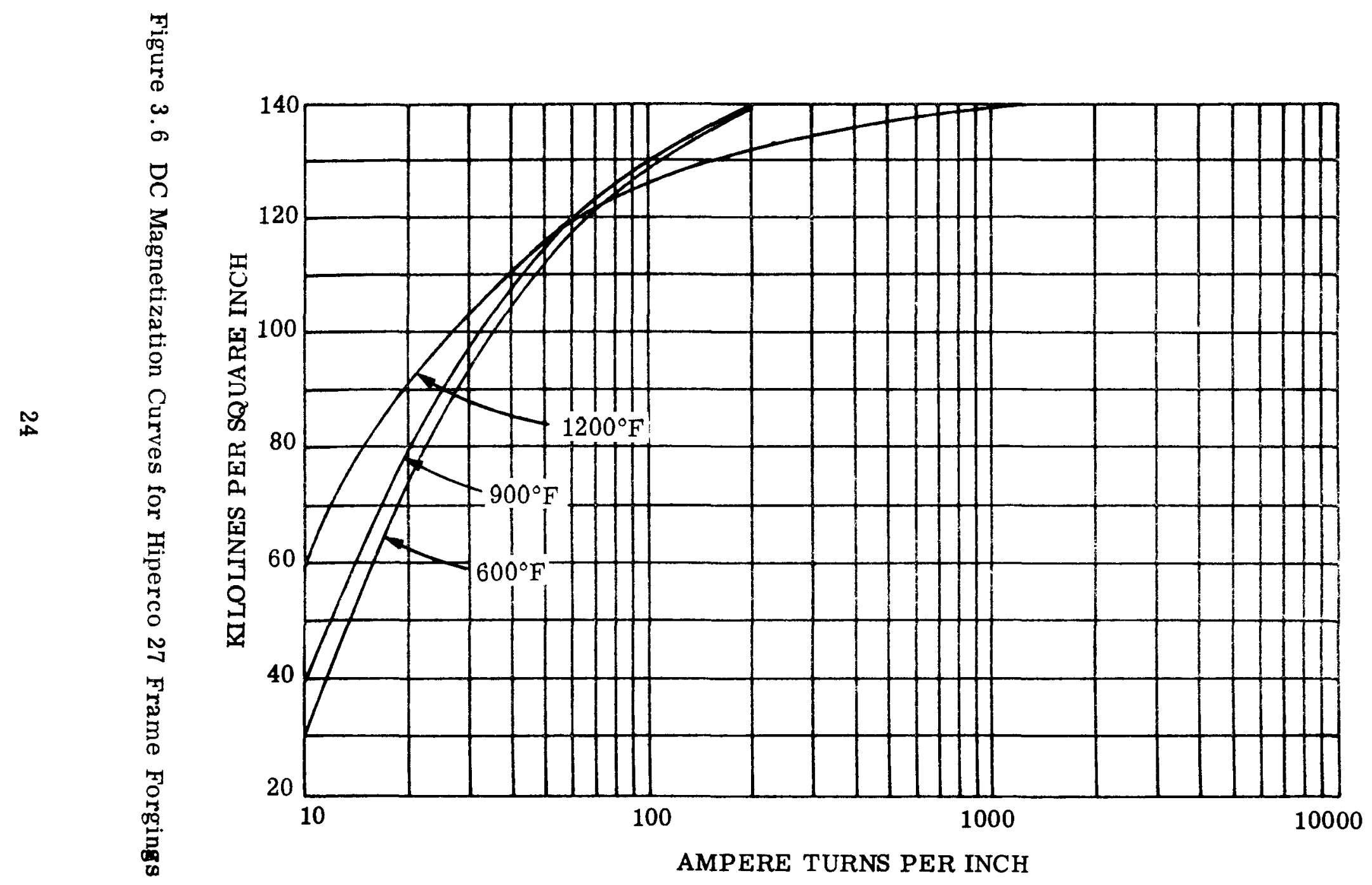




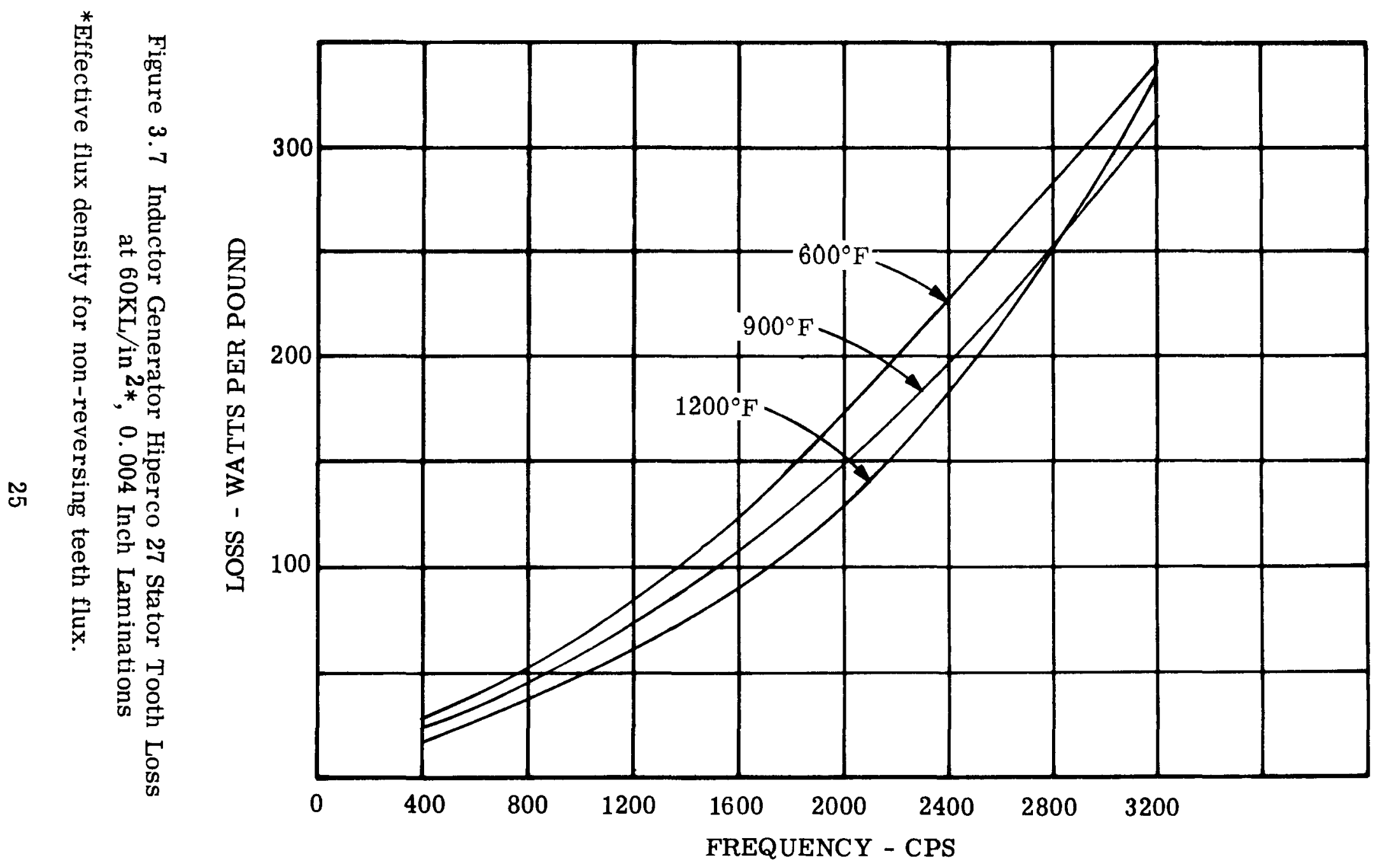




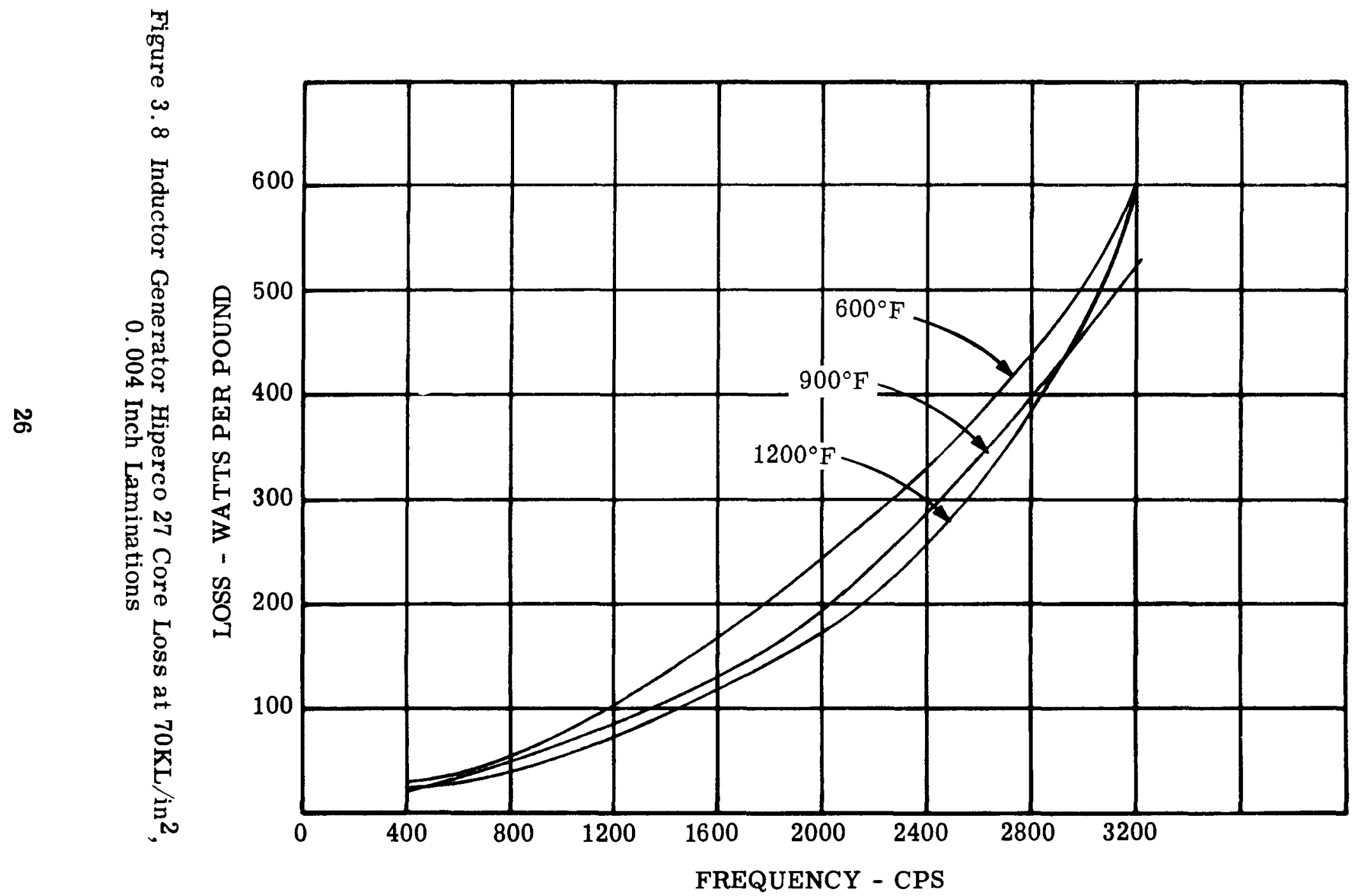




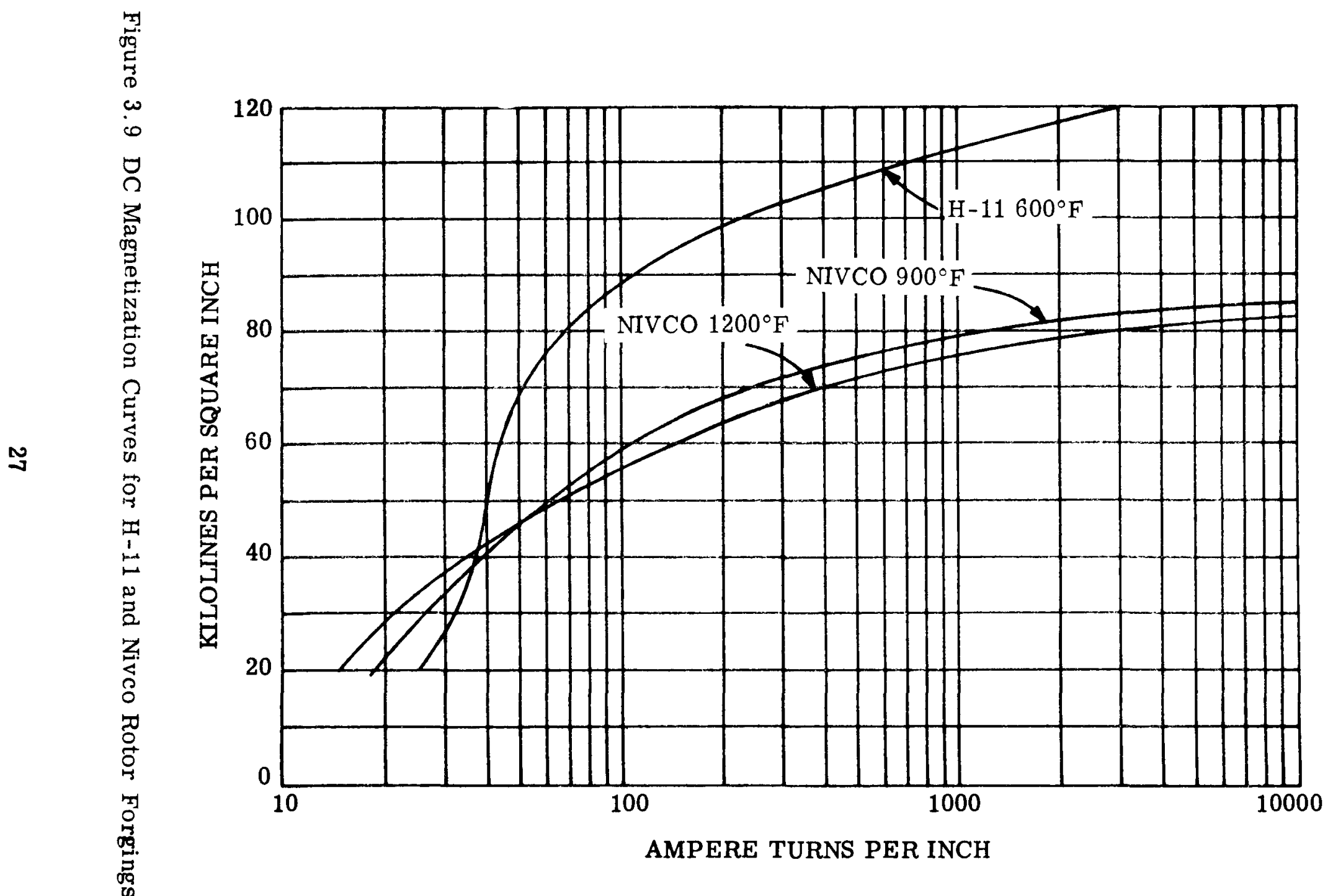




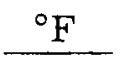

932

1600
Volts/mil

140

46

A conservative value of 50 volts $/ \mathrm{mil}$ will be used on $1100^{\circ} \mathrm{F}$ coolant designs where winding temperatures in the order of $1400^{\circ} \mathrm{F}$ are anticipated.

A conductor insulation thickness of 0.008 -inch per conductor side will be assumed to provide an electric strength of 400 volts as assumed for the Anadur insulation used in lower temperature designs.

The major portion of the phase-to-phase and phase-to-ground insulation is accomplished by the slot liners and separators and by phase insulation inserted in the end turns where necessary. The conductor insulation, besides providing some phase-to-phase and phase-to-ground insulation, also (1) provides separation between parallel conductors in the same slot, thus allowing more conductor surface area to reduce skin effect at higher frequencies and (2) insulates between series conductors in the same slot where they are used.

Inconel 600 -clad silver wire has a 75 percent average conductivity and dispersion strengthened copper wire has a 91 percent average conductivity relative to copper over the temperature ranges to be considered.

(4) Field Windings - Wire and wire insulation as described for the a-c windings will be used.

(5) Stator Slot Insulation - Two U-shaped slot cells and a wedge will be used for each slot. Alumina, 98.5 percent pure, will be used for these components for coolant temperatures of $500^{\circ} \mathrm{F}, 800^{\circ} \mathrm{F}$, and $1100^{\circ} \mathrm{F}$. The rigid alumina slot insulation will not completely isolate the conductors, because air gaps exist between the conductors and iron, between adjacent surfaces of the wedge and upper slot cell and between adjacent surfaces of the upper and lower slot cells. The wedge and cell thickness must the refore be chosen to provide the necessary electric leakage path length in the surrounding stator ambient. Choice of stator cavity pressure to allow a gradient of 50 volts $/ \mathrm{mil}$ will be assumed and the peak voltage to be insulated will be calculated by: (1. $414 \mathrm{x} \mathrm{rms}$ volts per phase minus 400 volts capability of conductor insulation) $\mathrm{x} 1.5$ safety factor.

Following are the wedge and cell thicknesses which are required and those which will be used. Since 0.018 -inch is the minimum thickness practical from a fabrication and handling standpoint, the 500 volt insulation thickness will be greater than required electrically. A minimum practical wedge thickness of 0.04 -inch was chosen. 


\begin{tabular}{|c|c|c|c|}
\hline \multirow[t]{2}{*}{$\begin{array}{l}\text { Rated } \\
\mathrm{V} / \mathrm{Ph} \\
\end{array}$} & \multicolumn{2}{|c|}{$\begin{array}{l}\text { Thickness to be } \\
\text { used-inches }\end{array}$} & $\begin{array}{l}\text { Minimum Cell ano } \\
\text { Thickness Requir }\end{array}$ \\
\hline & Cell & Wedge & \\
\hline 500 & 0.018 & 0.04 & 0.0 \\
\hline 1000 & 0.030 & 0.04 & 0.0 \\
\hline 1500 & 0.052 & 0.052 & 0.05 \\
\hline 2140 & 0.079 & 0.079 & 0.07 \\
\hline
\end{tabular}

(6) Stator Encapsulation - Aluminum orthophosphate plus zircon potting compound will be assumed for the $500^{\circ} \mathrm{F}$ designs to hold the windings in place and to provide better heat transfer. No potting compounds are presently available which would prove satisfactory on the $800^{\circ} \mathrm{F}$ and $1100^{\circ} \mathrm{F}$ designs.

(e) Electrical Design Parameters. Generator ratings of $0.4,1.2,6.0$, and $12.0 \mathrm{MVA}$ were chosen for the study. The $0.4 \mathrm{MVA}$ rating was chosen because it allows comparison and utilization of previous SPUR generator and systems data. The 1.2 MVA rating was likewise chosen because of commonalities with previous studies $(7),(8),(25)$. The 6 and 12 MVA ratings were chosen to complete coverage up to 12 MVA as required. The following electrical design parameters have been selected for use during the design study.

(1) Flux Density in Stator Frame, Core, and Teeth - The following flux densities will be used over an assumed $600^{\circ} \mathrm{F}$ to $1500^{\circ} \mathrm{F}$ ir on temperature range corresponding to the $500^{\circ} \mathrm{F}$ to $1400^{\circ} \mathrm{F}$ coolants:

$\begin{array}{lr}\text { Frame } & 115 \mathrm{KL} / \mathrm{in}^{2} \\ \text { Core } & 70 \mathrm{KL} / \mathrm{in}^{2} \\ \text { Teeth } & 120 \mathrm{KL} / \mathrm{in}^{2}\end{array}$

Past work on the SNAP-50/SPUR generator design showed that $70 \mathrm{KL} / \mathrm{in}^{2}$ for the core and $120 \mathrm{KL} / \mathrm{in}^{2}$ for the teeth provide the best combination of low weight and high efficiency for a $600^{\circ} \mathrm{F}$ coolant temperature; a frame flux density of $115 \mathrm{KL} / \mathrm{in}^{2}$ was used for the SPUR generator to provide a balanced magnetic design.

The HIPERCO 27 magnetization curves of NASA-CR-54091, pages 303 and 305 , show little variation in excitation requirements over a $600^{\circ} \mathrm{F}$ to $1500^{\circ} \mathrm{F}$ temperature range for flux densities between 70 and $120 \mathrm{KL} / \mathrm{in}^{2}$; therefore, stator densities will not be varied with coolant temperature.

(2) Flux Density in Rotor Core - The following rotor core flux densi ties will be used: 


\begin{tabular}{|c|c|c|c|}
\hline Coolant Temp. & $\begin{array}{l}\text { Assumed } \\
\text { Iron Temp. }\end{array}$ & Material & $\mathrm{KL} / \mathrm{in}^{2}$ \\
\hline $500^{\circ} \mathrm{F}$ & $600^{\circ} \mathrm{F}$ & $\mathrm{H}-11$ & 85 \\
\hline $800^{\circ} \mathrm{F}$ & $900^{\circ} \mathrm{F}$ & NIVCO & 50 \\
\hline $1100^{\circ} \mathrm{F}$ & $1200^{\circ} \mathrm{F}$ & NIVCO & 50 \\
\hline $1400^{\circ} \mathrm{F}$ & $1500^{\circ} \mathrm{F}$ & not yet se & \\
\hline
\end{tabular}

The $85 \mathrm{KL} / \mathrm{in}^{2}$ for $\mathrm{H}-11$ at $600^{\circ} \mathrm{F}$ was based on the value found to provide a satisfactory SPUR design. According to the curves of NASA-CR-54091, pages 431 and 482 , the chosen flux densities for NIVCO at 800 and $1100^{\circ} \mathrm{F}$ provide approximately the same excitation requirements as those for $\mathrm{H}-11$ at $600^{\circ} \mathrm{F}$.

(3) AC Winding Current Density Desired - A current density of 9000 amps/in2 was chosen based on past SPUR studies to optimize current density.

(4) Field Winding Current Density Desired - A current density of 4000 amps/in ${ }^{2}$ was arbitrarily chosen based on the previous SPUR and NAS 5-1234 designs. No tests or optimizing calculations for field current density have been run as on the a-c windings.

(5) Direct Axis Synchronous Reactance - The following values will be used initially as a desired goal. A plus or minus 10 percent tolerance will be allowed in order that designs can be obtained for each desired rating using standard conductor sizes.

\begin{tabular}{cc} 
Rating - MVA & Desired P.U. $\mathrm{X}_{\mathrm{d}}$ \\
\cline { 2 - 2 } .4 & 1.0 \\
1.2 & 1.2 \\
6.0 & 1.3 \\
12.0 & 1.3
\end{tabular}

These desired values were chosen on the basis of the 467 KVA SPUR design which had an $\mathrm{X}_{\mathrm{d}}$ of 0.935 and on the following average $\mathrm{X}_{\mathrm{d}}$ values of the best NAS 5-1234 designs.

\begin{tabular}{r} 
KW Rating \\
\hline 200 \\
600 \\
1000 \\
2000 \\
5000 \\
10000
\end{tabular}

$\mathrm{x}_{\mathrm{d}}$

1. 19

1.23

1.15 to 1.18

1.33

1.28

1. 29 
The chosen $X_{d}$ values will reasonably limit: (1) voltage unbalance for unbalanced loading conditions, (2) excitation power, (3) transient surges; and (4) increase of field power for overloads.

(6) Parallel Paths in Field - One parallel path was chosen. This can be changed later, depending on the excitation power supply, without significantly affecting size or weight.

(7) Maximum Desired Field Amps at Continuous Full Load - The following values were chosen:

MVA Rating

0.4

1.2

6.0

12.0 $\underline{\text { Amps }}$

25

48

240

480

These were based on a value of 25 amps used in the SPUR design and a value of $40 \mathrm{amps} / \mathrm{MW}$ used in the NAS 5-1234 study. Final designs can be varied by changing the number of field turns and standard wire size to correspond with the desired field amps.

(8) Minimum Power Factor Angle - A minimum power factor angle of $-31.8^{\circ}$, corresponding to a lagging power factor of 0.85 , will be used to comply with the contract work statement.

(9) Single Air Gap and Bore Seal Thickness - The following single air gaps will be used:

$\begin{array}{cc}\text { MVA Ratings } & \begin{array}{l}\text { Bore Seal Wall } \\ \text { Thickness-inches }\end{array} \\ 0.4 & 0.065 \\ 1.2 & 0.080 \\ 6.0 & 0.129\end{array}$

$12.0 \quad 0.175$ \begin{tabular}{c}
$\begin{array}{c}\text { Single Air Gap- } \\
\text { inches }\end{array}$ \\
\hline
\end{tabular}

0.1 (not dependent on bore seal)

0.125 (not dependent on bore seal) 0.229 (bore seal thickness and running clearance) 0.275 (bore seal thickness and running clearance)

Air gap width is dependent on desired electrical performance, allowable pole face losses, and required bore seal thickness. A preliminary study of NAS 5-1234 data showed a single air gap of 0.125 inches provided lowest weight and highest efficiency for 1-megawatt ratings. Two 1-MW conceptual 
designs of NAS 5-1234 had single air gaps of 0.125 -inch with rotor OD's of 14.3 and 14.7 and one had a single air gap of 0.100 -inch with a rotor OD of 14.0-inches. The SPUR generator design has a single air gap of 0.10 -inch, a rotor OD of 11.35-inches and a bore seal wall thickness of 0.070-inch. Data taken from NAS 5-1234 showed the following typical rotor diameters, and contacts with bore seal manufacturers (Coors Porcelain and Western Gold Co.) indicate that the following minimum bore seal thicknesses are practical for these diameters:

\begin{tabular}{|c|c|c|}
\hline KW Rating & $\begin{array}{l}\text { Avg. Rotor } \\
\text { OD - inches }\end{array}$ & $\begin{array}{l}\text { Minimum Practical Bore } \\
\text { Seal Thickness - inches }\end{array}$ \\
\hline 300 & 10.5 & 0.063 \\
\hline 600 & 12.9 & 0.078 \\
\hline 1000 & 14.3 & 0.086 \\
\hline 1000 & 11.7 & 0.070 \\
\hline 2000 & 14.9 & 0.090 \\
\hline 5000 & 21.4 & 0.129 \\
\hline 10000 & 28.8 & 0.175 \\
\hline
\end{tabular}

(10) AC Winding Temperature - An a -c winding temperature $300^{\circ} \mathrm{F}$ above the average coolant temperature will be assumed. The computer uses this only as a design starting point. Actual a-c winding temperatures are calculated and used to calculate winding $I^{2} R$ losses.

(11) Field Winding Temperature - A field winding temperature of $300^{\circ} \mathrm{F}$ above the average coolant temperature will be assumed for all designs. Since the computer does not calculate the actual field winding temperature, this assumed temperature is used to determine field losses. Actual field winding temperatures are calculated only after the field cooling configuration has been designed in detail.

(12) Stator Slot Configuration - The slot configuration to be used is shown below compared to conventional configuration:
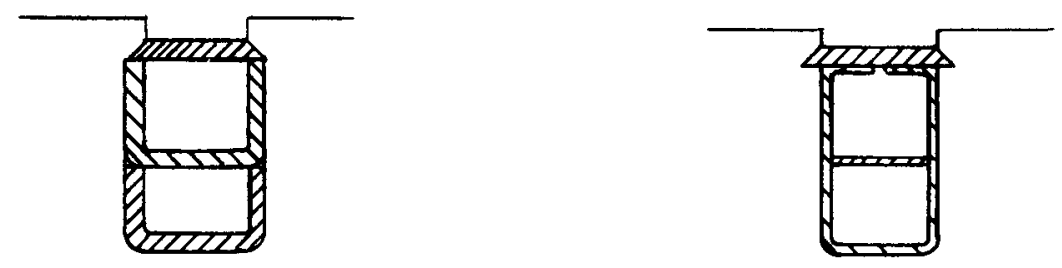
Use of the proposed variation from the conventional configuration allows a smaller slot opening to reduce pole face losses. Further reduction of the slot opening would further reduce the pole face losses but would require the a-c windings to be inserted axially and then joined on the turns. The proposed slot configuration was used on the SPUR generator design.

(13) Pole Embrace - A pole embrace of 67 percent will be used, based on a previous SPUR study. The study showed that 55 percent pole embrace provides minimum weight, 80 percent provides maximum efficiency, and 40 percent provides lowest conductor temperatures and rotor tangential stress. It concludes that 67 percent provides the best combination of advantages.

(14) Phase Belts - Phase belts of $60^{\circ}$ will be used in all designs to provide the lightest weight designs. The 67 percent pole embrace and $2 / 3$ pitch will be used to eliminate the third harmonic.

(15) Parallel Paths in AC Windings - The number of parallel paths affects the following: (1) effective conductor surface area and resulting skin effect, (2) required conductor size, and (3) synchronous reactance. Based on design experience, the following values will be used on initial designs.

$\begin{array}{lc}\begin{array}{l}\text { Nu. of } \\ \text { Poles }\end{array} & \begin{array}{c}\text { Parallel } \\ \text { Paths }\end{array} \\ \begin{array}{c}\text { 4, } 8 \\ 10,20\end{array} & 4 \\ 6,12,18,30,36,42 & 5 \\ 14,24,48 & 6 \\ 16,24, & 7\end{array}$

(16) AC Conductors in Parallel - Four conductors in parallel in the same slot will be used for initial designs.

The number of conductors in parallel determines (1) the effective conductor surface area and resulting skin effect, and (2) the required conductor size. The 120-volt SPUR generator used four conductors in parallel in each slot.

This parameter in conjunction with the number of parallel paths will be varied as required in conceptual designs to obtain the best combination of weight, efficiency, and ease of winding.

(17) Slot Skew - Slot skew in the stator stack to reduce slot harmonics will not be used because of the difficulty of inserting rigid ceramic slot liners into skewed slots.

(18) Clearances - The following clearances will be used, based on generator fabrication experience and Westinghouse Manufacturing Engineering recommendations. 
Inches

Clearance between end turns of a-c

0.075 windings

Slot width clearance

$400 \mathrm{kva}$ and $1200 \mathrm{kva}$ ratings

0.018

$6 \mathrm{mva}$ and $12 \mathrm{mva}$ ratings

0.026

Slot Depth Clearance

0.02

Clearance between top of field winding

0.09

and frame

Clearance between bottom of field

0.03

and $\mathrm{a}-\mathrm{c}$ windings

Frame air gap to allow for fit tolerances

0.0015

between flux carrying sections of the

frame

Field winding clearance between conductors

0.002

Field winding end clearance

0.014

(19) Tolerances - The following tolerances were chosen to limit the computer time required for each design and to allow designs to be obtained using standard conductor sizes.
Flux Densities
$\pm 2 \%$
Coil Throw
$\pm 10 \%$
Direct Axis Synchronous Reactance
$\pm 10 \%$
Ratio of Generated to Terminal Volts
$\pm 3 \%$

(f) Pertinent Mechanical Design Parameters. The calculated stresses and temperatures within the rotor will be combined with creep data for the various rotor materials to determine the creep strain of the rotor. Typical creep data for $\mathrm{H}-11$ and NIVCO is given in Figure 3.10. Any creep strain over 0.2 percent near the outer rotor core will be considered excessive; on the other hand, creep strains up to 0.5 percent near the central portion of the rotor will be considered acceptable. The actual stress in the rotor for a given rating, rotor speed and frequency, can be increased or decreased by 

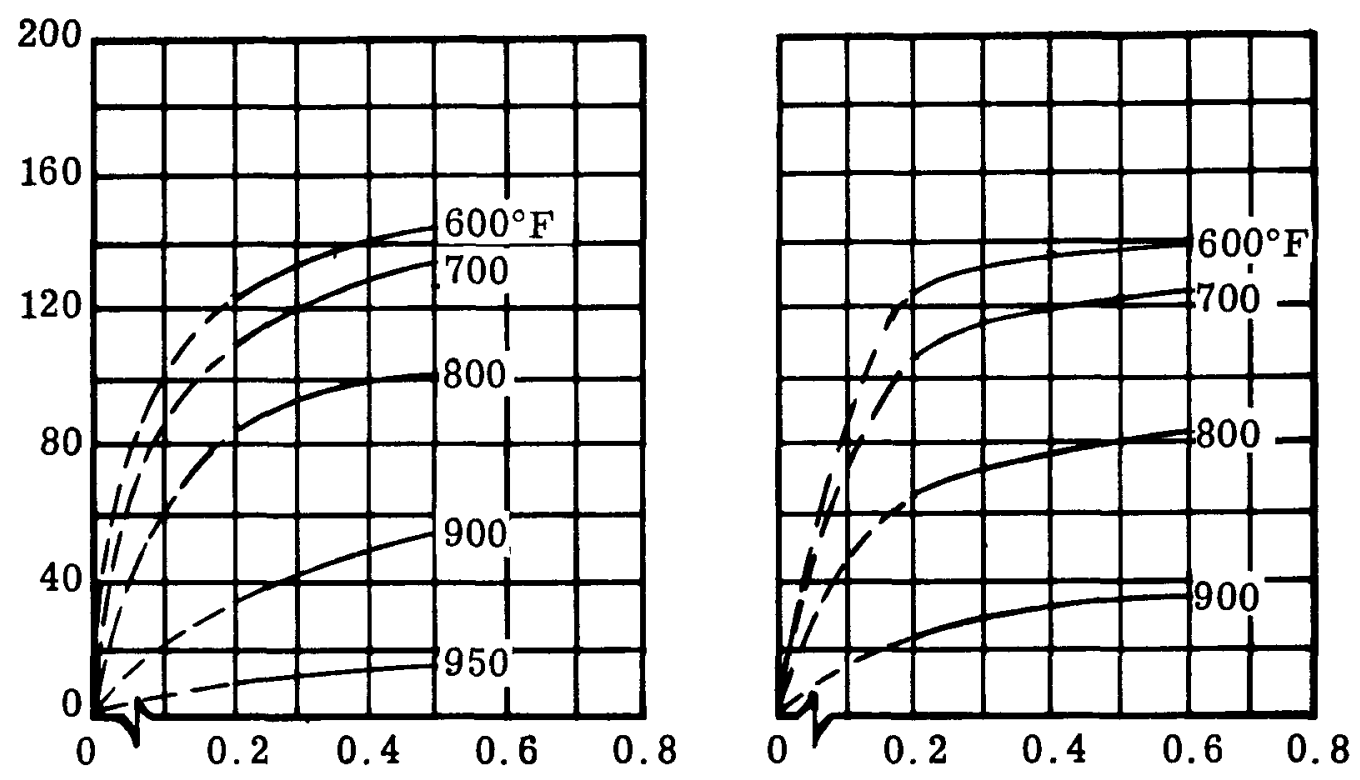

3.10a 10,000-Hr. Creep Strain H-11 Alloy Steel Bar

3. $10 \mathrm{~b} 40,000-\mathrm{Hr}$. Creep Strain H-11 Alloy Steel Bar

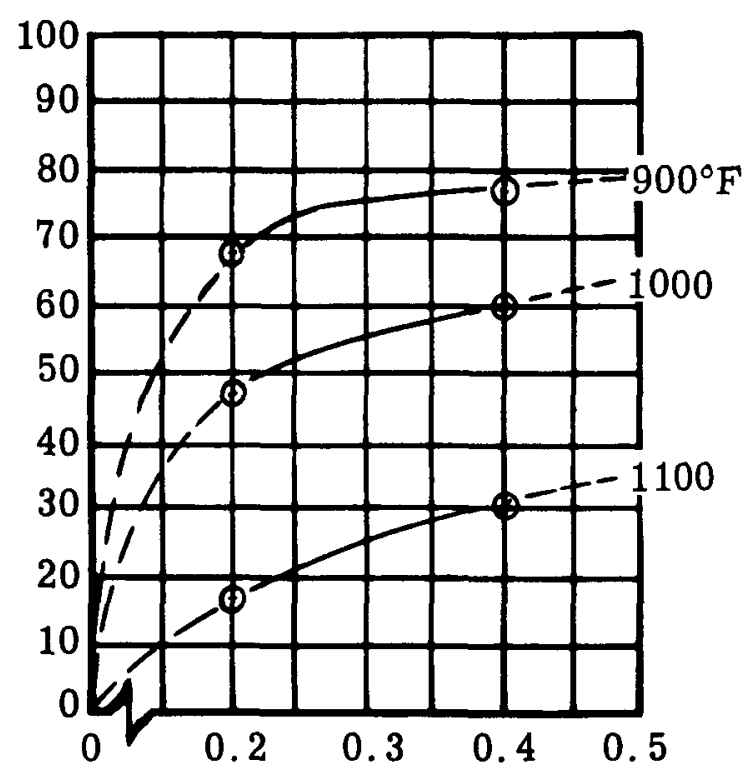

3.10c 10,000-Hr. Creep Strain Nivco Alloy Bar

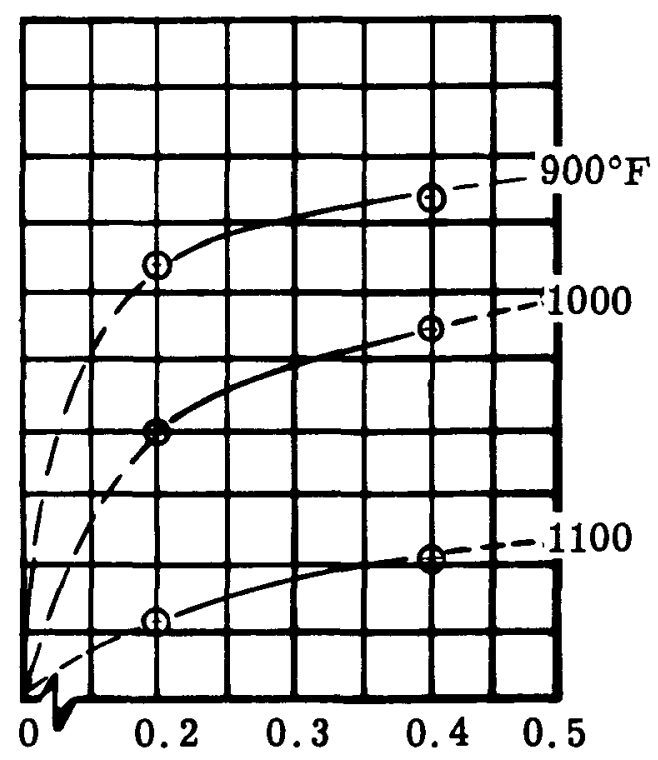

3.10d 40,000-Hr. Creep Strain Nivco Alloy Bar

Figure 3.10 Creep Strain Data 
increasing or decreasing the number of slots in the armature or by changing the leakage flux around the poles to change the rotor OD. These parameters will be varied in order to obtain the best combinations without exceeding the stress limitations on the rotor material.

A rotor cooling configuration which has several coolant passages through the core of the rotor will be used. The coolant passages are located in the core such that the maximum hot spot in the rotor can be maintained at less than the specified limiting design temperatures.

The stator coolant configuration will be represented by a constant temperature sink on the armature stack OD or on the stator frame OD, selection of which depends on the relative dimensions of the stacks. Other cooling configurations such as cooling tubes in the laminations or armature slots will not be considered because of their fabrication complexities and the added tooth and core losses which result from their use.

The ambient atmosphere in the stator will be an inert gas at more than 100 torr or less than 0.1 torr absolute pressure. Gas pressure at one atmosphere will not be used due to the undesirability of having excessive pressure differential across the ceramic bore seal; intermediate vacuum between 0.1 and 100 torr will not be considered because of possible corona difficulties. Because the stator materials will outgas over the operating life of the generator, the preferred pressure is 100 torr rather than 0.1 torr. The likelihood of the stator cavity being vented to space to maintain a hard vacuum at less than 0.1 torr has not yet been evaluated and could alter this conclusion during the course of the study. Even with the stator cavity vented to space, there is no guarantee that gas in the slots will be less than 0.1 torr due to the outgassing.

The ambient atmosphere in the rotor cavity will be potassium vapor at a pressure compatible with the coolant temperature, rotor speed, stub shaft sizes, shaft seal losses and windage losses. Use of Holweck pump vapor shaft seals will allow the optimum combination of the se parameters to be chosen nearly at will. Dynamic liquid shaft seals such as viscoseals or dynamic slingers will be chosen according to their applicability to specific design conditions.

The rotor stub shaft sizes, bearing bore sizes, friction loss coefficients, etc., will be chosen to match actual operating conditions and will be in accordance with liquid metal bearing practices. Pivoted pad bearings (or equivalently stable journal bearings) will be the type bearing specified for determining configuration dependent parameters. Bearing load pressure will be limited to $15 \mathrm{psi}$ based on the static weight of the rotor for the initial parametric screening studies.

Rotor pole faces will be slotted with 0.005 -inch wide by 0.062 -inch minimum deep slots. Optimum slot pitch will be selected as part of the design study. 
Ceramic bore-seals will be used in the air gap to protect the stator components from the potassium vapor in the rotor cavity; the thicknesses to be used have been presented previously. Metal bore-seals, while having attributes relative to fabricability and reliability, have prohibitively high can losses in high speed machines. These losses may be calculated with the equation (9).

$$
\mathrm{w}=\frac{15.5(\mathrm{Bac} * \mathrm{RPS} * \mathrm{SL})^{2} \mathrm{D}^{3} \mathrm{t}^{*}+10^{-16}}{2 \rho\left(\mathrm{SL}+\frac{\mathrm{LBS}}{2}\right.} * \mathrm{~K}_{\mathrm{S}}
$$

where $\quad \mathrm{Bac}=\frac{\mathrm{P} * \mathrm{Eg} * 10^{8}}{8 * \mathrm{FF} * \mathrm{f}^{*} \mathrm{~N}_{\mathrm{ph}}{ }^{*} \mathrm{D} * \mathrm{SL}} \quad$ (lines $\left./ \mathrm{in}^{2}\right)$

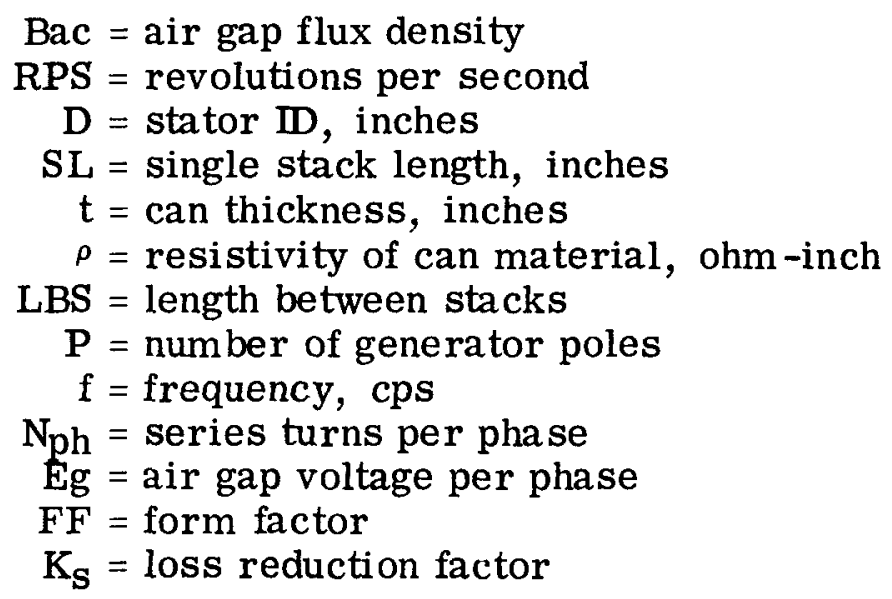

For illustrative purposes, the losses in a metal can for the SNAP-50/ SPUR $467 \mathrm{kva}$ experimental gene rator would have been $228 \mathrm{kw}$ for a 0.010 inch thick can of Inconel X-750 or $135 \mathrm{kw}$ for a 0.010 -inch thick can of Titanium $-12 \%$ Aluminum alloy. The titanium -aluminum alloy has one of the highest resistivities of commercially available materials.

The can loss can not be arbitrarily reduced by operating at lower frequencies if the turbo-generator is to remain a high-speed unit for minimum weight and maximum efficiency since can loss is proportional to rotor peripheral speed. This is illustrated below. Let:

peripheral speed $=\mathrm{v}=(\mathrm{RPS})(\pi \mathrm{D})$, inches $/ \mathrm{sec}$ can volume $=\mathrm{Vol}=\pi(\mathrm{D})(\mathrm{t})(\mathrm{SL})$, cubic inches assume $\mathrm{LBS} \approx \mathrm{SL}$ 
Then:

$$
\mathrm{w} \approx \frac{15.5 * \mathrm{Bac}^{2} \mathrm{~V}^{2} \mathrm{Vol} . * 10^{-16}}{1.5 \pi^{3} \rho}
$$

(watts)

which shows that can losses are proportional to the square of the rotor peripheral speed, the can volume and the inverse resistivity. Since rotor stress is proportional to rotor peripheral speed too, "v" will be high for all highly stressed generator rotors. This indicates that, in general, losses in metal bore seals will be very high for turbine-driven space power generators.

To illustrate the reduction in can loss that can be achieved by lowering the peripheral speed, a low stress design for a $316 \mathrm{kva}$ generator was chosen from the NAS 5-1234 reports for analysis of can losses. Pertinent design information is listed in Table 3.1 along with that for SNAP-50/SPUR for comparison.

\section{Table 3.1 Comparative Can Loss Data}

\begin{tabular}{|c|c|c|}
\hline Item & $\begin{array}{c}\text { Low Stress } \\
\text { Configuration }\end{array}$ & $\begin{array}{c}\text { SNAP-50/SPUR } \\
\text { Configuration }\end{array}$ \\
\hline Generator Rating, kva & 316 & 467 \\
\hline Voltage & $1000 / 1730$ & $120 / 208$ \\
\hline Frequency, cps & 1000 & 3200 \\
\hline Speed, rpm & 15000 & 24000 \\
\hline Diameter, inches & 11.2 & 11.6 \\
\hline Number poles & 8 & 16 \\
\hline Eg, Volts & 1150 & 148 \\
\hline $\mathrm{Nph}$ & 70 & 5 \\
\hline $\mathrm{FF}$ & 0.855 & 0.885 \\
\hline SL, inches & 2.26 & 3.3 \\
\hline LBS, inches & 4.28 & 2.04 \\
\hline $\begin{array}{l}\text { Loss reduction factor (due to can } \\
\text { extension beyond stack) }\end{array}$ & 0.87 & 0.97 \\
\hline Can Mtl. resistivity, microhm-inch & 106, Ti & $-12 \%$ Al Alloy \\
\hline Rotor Peripheral Speed, inch/sec & 8800 & T 14600 \\
\hline Average Stress, psi & 21000 & 57000 \\
\hline Bac, kilolines/in 2 & 71.4 & 55 \\
\hline $\begin{array}{l}\text { Can Loss - kw per } 10 \text { mil can } \\
\text { thickness }\end{array}$ & 33 & 134 \\
\hline
\end{tabular}

As shown in the table, the losses can be reduced considerably; however, they are still too high for practical space power generator requirements. 


\subsubsection{Plans for Coming Quarter}

(a) 1st Cycle of Design Study. Designs will be calculated to determine which combinations of rating, coolant temperature, speed, frequency, and output voltage result in designs with the best combinations of low weight and high efficiency and to screen out combinations of these parameters which result in designs exceeding materials limitations.

A frequency study will first be conducted by the calculation of designs combining the following parameters:

\begin{tabular}{|c|c|c|c|c|}
\hline $\begin{array}{c}\text { Generator } \\
\text { Rating } \\
\text { (MVA) } \\
\end{array}$ & $\begin{array}{c}\text { Coolant } \\
\text { Temp. } \\
\left({ }^{\circ} \mathrm{F}\right) \\
\end{array}$ & Volts & RPM & $\begin{array}{l}\text { Frequency Points } \\
\text { (CPS) }\end{array}$ \\
\hline 0.4 & 8 & 1000 & 24000 & $800,1200,2000,2800,3200$ \\
\hline 1.2 & & 1000 & 15000 & $500,1000,2000,2500,3000$ \\
\hline 6.0 & & 1000 & 10000 & $500,1000,2000,2500,3000$ \\
\hline 12.0 & 은 & 1000 & 8000 & $400,1200,2000,2800,3200$ \\
\hline
\end{tabular}

From the above designs, a frequency will be selected for each rating which provides the best combination of low weight and high efficiency.

Following the frequency study, a speed study will be conducted using the following combinations of parameters:

\begin{tabular}{|c|c|c|c|c|}
\hline $\begin{array}{c}\text { Generator } \\
\text { Rating } \\
\text { (MVA) } \\
\end{array}$ & $\begin{array}{l}\text { Coolant } \\
\text { Temp. } \\
\left({ }^{\circ} \mathrm{F}\right) \\
\end{array}$ & Volts & Frequency & $\begin{array}{c}\text { Speed Points } \\
\text { (RPM)** }\end{array}$ \\
\hline 0.4 & 8 & 1000 & $*$ & 12000 to 30000 \\
\hline 1.2 & & 1000 & $*$ & 8000 to 20000 \\
\hline 6.0 & 8 & 1000 & * & 4000 to 15000 \\
\hline 12.0 & 号 & 1000 & * & 2000 to 12000 \\
\hline
\end{tabular}

*As chosen from preceding frequency study.

**The exact speed points will depend on the frequencies selected.

Five speed points will be chosen from the speed ranges shown. 
From the selected designs, frequency and speed combinations will be selected for each rating which provide the best low weight and high efficiency design and a voltage study will be conducted using the following combinations of parameters:

\begin{tabular}{|c|c|c|c|c|}
\hline $\begin{array}{l}\text { Generator } \\
\text { Rating } \\
\text { (MVA) } \\
\end{array}$ & $\begin{array}{l}\text { Coolant } \\
\text { Temp. } \\
\left({ }^{\circ} \mathrm{F}\right) \\
\end{array}$ & Frequency & $\mathrm{RPM}$ & $\begin{array}{l}\text { Voltage Points } \\
\text { Line-to-Neutral }\end{array}$ \\
\hline 0.4 & 8 & + & + & $500,1000,1500,2140$ \\
\hline 1.2 & - & + & + & $500,1000,1500,2140$ \\
\hline 6.0 & ৪ & + & + & $500,1000,1500,2140$ \\
\hline 12.0 & 8 & + & + & $500,1000,1500,2140$ \\
\hline
\end{tabular}

+Selected from the preceding studies.

All designs calculated will be reviewed and ranges of speed, frequency, voltage and coolant temperature will be tentatively selected for 2nd cycle designs.

(b) 2nd Cycle of Design Study. Results from the first cycle of the design study and data from other studies in the program will be combined to establish generator ratings, speeds, frequencies, voltages, and coolant temperatures to be included in 2 nd cycle designs.

Conclusions reached from analyzing these designs will be used in evolving the conceptual designs for the concluding phases of the program.

\subsection{AC MOTOR PARAMETRIC STUDY}

\section{ABSTRACT}

A review of background information related to the present motor parametric study was made for purposes of determining motor design guidelines, screening study procedures, significant study parameters, and probable problem areas. Approximately 140 preliminary parametric motor designs were made to check out computer design programs, to help establish guidelines for running the actual parametric data, and to help choose materials. Materials were selected and a portion of the supporting materials property data was compiled for use in the screening study. A definitive step-by-step procedure was formulated for efficient implementation and execution of the generation of parametric data. 


\subsubsection{Basis for Parametric Study}

(a) Review of Background Information. A review of previous parametric or design studies (11), (12),(13), (14), (15) on high temperature, liquidalkali-metal-cooled a-c induction motors was conducted to ascertain applicability or usefulness of information contained in those reports to the parametric screening study. The information was found to be useful for:

1. Providing motor design guidelines for high temperature motors operating in unusual or hostile environments of the type pertinent to this design study and eliminating much preliminary "trial and error" design work which would have otherwise been necessary. (Some of these guidelines are discussed in Sections 3.2.1(b) and (c).

2. Determining procedures for generating parametric data in conjunction with item 1 . above. (The parametric study plan of approach is outlined in Section 3.2.2(b).

3. Determining significant parameters for the parametric study. (These parameters are defined in Section 3.2.2(a).

4. Anticipating probable problem areas (e.g., interface temperature rise, outgassing of certain motor components, unique material and fabrication requirements) so that appropriate allowances can be made for these problem areas in generating the parametric data and so that their effects will be reflected in the parametric study results.

5. Helping to choose materials for the various motor components for purposes of the parametric study. (These materials are discussed in Section 3.2.2(a).

It was found that motor performance data produced by these previous studies can only be used a a comparative check on data produced by the present study rather than as a direct and integral part of the data. The reasons for this are:

1. Advances in materials development (3), (4), (16) for application to high temperature machinery since the previous studies plus preliminary results of current work* indicate improved material choices for some motor components. High temperature properties of

*Materials Development under NASA Contract NAS 3-6465 and a concurrent WAED independently funded in-house program. 
materials significantly affect motor performance; therefore, motor performance points determined using different materials properties cannot be used in direct conjunction with each other.

2. Certain design requirements which affected motor performance (e.g., shaft diameter - rotor laminated stack ID - soak conditions, etc.) applicable to the former studies are no longer applicable to the present parametric study. 3 The design procedures in the former studies emphasized producing highly optimized designs for specific SNAP -50/ SPUR applications. It will not be the intent in the present parametric study to produce truly optimized motor designs, but to generate motor performance data on representative motor designs over a larger range of power.

The present study specifies an a-c induction motor design as a basis for the parametric designs; before continuing further, it is appropriate to point out the attributes which make this type of design attractive for prime movers of centrifugal pumps for nuclear electric power plants. These attributes are:

1. Performance characteristics (speed-torque relationship) are compatible with characteristics of centrifugal devices where constant delivery is required. For instance, centrifugal pumps normally do not require high starting torques a-c induction motors are not noted for high starting torques when compared to $d-c$ machines. The a-c induction motor is essentially a constant speed device - centrifugal pumps are normally designed for maximum efficiency at one point comprised of single values of head, capacity, and speed.

2. The basically uncomplicated, electromechanical configuration makes it easier to provide protective cladding for the electromagnetic components. Absence of electrical commutating devices such as slip rings, commutators, brushes, or electronic switching devices vulnerable to hostile environments makes the motor inherently more reliable for long life, trouble-free operation.

(b) AC Motor Design. Parametric data is being produced for threephase, wye-connected induction motors with squirrel cage rotors. The stator and rotor electromagnetic components are protected from the effects of contact with alkali metal in the liquid or vapor phases by hermetically sealed assemblies which incorporate a ceramic bore seal for the stator and a refractory metal cladding system around the rotor. Figure 3.11 is a simplified sketch of the longitudinal cross-section of a typical motor of this type and depicts the basic motor components. 


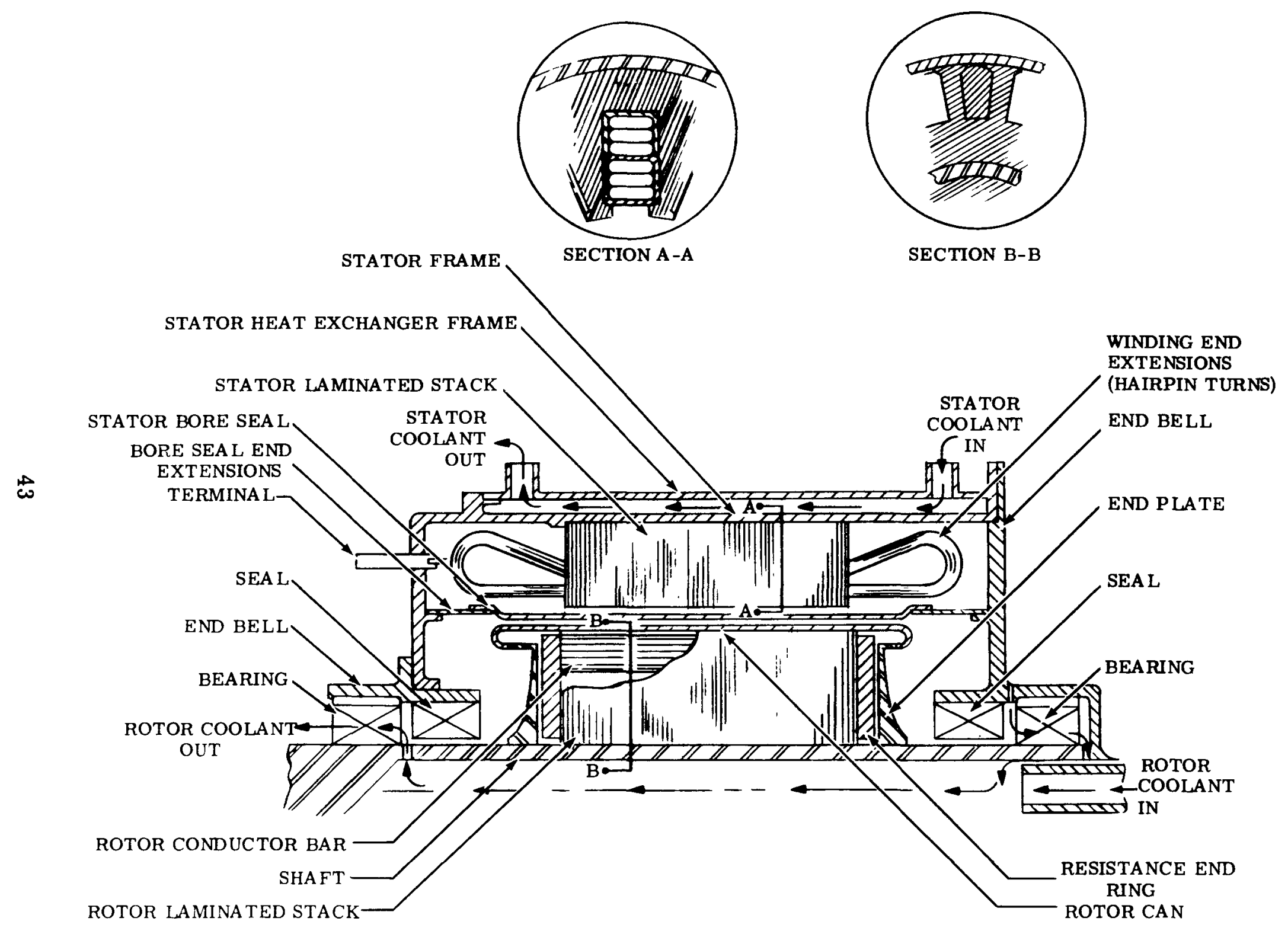

Figure 3.11 AC Motor Configuration 
The stator assembly consists of a primary winding and a laminated stack supported in a hermetically sealed cavity formed by the stator frame, end bells, bore seal, and bore seal end extensions. The motor stator frame serves to position and support the wound stator laminated core as well as protect the core from degradation from exposure to the alkali metal coolant. The heat exchanger frame (or outer half of the motor frame) and motor stator frame jointly form the stator heat exchanger.

The primary windings (stator conductors) are electrically insulated with high temperature resistant insulation. The conductor system is potted with encapsulating compound in the slot cell between the conductors and slot liners and phase separators, and between the slot liner and punching iron. The potting compound is required to promote heat transfer away from the windings and to prevent shifting of the conductors and slot liners.

The stator laminated stack must support the primary windings, provide magnetic flux paths, transmit heat to the stator frame, and transmit the reaction torque to the stator frame. The stator laminations are electrically insulated to reduce eddy-current losses by interlaminar insulation.

The end bells form a part of the stator electromagnetic components encapsulation assembly and support the bearings and rotating seals.

The bore seal, with its end extensions, forms the final sealing element for the stator assembly. The bore seal itself is made from a refractory ceramic composition for high electrical resistance and for alkali metal compatibility.

The rotor assembly consists of the electromagnetic components (laminations, conductor bars, and end resistance rings) surrounded by the cladding system to form a hermetically sealed cavity. The cladding system, which in cludes the rotor shaft, end plates and rotor can, is required to protect the rotor electromagnetic components from the alkali metal. The electrical losses of a metal "can" in the magnetic air gap will not be detrimental so long as contact is maintained with the rotor laminations (14).

The rotor conductor bars conduct the electrical current and complete the electrical circuit through the end resistance rings. Both rotor conductor bars and resistance end rings require high mechanical strength to withstand the rotational stresses at elevated temperature. The rotor laminations provide magnetic flux paths, heat transfer paths, support the conductor bars, and transmit motor torque to the shaft.

The shaft not only supports the rotor laminated stack and transmits motor output torque to the load but also provides a coolant path through the rotor for cooling.

The bearings are of the sleeve type suitable for operation with liquid alkali metal as lubricant and coolant.

The seals are expected to be a hydrodynamic, non-contacting type suitable for operation with alkali metal where the fluid being sealed forms its own barrier. These seals are required to exclude liquid metal from the air gap during operation. 
Applications of motors to the nuclear electric power plant has required extension of current motor design technology to elevated temperature regions. The design remains basically conventional in nature, but allowances must be made for the higher operating temperatures and the unique features required to permit operation in an unusual environment.

The air gap of the motor is extremely wide by ordinary standards because of the presence of the ceramic stator bore seal and the rotor cladding in the electrical "air" gap. The wide air gap results in high exciting current and low power factor. The high temperatures cause the stator winding resistance to be higher than normal; this high resistance in combination with the high exciting current results in increased no-load copper losses.

The inorganic insulation used in the stator slots and on the stator conductors requires much more space than conventional insulation; therefore, the available stator conductor area is less than in a conventional motor. For this reason, the ratio of steel area to copper area is larger than it would be in a conventional design.

The rotor cladding acts like another rotor cage and contributes some useful torque. However, ripples in the flux field caused by the slot openings generate high frequency losses in the cladding of such a magnitude that they cannot be neglected.

To illustrate and to provide an insight into the complexity of formula ting a meaningful procedure for generating motor parametric data (discussed in Section 3.2.2(b)) a discussion of some of the significant motor design parameters and their effects on motor design is presented in the following paragraphs.

The main variables which affect the design of the motor include: stator stack OD, stack length, number of slots, pitch or coil throw, turns per coil, stator stack ID, and the ratio of iron to copper in both the stator and the rotor. The effect of each is discussed below.

(1) Stator Stack OD - The following basic equation applies to any induction motor:

$$
\text { Flux }=\frac{(\text { Constant })(\text { Voltage })}{\text { (Frequency) (Turns) }}
$$

To determine the effect of size (stator stack OD) changes, the frequency and flux density are held constant. Visually, when the diameter is changed, all dimensions in the motor change proportionately. The variation will not be exactly as described below since the relations are greatly oversimplified. However, the relations do indicate trends.

a. Diameter is reduced -- direct first power variation.

b. Flux decreases because of constant density and less area due to both diameter and length reduction. Flux varies directly as the diameter squared. 
c. Turns increase -- frequency and voltage are constant; therefore, because flux reduces, turns must increase inversely as the diameter squared.

d. Resistance increases. More turns means that finer wire must be used, giving a direct squared effect based on the turns change or an inverse fourth power change based on diameter. However, area is also reduced (second power inverse effect based on diameter) and length is reduced (first power direct effect based on diameter). Therefore, the resistance increases inversely as the fifth power of the diameter.

e. Mutual reactance (which governs exciting or no-load current) and leakage reactance increase directly as the turns squared which makes it an inverse fourth power effect based on diameter. However, area (of the flux path) varies directly as the diameter squared and the length directly as the first power. This makes permeance vary inversely as first power of the diameter. Since reactance varies directly with permeance, the net effect is that reactance increases inversely as the diameter cubed.

f. The cooling area, which has the major effect on temperatures since most of the temperature rise is across insulation and interfaces whose length remains constant, reduces directly as the diameter squared.

g. From d. and e., the secondary resistance over leakage reactance ratio increases inversely as the diameter squared.

h. For a negligible resistance (in the total impedance), the exciting current varies inversely with reactance or varies directly as the diameter cubed. Negligible resistance is usually the case.

i. From d. and h., the no-load copper losses decrease directly as diameter to the first power.

j. The output decreases directly as the diameter cubed.

k. Therefore, for constant efficiency, full load losses would decrease as the diameter cubed.

It is possible to conclude from the effects above that as the diameter is reduced, the no-load losses become more and more predominant in the total losses because output is reduced as a third power effect and no-load losses as a unity power effect. If no-load losses are predominant, cooling becomes more difficult as diameter is reduced because the cooling a rea is reduced as a second power effect while no-load losses are reduced as a first power effect. Therefore, at some point, it becomes nearly impossible to cool the motor.

Conversely, as the diameter increases, the load losses will increase as a third power effect, eventually making the no-load losses a small factor. 
Cooling area will increase only as a second power effect. Therefore, eventually motors become too large to cool easily.

Motor weight and the point at which cooling difficulties are encountered can be affected by design manipulation. For instance, if a larger copperto-steel ratio is used in arriving at the shape of the slots, larger and fewer slots are obtained. This results in more efficient slot utilization because of less insulation area and higher efficiency. However, this improvement is limited by an increase in exciting current because of the proportional increase in the slot openings to the total steel surface at the air gap. In other words, Carter's Coefficient - a factor multiplying the air gap length to account for the flux bunching in the teeth - increases.

(2) Stack Length - It is advi sable to maintain the stack length approxi mately equal to the stator ID because of practical manufacturing reasons and because experience has shown that better performance is obtained. This is a compromise between two offsetting tendencies. The torque capability of a motor is approximately proportional to the total valume of material used. Therefore, for the same output, if the OD increases, the stack length must decrease and vice versa. From a purely electrical standpoint, the actual optimum design would tend toward very short stack lengths. The larger diameter, shorter stack length motor tends to have more copper space but also tends to have longer end extensions which contribute more strength, fabrication, and cooling difficulties. The motor running temperatures tend to be lower if, for a given required volume, the diameter is proportionally smaller and the stack length longer. This results in smaller temperature rises above a given coolant temperature because the radial cooling paths of the stack and the winding end extensions are shorter. To obtain a true comparison between individual designs, the stack length should be maintained nearly constant. This is extremely difficult to accomplish because it makes fine design changes very difficult when considering the motors' typically small number of turns-per-coil which must be a whole integral. Therefore, the stack lengths are limited to an equivalent dimension between the stator OD and the stator $\mathrm{ID}$.

(3) Number of Slots/Pitch/Turns per Coil - It is difficult to obtain fine adjustments in the total series conductors per phase and the resultant total flux when the turns per coil is small. Contributing to the difficulty in making fine design changes is the necessity for limiting the number of parallel paths. The use of more parallel paths allows more turns-percoil permitting a finer adjustment. More parallel paths result in more conductors per slot with increased insulation penalties and increased cooling difficulties. The flux level can be adjusted by changing the pitch and by slightly varying the number of slots. With the same total flux, the torque output can be increased by shortening the stack length and increasing flux densities. 
(4) Stator ID/Iron-to-Copper Ratios - Increasing the stator ID has the effect of lowering stator copper area, increasing rotor copper area, and increasing the slot opening. For any given design, if the speed is low, the ID can be increased to increase rotor copper and reduce slip.

For any given design having sufficient speed, the iron-to-copper ratio in the rotor can be increased. Since the maximum rotor magnetic density is fixed by the steel, the stack length must be decreased to continue working the steel at that flux density. The consequent higher gap density results in higher output but the speed decreases because the rotor copper is decreased. Another related effect of smaller stack length is the decrease in cooling area which produces higher temperatures.

(c) Cooling Arrangement and Heat Transfer. The motor cooling arrangement that is assumed for the parametric study is the arrangement conceived during past studies (11), (12), (13), (14), (15) performed by the Westinghouse Aerospace Electrical Division. Essentially, it consists of separate heat sinks for the stator and rotor assemblies formed by the stator heat exchanger and the interior of the motor shaft, respectively.

An alternative cooling scheme is to eliminate the separate stator and rotor heat sinks and cool by passing the liquid metal coolant through the motor bore. This forms a common heat sink for the stator and rotor in the running clearance between the rotor can OD and the stator bore seal ID. It also eliminates the need for the hydrodynamic seals and, for any given mean coolant temperature, would probably permit lower stator and rotor temperature levels (motor losses remaining the same). Conversely, there are indications $(12),(13),(14),(15)$ that problems associated with this mode of operation outweigh the advantages. Drag forces exerted on the spinning rotor by the liquid metal create losses of sufficient magnitude to detrimentally affect the overall motor efficiency. A limited evaluation of one effect of liquid metal being entrained in the running clearance on electrical performance at half synchronous speed was made in a previous motor design study(14), (15). The results showed that electrical losses created in the liquid metal layer reduced the motor efficiency by an additional 11 percent, but increased the power factor by an additional 6 percent. Because of time limitations, these calculations were based on assumptions and approximations which did not include analysis of fluid friction losses.

Another consideration is heat transfer from the stator stack and winding end extensions through the bore seal to the liquid metal coolant. Previous design analyses (14), (15) showed that the ceramic bore seal will not contact the stack ID during operating conditions. Materials for the stator punchings have higher linear coefficients of thermal expansion than the bore seal ceramic material and the relatively high modulus of elasticity and fabrication difficulties prevent using a sufficiently high interference fit between the stator ID and bore seal OD to offset this. This means that heat from the stack must either be radiated to the bore seal OD or be transmitted around through the bore seal end extensions via the stator frame. 
The nature of heat transfer within the motor based on the cooling scheme to be used for the parametric study is discussed in the following paragraphs.

Stator losses occur in the conductors, the stator iron, and the stator bore seal. The major portion of the stator losses occur in the conductors. This heat is generated uniformly throughout the conductor lengths including the end turns. Iron losses occur in both the teeth and the DBS (depth-behindslot) of the punching. It is assumed that the iron losses do not vary from punching to punching so that heat generation in the iron is uniformly distributed axially along the stack.

The rotating electrical field cutting the stator bore seal can produce losses in the bore seal, depending on the material selected. The high electrical resistance of the usual bore seal material - a ceramic composition keeps the se losses to a negligible level.

The heat transfer paths within the stator are axial, cimcumferential, and radial as shown on Figure 3.12. All the heat generated in the winding end turns is assumed conducted axially inward to the stack along each conductor since there is no provision for removing the heat directly to the stator frame. The end turns are presently not considered to be encapsulated with potting compound because the mechanical integrity and the exact heat transfer effects are unknown. A more detailed discussion of some aspects of potting compound is contained in paragraphs to follow on interface thermal resistance. The additional heat from the end turns causes a temperature rise in the punchings at the outer portions. Therefore, there is axial heat flow from punching to punching through the interlaminar insulation toward the middle of the stack.

Heat from the top coil in the slot flows primarily in a circumferential direction through the wire insulation, a layer of potting compound, the slot liner, and the final layer of potting compound to the teeth on either side of the coil, thence radially outward along the teeth to the DBS. The heat from the bottom coil flows both circumferentially through wire insula tion, potting compound, and slot liner to the teeth on either side and radially outward through wire insulation, potting compound, and slot liner to the DBS. Heat from the teeth loss flows radially outward through the punchingframe interface and frame to the coolant.

An a spect of heat transfer of primary concern in cooling the stator is the temperature drop or resistance to heat flow across a joint or interface. Interface thermal resistance seriously affects the flow of heat from the conductors to the iron and, to a smaller degree, from the stator core to the coolant.

In passing from the conductors to the iron, heat must flow through three interfaces: (1) conductor-wire insulation interface, (2) wire insulation-slot liner interface; and (3) slot liner-tooth interface. Westinghouse Aerospace Electrical Division experience has been that temperature drop across the conductor-wire insulation interface is insignificant; the others are usually significant however. 

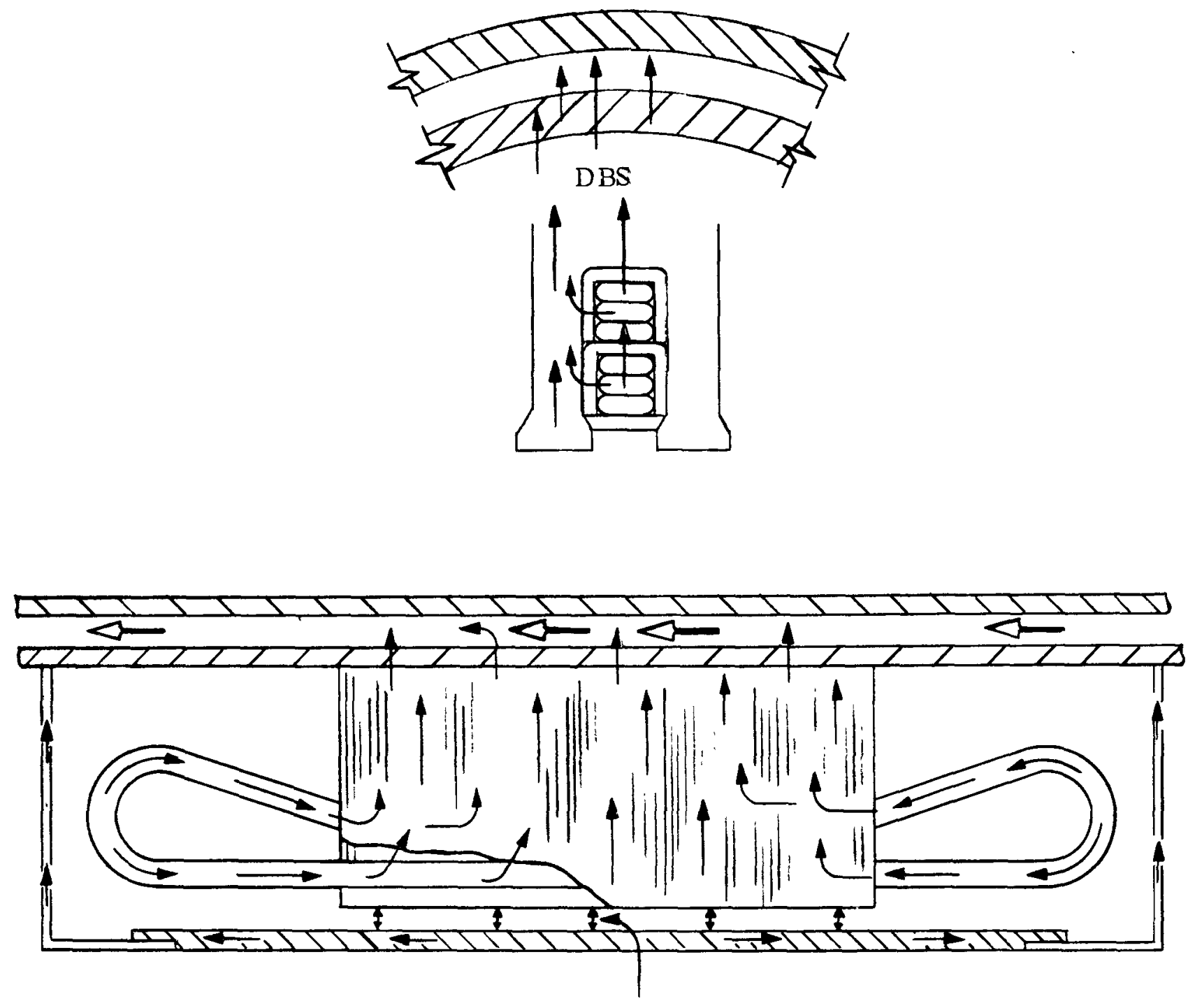

Radiation

Figure 3.12 Stator Heat Transfer Paths 
Heat must flow through the punching-frame interface from the stator core to the coolant. References 17,18 , and 19 present various methods of predicting the temperature drop across an interface. Of the three, Reference 19 presents the most workable design technique. This reference presents results of actual tests with several different materials to determine the thermal conductance coefficient across metal joints. The results are presented in the form of curves where the ordinates and abscissae are expressed in dimensionless quantities. Results vary considerably between the tests, but it is possible to draw a mean curve between the limits of the available data to obtain a design estimate. The curve which will be used to estimate thermal conductance across inter faces in the parametric study is shown on Figure 3.13. Basically, the tests indicate that thermal conductance across a joint is a function of (1) the contact or interface pressure between the two surfaces, (2) the finishes on the two surfaces, (3) the mean interface temperature, and (4) the following properties of the materials which compose the joint: (a) thermal conductivity, (b) density, and (c) hardness.

The curve in Figure 3.13 may be expressed in an empirical expression by: $h_{c}$ is proportional to

$$
\left(\frac{\rho \mathrm{k}}{\mathrm{B}}\right)\left(\frac{\mathrm{p}_{\mathrm{c}}}{\mathrm{B}}\right)^{\cdot 17}
$$

$$
\text { where } \begin{aligned}
\mathrm{h}_{\mathrm{c}} & =\text { thermal conductance, } \frac{\mathrm{BTU}}{\mathrm{hr}-\mathrm{ft}^{2}-{ }^{\circ} \mathrm{F}} \text { or } \frac{\text { Watts }}{\mathrm{in}^{2}-{ }^{\circ} \mathrm{C}} \\
\rho & =\text { material density, } \frac{\mathrm{lbs}}{\mathrm{ft}^{3}} \text { or } \frac{\mathrm{lbs}}{\mathrm{in}^{3}} \\
\mathrm{k} & =\text { thermal conductivity, } \frac{\mathrm{BTU}}{\mathrm{in}-\mathrm{ft}-{ }^{\circ} \mathrm{F}} \text { or } \frac{\text { Watts }}{\mathrm{in}-^{\circ} \mathrm{C}} \\
\mathrm{P}_{\mathrm{c}} & =\text { interface pressure, } \frac{\mathrm{lbs}}{\mathrm{ft}^{2}} \text { or } \frac{\mathrm{lbs}}{\mathrm{in}{ }^{2}} \\
\mathrm{~B} & =\text { Brinell hardness, } \frac{\mathrm{lbs}}{\mathrm{ft}^{2}} \text { or } \frac{\mathrm{lbs}}{\mathrm{in}^{2}}
\end{aligned}
$$

This expression indicates that, of the factors involved, material hardness is the most significant and that softer materials improve thermal conductance across a joint. Also, introduction of a third (soft) material 


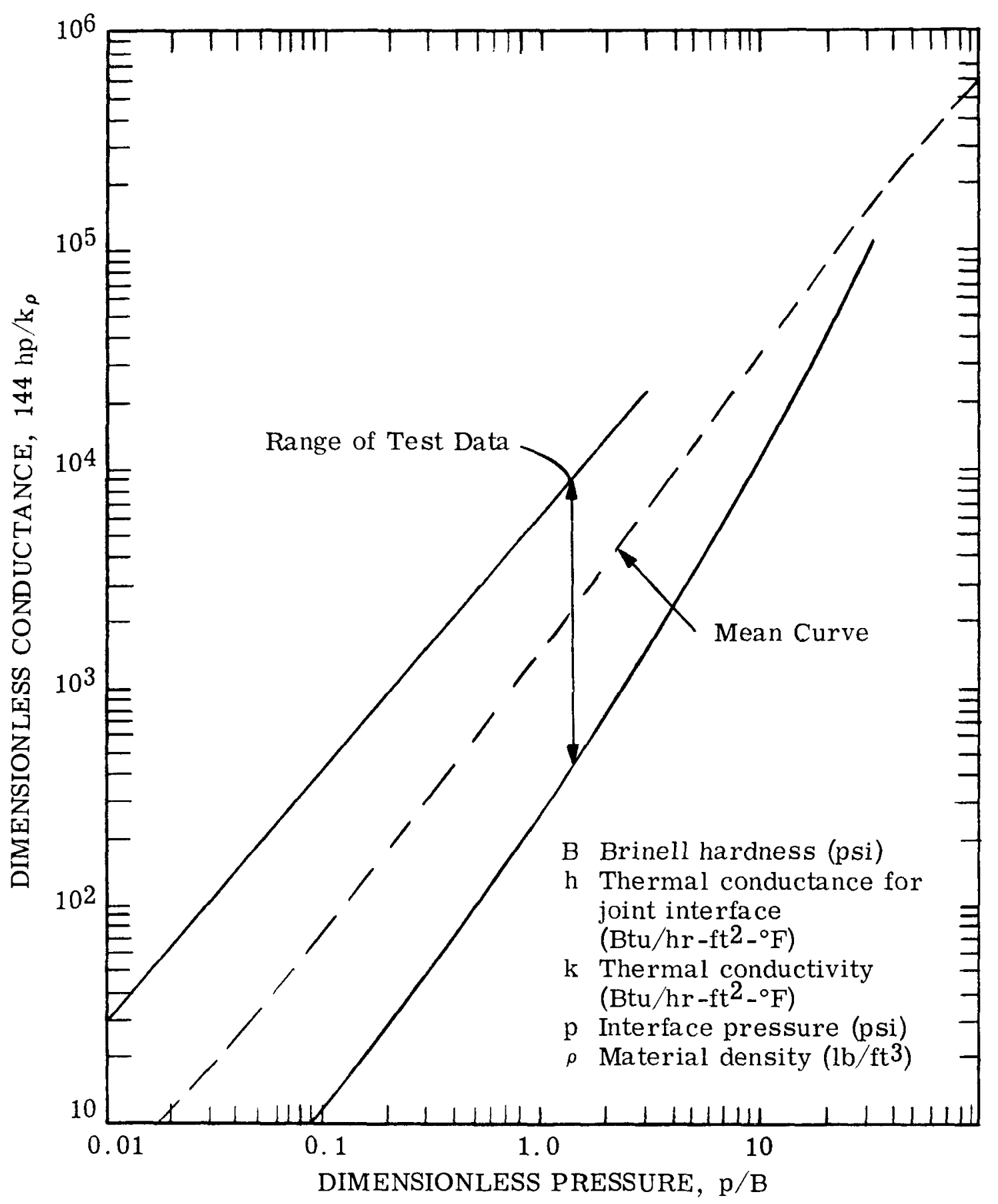

Figure 3.13 Thermal Conductance Across Metal Interfaces 
in the interface between two relatively hard materials improves the the rmal conductance of the joint.

The thermal conductance is directly proportional to approximately the eight root of the contact or interface pressure. There is an upper limit in practice where any further increase of contact pressure does not improve interface thermal conductance appreciably, but this limit can only be determined by considering several complex factors. Usually, maintaining acceptable stress levels limits the contact pressure which may be achieved.

Although neither the finishes of the contacting surfaces of the joint or mean interface temperature appear in the previous expression, both affect thermal conductance. The effect of surface finish is reflected in the variation of test results in Figure 3.13 since the joints tested had various degrees of surface finish. Generally, the better the surface finish of the two surfaces the better the thermal conductance of the joint. Other complex factors must be known before the exact effect of surface finish can be predicted with great accuracy; for instance, it can be shown that thermal conductance is improved if an accurate profile of the microscopic irregularities of both surfaces is available so that the surfaces may be fitted together in such a way that maximum contact area is achieved.

Mean interface temperature variations also contribute to variations of test results in Figure 3.13. There are differences of opinions among investigators about the effect of mean interface temperature but test results from Reference 19 indicate that higher mean interface temperatures tend to improve thermal conductance.

Data for the curve on Figure 3.13 is for joints between two pieces of the same material. The method may be applied to an interface between two dissimilar materials by determining an equivalent thermal conductance:

$$
\mathrm{h}_{\mathrm{eq}}=\frac{2 \mathrm{~h}_{1} \mathrm{~h}_{2}}{\mathrm{~h}_{1}+\mathrm{h}_{2}}
$$

where

$$
\begin{aligned}
\mathrm{h}_{\mathrm{eq}}= & \text { equivalent thermal conductance } \\
\mathrm{h}_{1}= & \text { thermal conductance of a joint composed of two } \\
& \text { pieces of the first material calculated by method } \\
& \text { previously presented. } \\
\mathrm{h}_{2}= & \text { thermal conductance of a joint composed of two } \\
& \text { pieces of the second material calculated by the } \\
& \text { method previously presented. }
\end{aligned}
$$

While the accuracy of the method for estimating thermal conductance across an interface is not known, it is considered considerably better than those neglecting or even estimating interface temperature drops. Using 
this method, calculations have shown that the number of interfaces of the type between the stator punchings and frame should be kept to a minimum. In particular, the punching-frame interiace may account for as much as 25 percent of the total temperature rise between the coolant temperature and winding end turns depending on the materials involved.

The method presented above to determine interface thermal conductance is applicable only where some estimate or calculation of the contact pressure can be made. In the conductor slots, however, the contact pressure at the interfaces cannot be readily estimated. Because the slot liner material is usually brittle and of low flexural strength, it is not desirable to design for an interference fit to assure good contact between the conductors, slot liners, and teeth. To promote heat transfer through the slot the interfaces may be filled with a soft interstitial material such as potting compound. Even the use of potting compound does not guarantee 100 percent contact. At the present time, more investigation is needed to determine the degree of contact which may be expected using potting compound.

Environment must also be considered when evaluating heat transfer across an interface. For instance, under hard vacuum, it is difficult to determine the exact amount of heat transfer between surfaces forming a mechanical joint. It is probably valid to conclude conditions will be worse than when the joint is surrounded by some gas such as air, argon, nitrogen, etc. In this regard, it is important to know the conditions that exist within the sealed stator and rotor assemblies. There are several possibilities:

(1) Stator Cavity Open to Space Vacuum - Besides having the problem discussed above at the stator stack-frame interface, other problems may develop in the slots. Outgassing at elevated temperatures of slot components in the confined spaces of the slot may cause the pressure to build up in the voids and crevices to a value which produces minimum electrical strength and a phenomenon called electrical discharge corona occurs. Even though the outgassing products may promote heat transfer, conditions must be maintained such that corona effects are minimized and breakdown is prevented.

(2) Stator and Rotor Cavity Evacuated and Hermetically Sealed - In this instance the danger of rupture of component cladding with pressure buildup from outgassing exists unless the unit is designed to maintain a pressure differential.

(3) Preliminary Outgassing of Stator and Rotor Components, Evacuation, Backfilling with Inert Gas, and Hermetically Sealing - This introduces unknowns relative to fabrication techniques and the possibility of the problem described in (2) occurring cannot be totally eliminated. It is also undesirable from a systems standpoint since the non-condensable gas could eventually permeate into the turbine condenser system. 
For purposes of the parametric study, it was assumed that the stator and rotor cavity are hermetically sealed and that solutions to avoid corona pressures or excessive outgassing pressure build-up have been found. This will permit thermal conductance across interfaces to be treated as described in previous paragraphs.

Significant improvements in stator cooling could be made by providing a means of removing heat generated in the winding end extensions directly to the frame. This would involve, among other considerations, radiation to the end bells or potting the winding end extensions. Experimental evaluation is needed before any analytical improvements can be determined for reasons previously discussed.

The rotor losses occur in the conductor bars, end rings, at the tips of the punching teeth, and in the rotor can. The major portion of the rotor losses occur in the conductor bars where heat is generated uniformly throughout. The rotor can losses may be assumed to be distributed uniformly over the entire can. Heat transfer paths within the rotor are cimcumferential, radial, and axial as shown in Figure 3.14.

Heat from the conductors flows circumferentially through an oxide coating on the conductor bar surface and through the conductor bar-rotor tooth interface to the rotor teeth. Heat from the rotor can combines with this heat to flow radially inward to the rotor coolant through the punchingshaft interface and the shaft itself. Heat from the end rings flows inward to the conductor bars or into the shaft depending on whether the end ring ID contacts the shaft. This is determined by permissible geometrical proportions of the ring that yield the correct volume required by electrical design considerations.

Interface thermal resistance is again of concern in cooling the rotor. There are four interfaces to be considered in the rotor. These interfaces are (1) the conductor bar-tooth interface, (2) the rotor can-punching interface, (3) the punching-shaft interface, and (4) the resistance end ring-shaft interface, if present. The punching-shaft interface is the most critical; calculations (14), (15) show that the conductor bar-tooth interface is not a problem. Sufficient contact pressure can be maintained between the conductor bar and tooth to provide adequate heat transfer. So long as contact pressure is maintained between the rotor can and punchings (even as low as 40 psi), sufficient heat transfer can be maintained across the rotor can-punching interface.

\subsubsection{Parametric Study}

(a) Status to Date. Initial efforts were directed toward defining the basic motor design points for which parametric relationships would have the most significance to the overall system definition. This includes a means of comparing motor-driven centrifugal pump packages to electromagnetic pumps. The parameters chosen and their range of values to be investigated are: 


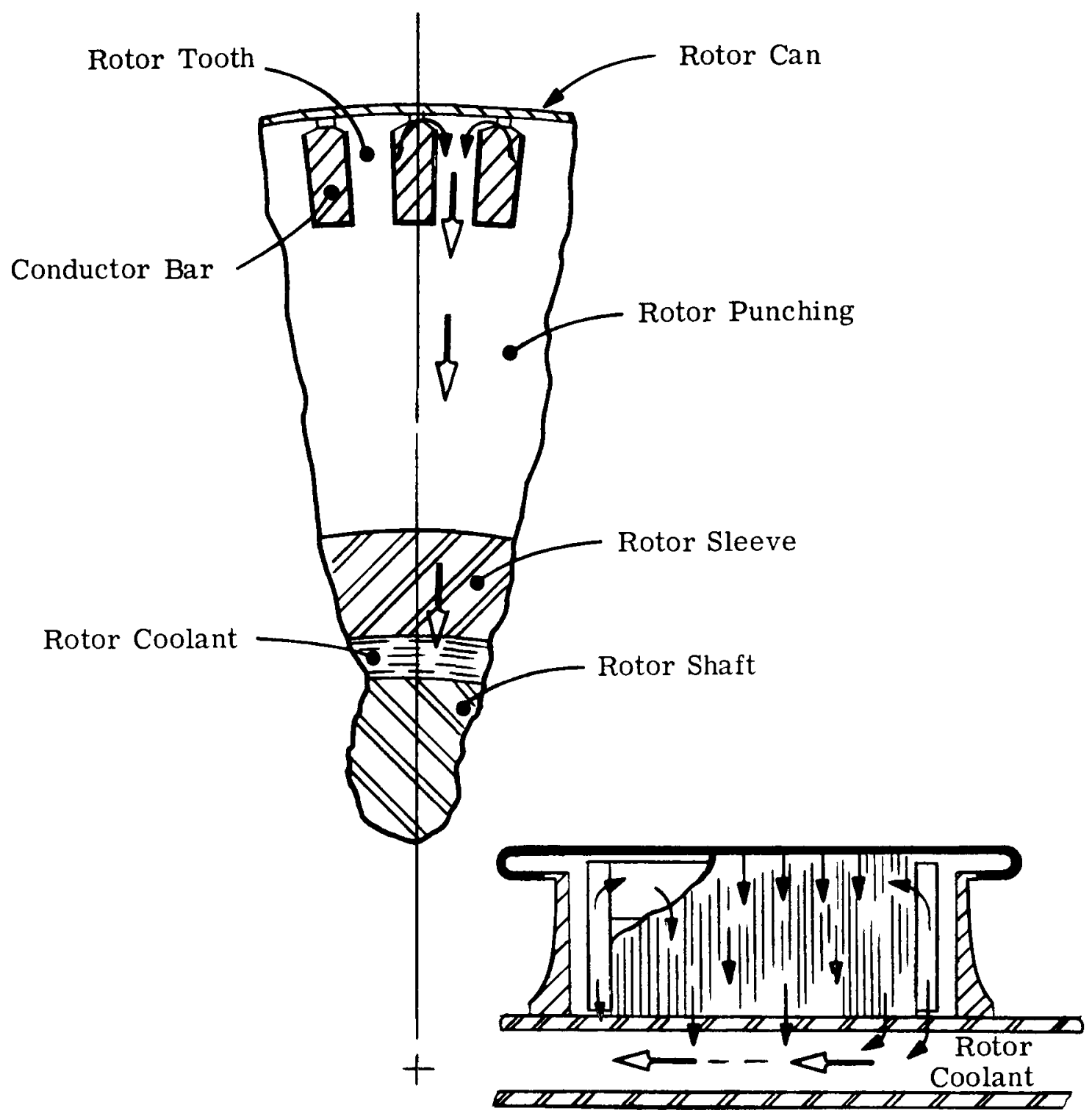

Figure 3.14 Rotor Heat Transfer Paths 
Parameter

Rating

Speed

Voltage

Frequency
Range

5, 30, 60, 100, 250 Horsepower

$4000,8000,10000,15000$, $20000 \mathrm{RPM}$

$120,240,480,1000$ Volts

(line-to-neutral)

$200,400,600,800,1000$, $2000 \mathrm{CPS}$

$500,800,1100^{\circ} \mathrm{F}$

These particular values were chosen because (1) they are natural, basic input items to the motor-design computer program (see Section 3.2.2(b)), (2) they correspond to related parameters used in the generator parametric study, or (3) they comply with the contract work statement. Parametric relationships between three other significant motor characteristics (weight, efficiency and power factor) are derived by varying the parameters above. Remaining motor design parameters fall into two general categories:

1. Those which must be varied to achieve practical designs for the combinations of basic parameters listed above. The most significant of these parameters have been listed and discussed in previous sections.

2. Those which may be held constant throughout the parametric study.

Discussion of the parameters in category 2 above is presented in the following paragraphs. Assumptions involved in determining values for some of these parameters are extremely important in both the conclusions and the significance of the conclusions drawn from the parametric data.

Extensions of current motor design technology to the elevated temper ature regions necessitates paying close attention to the interdependences between electrical design, mechanical design, and materials considerations. Electrical designs are more sensitive to mechanical design considerations than in conventional motor design; materials considerations influence both electrical design and mechanical design by imposing more design restrictions than usal. This is because of the elevated temperature, alkali metal compatibility, and low weight-high performance requirements imposed on both electromagnetic and structural materials. Careful attention must be given to selection of motor materials not only because of the effect of their contribution to determining practical motor design performance but also 
because materials limitations most often determine the upper limit of practical design feasibility.

Much of the effort in the first quarter has been concentrated toward defining materials choices to use for design throughout the parametric study. An effort was made to use materials consistent with those used in the generator for similar applications wherever possible. Table 3.2 is a summary of the materials selection for the parametric study listing the basic motor component, component material choice (different materials selections for different temperature ranges where applicable), and a short statement of reason for choice.

There are numerous alloys which could have been selected for the motor structural components - depending upon individual combinations of temperature, alkali metal coolant involved, and relative thermal expansion characteristics. One design consideration that is different from the generator is that the motors will be required to operate in all the power plant system loops; therefore, consideration of more than one alkali metal coolant must be given in the choice of motor materials. This may be done either by selecting a satisfactory material for all contemplated coolants or by selecting different materials for each coolant. Usually, a tradeoff is involved between obtaining the best over all combination of properties and obtaining compatibility with the largest number of different alkali metals. For purposes of the parametric study, one material was selected for all coolant designs to (1) reduce the number of design variations between parametric designs and (2) to simplify handling material property data in the analysis. It was assumed the probable coolants involved would be lithium, potassium, and eutectic sodium-potassium (NaK) based on heat transfer media used in the SNAP-50/SPUR power plant and others $(7),(8)$. Consideration of a single material with long term resistance to all three alkali metals restricted choice to a refractory metal because of lithium compatibility requirements. Of the three refractory metal alloys considered - columbium, tantalum, and molybdenum - tantalum T-111 was chosen because it: (1) exhibits mechanical properties at elevated temperature as good as the other candidate materials including good creep strength favorable for long life service, (2) shows promise of requiring no post-weld heat treatment which permits less complicated canned motor fabrication techniques, and (3) is being used more extensively in current liquid metal technology programs which may indicate extensive use throughout future power plant systems. In this respect, fabricating the motor using tantalum $T-111$ would tend to prevent undesirable bi-metallic systems.

Results of preliminary motors designs mode using the motor design computer program in conjunction with the detailed temperature calculation subroutine indicate that stator conductor hot spot temperatures, which usually occur in the winding end extension hair-pin turns, may exceed the maximum temperature $\left(1400^{\circ} \mathrm{F}\right)$ permissible for long term stability of the Inconel 600 clad silver wire. For those designs, two alternatives are possible: (1) Increase the size of the motor or otherwise improve cooling so that the hot spot temperature is reduced to less than $1400^{\circ} \mathrm{F}$ or, (2) substitute dispersion- 
Table 3.2 AC Motor Component Material Selection for Parametric Design Study

Component

1. Stator Frame

2. Stator Laminations

\section{$500^{\circ} \mathrm{F}$ coolant}

Tantalum T-111

Basis:

Long term compatibility with system alkali metal coolants ( $\mathrm{Li}, \mathrm{K} . \mathrm{NaK}$ ) contemplated in the past (coolants for present systems have not been defined) together with good mechanical properties at elevated temperature.

3. Stator Interlaminar Insulation
Material

$800^{\circ} \mathrm{F}$ coolant

Tantalum T-111

Basis:

Same as $500^{\circ} \mathrm{F}$

$1100^{\circ} \mathrm{F}$ coolant

Tantalum T-111

Basis:

Same as $500^{\circ} \mathrm{F}$

\section{Hiperco 27}

Basis:

Based on results of work presented in Reference 3 .

Hiperco 27

Basis:

Same as $500^{\circ} \mathrm{F}$

Plasma - arc Sprayed Alumina Basis:

Based on results of work presented in Reference 4.

Aluminum Orthophosphate Basis:
Based on results of work presented in Reference 4. Better stability and mini mum outgassing at the higher temper ature levels.
Hiperco 27

Basis:

Same as $500^{\circ} \mathrm{F}$

Plasma - arc

Sprayed Alumina Basis:

Same as $800^{\circ} \mathrm{F}$ 
Table 3.2 AC Motor Component Material Selection for Parametric Design Study (continued)

\section{Component}

4. Stator Conductor

5. Stator Conductor Insulation

\section{$500^{\circ} \mathrm{F}$ coolant}

Inconel 600 Clad Silver Basis:

Based on results of work presented in Reference 4 .

Anadur - refractory oxide and glass frit over E-glass fiber serving with silicone resin bonding.

Basis:

Based on results of work presented in Reference 4.
Material

$800^{\circ} \mathrm{F}$ coolant $\quad 1100^{\circ} \mathrm{F} \mathrm{coolant}$

Inconel 600 Clad

Silver $<1400^{\circ} \mathrm{F}$

Dispersion Strength ened Copper (Cube)

$>1400^{\circ} \mathrm{F}$

Basis:

Inconel 600 Clad

Silver $<1400^{\circ} \mathrm{F}$

Dispersion Strengthened Copper (Cube)

$>1400^{\circ} \mathrm{F}$

Basis:

Based on results of work presented in Reference 4. DS

Copper required for metallurgical stability at temperatures $>1400^{\circ} \mathrm{F}$.

Anadur $<1150^{\circ} \mathrm{F}$

Anadur $<1150^{\circ} \mathrm{F}$

Plasma - arc Sprayed Alumina on preformed coil $>1150^{\circ} \mathrm{F}$

Basis:

Plasma - arc Sprayed

Alumina on preformed coil $>1150^{\circ} \mathrm{F}$

Basis:

Based on results of Same as $800^{\circ} \mathrm{F}$

work presented in Reference 4. Plasmaarc sprayed alumina required at temperature $>1150^{\circ} \mathrm{F}$ for long term stability.

\section{Same as $800^{\circ} \mathrm{F}$}


Table 3.2 AC Motor Component Material Selection for Parametric Design Study (continued)

Component

6. Stator Slot and Phase Insulation

7. Stator Slot Wedges

8. Stator Encapsulation

(Potting Compound) $500^{\circ} \mathrm{F}$ coolant

Alumina, $98.5 \%$ Purity Basis:

Based on results of work presented in Reference 4.

Alumina, 98. 5\% Purity

Basis:

Based on results of work presented in Reference 4.

Westinghouse W839

(Aluminum Orthophosphate bonded Zirconium silicate) Basis:

Based on results of work presented in Reference 4 .
Material

$800^{\circ} \mathrm{F}$ coolant

Alumina, $98.5 \%$

Purity

Basis:

Same as $500^{\circ} \mathrm{F}$

Alumina, $98.5 \%$

Purity

Basis:

Same as $500^{\circ} \mathrm{F}$

W839 $\leq 900^{\circ} \mathrm{F}$

(Boron Nitride com pound presently in development stage for $>900^{\circ} \mathrm{F}$ )

Basis:

Based on results of work presented in Reference 4. For temperatures $>900^{\circ} \mathrm{F}$, Boron Nitride com pound appears attractive at this time but it is in development state only. $1100^{\circ} \mathrm{F}$ coolant

Alumina, $98.5 \%$

Purity

Basis:

Same as $500^{\circ} \mathrm{F}$

Alumina, $98.5 \%$

Purity

Basis:

Same as $500^{\circ} \mathrm{F}$

W839 $\leq 900^{\circ} \mathrm{F}$

(Boron Nitride compound presently in development stage for $>900^{\circ} \mathrm{F}$ )

Basis:

Same as $800^{\circ} \mathrm{F}$ 
Table 3.2 AC Motor Component Material Selection for Parametric Design Study (continued)

\section{Component}

9. Stator Bore Seal

10. Rotor Can

11. Rotor Conductor Bar

\section{$500^{\circ} \mathrm{F}$ coolant}

Alumina, 99\% Pure Basis:

Based on results of work presented in Reference 16. Offers alkali metal compatibility with high electrical resistance.

Tantalum T-111

Basis:

Good mechanical properties at elevated temperatures combined with compatibility with all probable alkali metal coolants.

\section{Dispersion Strengthened} Copper (Cube) Basis:

Based on results of work presented in Reference 4. Good mechanical proper ties and stability at elevated temperatures to resist centrifugal loads in rotor for long life.

Material

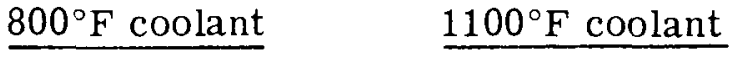

Alumina, $99 \%$ Pure Basis:

Same as $500^{\circ} \mathrm{F}$

Tantalum T-111

Basis:

Same as $500^{\circ} \mathrm{F}$

Dispersion Strengthened Copper (Cube)

Basis:

Same as $500^{\circ} \mathrm{F}$
Beryllia, $99.8 \%$ purity, high density Basis:

Based on results of work presented in Reference 16. Required for long term, alkali metal compati bility at higher tem perature levels.

Tantalum T-111

Basis:

Same as $500^{\circ} \mathrm{F}$

Dispersion Strengthened Copper (Cube) Basis:

Same as $500^{\circ} \mathrm{F}$ 
Table 3.2 AC Motor Component Material Selection for Parametric Design Study (continued)

\section{Component}

12. Rotor Resistance End Ring

13. Rotor Laminations

\section{$500^{\circ} \mathrm{F}$ coolant}

Cube

Basis:

Based on results of work presented in Reference 4. Good mechanical properties and stability at elevated temperatures to resist centrifugal loads in rotor for long life.

Hiperco 27

Basis:

Based on results of work presented in Reference 3 .

Tantalum T-111

Basis:

Good mechanical properties (including fatigue properties) at elevated temperatures combined with compatibility with all probable alkali metal coolants.
Material

$800^{\circ} \mathrm{F}$ coolant

$1100^{\circ} \mathrm{F}$ coolant

Cube

Basis:

Cube

Basis:

Same as $500^{\circ} \mathrm{F}$

Same as $500^{\circ} \mathrm{F}$

Nivco

Basis:

Niveo

Basis:

Based on results of work presented in Reference 3 . Required for better strength and creep strength at higher tempe rature levels.

Tantalum T-111

Basis:

Tantalum T-111

Same as $500^{\circ} \mathrm{F}$
Basis:

Same as $800^{\circ} \mathrm{F}$

Same as $500^{\circ} \mathrm{F}$ 
strengthened (D.S.) copper for the clad silver conductor. Alternate number (1) might cause many high temperature designs to appear unfavorable or be eliminated from consideration because of excessive weight. Therefore, it would appear that despite the slightly inferior electrical properties of D.S. copper, alternative number (2) would be the better of the two. There is one serious draw-back to use of D.S. copper; forming stator winding coils from pre-insulated D.S. copper does not appear feasible at the present time, and there are currently no techniques developed capable of insulating formed coils of D.S. copper. However, for purposes of the parametric study, it was considered more reasonable to expect that such techniques could be developed, if required, than to eliminate potential designs due to unfavorable weight considerations.

The preliminary designs also indicated that temperatures of the potting compound in the stator slots for the higher coolant temperature (some at $800^{\circ} \mathrm{F}$, all at $1100^{\circ} \mathrm{F}$ ) designs may exceed $900^{\circ} \mathrm{F}$. Currently, there is no potting compound having combined compatibility with the electromagnetic materials involved and acceptable outgassing rates suitable for service above approximately $900^{\circ} \mathrm{F}$. The parametric study will proceed on the assumption that a boron nitride compound presently in the development stages and which shows some promise will ultimately become available. Since effects of the potting compound in the parametric study is limited to effects on temperature distribution and since calculation of temperature drop in the slots is inexact it is believed that differences in assumptions regarding the potting compound will have minor effects on results of the parametric study.

Finally, it should be pointed out that problems with application techniques of plasma-arc sprayed alumina to conductors will have to be eliminated before this form of insulation can be considered available for practical use for temperatures above $1150^{\circ} \mathrm{F}$.

Additional electrical and mechanical design parameters for which definitions have been established, assumptions made, or are in the process of being determined are listed with short discussions below. Note that some assumptions are in the form of rules of estimation for use throughout the parametric study and that materials considerations again help determine some of the assumptions.

(1) Maximum Torque Ratio - For centrifugal device applications it is usually satisfactory to have a maximum torque of 200 percent of rated torque (for small motor ratings). This usually gives close to optimum efficiency and power factor. It also allows for some variation in voltage and frequency. Variations in voltage and frequency cause higher losses, which become worse as the ratio of maximum torque to rated torque decreases. For larger ratings and for general purpose motors that require some starting torque, this ratio of maximum torque to rated torque is sometimes increased to 250 percent or higher to obtain better efficiency. This is done at the sacrifice of a higher starting current. However, since larger motors generally are difficult to cool, higher efficiency is more desirable. A ratio of maximum torque to rated torque 
of 2.25 was selected for this study. Since the output torque varies with the volume of steel, it will be necessary to hold this ratio constant to obtain a true comparison.

(2) Stator Conductor and Slot Configuration - Rectangular wire, called strap, has been chosen for the stator conductor instead of the more conventional round wire. A previous study (12), (13) conducted by Westinghouse Aerospace Electrical Division determined that a wire-wound motor for this application would be impractical. It was concluded that the reasons for this were:

a. Higher wire-wound stator resistance from less efficient slot use; i.e., inability to completely fill the available slot winding space with conductor because of the circular cross-section of the wire. Higher stator resistance results in higher stator losses.

b. Higher resistance to heat transfer within the slot because of lower equivalent thermal conductivity than for strap and less cross-sectional area available for heat transfer perpendicular to direction of heat flow from conductors to iron. This results in higher slot temperatures for a given coolant temperature.

The combination of factors above caused losses and temperatures to be of impractical proportions for the wire-wound designs.

Normally, the wire-wound stator would have an offsetting advantage. Because it is possible to use partially closed slots with a wire-wound motor, it is possible to make the teeth thinner without increasing the slot opening. Thus, the teeth could be thinned to the point where they are worked at the maximum magnetic density as determined by the steel properties. More winding area could be obtained in this manner. Thinning the teeth of the strap-wound motor results in wide slot openings because a strap to fit the wider slot must be inserted through the slot opening. The wide slot openings cause the flux to bunch under the teeth and increase the effective length of the air gap. However, there are two factors which reduce the significance of this advantage for wire-wound designs:

a. The motor designs being contemplated for this application have long air gaps compared to normal standards because space must be allowed for the bore seal and rotor can as well as for running clearance. The long air gap tends to reduce the detrimental effect of wider slot openings required by strap designs.

b. A slot configuration different than the conventional slot and similar to that employed in the generator will be employed to partially close the slot while still using strap. 
The better utilization of winding space and the better heat transfer for the strap-wound motor more than offset the advantages of the wire-wound motor. Therefore, it is concluded that the motor should be strap wound.

(3) Rotor Bar Configuration - Parallel sided teeth in the rotor lamina tions result in a trapezoidal slot shape. The rotor conductors will have a trapezoidal shape also to fully utilize the available conductor area. Trapezoidal conductor bars decrease the electrical resistance at high operating temperatures by providing maximum conductor cross-sectional area. This maintains high operating speed (decreases slip).

(4) Air-Gap Length - The following formula is used to determine the, electrical air-gap length:

Air - Gap Length $=$ Rotor - Can Thickness + Stator Bore Seal Thickness + Running Clearance + BoreSeal Clearance.

a. Rotor-Can Thickness - To be determined at all ratings for various speeds and temperatures. Previous studies (14), indicate that a thickness of 0.015 inches will be satisfactory for most of the 5 to $30 \mathrm{HP}$ designs. For purposes of the parametric study, a rule of estimation of rotor can thickness will be established based on proportioning results of previous studies as a function of diameter, speed, and temperature.

b. Stator Bore-Seal Thickness - The ceramic stator bore-seal thickness is dictated by the minimum manufacturable thickness which is impermeable to the liquid metal. The bore seal thicknesses to be used for the motor parametric study are as follows:

Bore Seal O.D.

(inches)

4.0

6.0

8.0

10.0

12.0

Thickness (inches)

Alumina $\quad$ Beryllia

0.024

0.036

0.048

0.060

0.072
0.070

0.080

0.090

0.100

0.110

c. Running Air Gap - This is the radial clearance between the rotor can OD and the stator bore seal ID. Past analysis (12), $(13),(14),(15)$ have shown that 0.0125 -inch is adequate for the lower ratings $(5-30 \mathrm{HP})$, and this figure will be used for the current parametric study. An adequate clearance will be determined for the larger ratings (60-250 HP). 
d. Bore Seal Clearance - The bore seal will probably not contact the stator stack ID during rated operating conditions for reasons stated previously. Radial clearance between the bore seal and stator stack ID of 0.002 -inch will be assumed throughout this parametric study.

(5) Stator and Rotor Slot Component Dimensions, Allowances, and Tolerances - In general, these parameters are used to determine stator and rotor slot dimensions. Ability of the part to satisfactorily perform its function determined the dimensions which were based on mechanical strength, electrical strength, and fabrication considerations. Allowances and tolerances are based on fabrication limitations. These parameters and their values for the motor parametric study are listed below along with brief, amplifying statements on their functional significance where it is considered important.

a. Stator Slot Liner Thickness and Tolerance - The following thicknesses were chosen to provide the necessary electrical strength at temperature, to resist corona glow and electrical breakdown between the conductors and stator iron under the unique stator cavity environment, and to reflect current fabrication limitations:

$\begin{array}{lcc}\text { Voltage } & \begin{array}{c}\text { Slot Liner } \\ \text { Thickness } \\ \text { (inches) }\end{array} & \begin{array}{c}\text { Tolerance } \\ \text { (inches) }\end{array} \\ {\text { (line-to-neutral) }} } & 0.018 & \\ 240 \mathrm{~V} \text { (line-to-neutral) } & 0.018 & \pm 0.002 \\ 480 \mathrm{~V} \text { (line-to-neutral) } & 0.018 & \pm 0.002 \\ 1000 \mathrm{~V} \text { (line-to-neutral) } & 0.030 & \pm 0.002\end{array}$

b. Stator Conductor Insulation Thickness - The following thicknesses were chosen to provide sufficient electrical strength at temperature, to resist corona glow and electrical breakdown between the conductors and stator iron under the unique stator cavity environment, and to reflect current fabrication limitations: 
Insulation Thickness (inches)

Plasma-arc

Voltage

$\underline{\text { Anadur }}$

sprayed Alumina

$120 \mathrm{~V}$ (line-to-neutral)

0.011

0.008

$240 \mathrm{~V}$ (line-to-neutral)

0.011

0.008

$480 \mathrm{~V}$ (line-to-neutral)

0.011

0.008

$1000 \mathrm{~V}$ (line-to-neutral)

0.011

0.008

c. Insulated Stator Conductor Dimensional Tolerance - These tolerances are:

Insulation

Anadur

Plasma-arc sprayed Alumina
Tolerance

(inches)

$\pm 0.002$

$+0.005$

$-0.002$

d. Rotor Trapezoidal Bar Dimension Tolerance - There, the tolerances are:
(1) Height +0.003
$-0.000$
(2) Width +0.001
$-0.002$
inches

e. Slot Clearances - These allowances are as follows:

1) Stator Slot

a) Circumferential (lateral) - 0.005-inch

b) Radial (vertical) - 0.001-inch per conductor +0.002 -inch

\section{2) Rotor Slot}

a) Circumferential (lateral) - 0.008-inch + an addi tional allowance proportional to the excess of rotor OD over 2.5 -inches. The latter additional allowance is determined from an empirical rule which has given good results in the past. The intent of this allowance is to allow for possible difficulties involved with skewing the rotor stack.

b) Radial (vertical) - 0.006 -inch + an additional allowance proportional to the excess of the rotor OD over 2.5 -inches. 
f. Allowance for Stator Punching Tolerance and Punching Stagger - The allowances to be used in the motor parametric study are (1) radial - 0.008-inch, and (2) circumferential - 0.008-inch. (Allowance for rotor punching tolerance is included in the rotor slot clearances given in item e.2) above. Allowance for rotor punching stagger is not required because the rotor bar is inserted in the rotor slots while the rotor punchings are still loose in the angular direction.

(6) Rotor Stack ID - This corresponds to the necessary shaft diameter to support the rotor mass within acceptable limits of deflection, to transmit maximum torque without failure for the required life, and to provide an adequate coolant passage for the rotor. A rule for estimating the required shaft size for the various combinations of sizes, speeds, and temperatures is currently being determined. Precise effects of bending loads from pump impellers will not be considered in shaft sizing for the parametric study because of lack of definition at this time.

(7) Minimum Bending Radius of Stator End Extensions Hair-Pin Turns This factor is determined by coil forming techniques. There is a limit to the sharpness of bends which may be made in the insulated conductor when forming the coils. This factor affects the mean length of turns in the stator coil; therefore, it affects the weight of the windings and winding resistance. A rule of thumb for specifying the minimum bending radius of the rectangular conductor as a function of its smallest dimension is being prepared.

(8) Heat Sinks - All heat generated in the stator will be assumed removed at the stator heat exchanger by the stator coolant. This includes heat generated in the winding end extensions which is assumed to flow entirely into the stator stack and then into the stator coolant. Likewise, all heat generated in the rotor is assumed removed at the shaft ID by the rotor coolant. In other words, for the parametric study, it is assumed that there is no heat exchange between the stator and rotor assemblies by conduction, convection, or radiation.

(9) Windage - This is the term used to designate motor losses from viscous friction forces acting between the fluid (liquid or vapor) and the spinning rotor or between portions of the fluid with imparted velocity and the stationary stator and end bells. Windage affects motor efficiency by absorbing some of the useful motor output. Accurate evaluation of windage losses is complex; however, a means of approximating these losses as a function of size, speed, temperature, geometry and fluid properties will be developed so that the effect of windage can be reflected in relative motor performance for the parametric study. At this time it is expected that the appropriate properties of potassium will be used to determine windage losses. 
(10) Friction - This is the term used to designate motor losses which occur in the motor bearings and seals. A means of estimating these losses as a function of speed and fluid properties is all that will be developed for the parametric study because a detailed analysis is not considered appropriate at this stage of the study.

(b) Procedure for Completing the Parametric Study. Preliminary parametric motor designs (without detailed temperature calculations) tabulated be low were made, reviewed, and the significant parameters were compiled and tabulated for quick reference and comparison. These designs covered the following range of parameters:

\begin{tabular}{|c|c|c|c|c|}
\hline$\underline{\mathrm{HP}}$ & $\begin{array}{l}\text { Voltage } \\
\text { (L to L) }\end{array}$ & $\begin{array}{l}\text { Frequency } \\
\text { (cps) }\end{array}$ & RPM & $\begin{array}{l}\text { Coolant } \\
\text { Temp }\left({ }^{\circ} \mathrm{F}\right)\end{array}$ \\
\hline 5 & 120 & $\begin{array}{l}200,400,600 \\
800,1000\end{array}$ & $\begin{array}{l}4000,8000,10000 \\
15000,20000\end{array}$ & 500 \\
\hline 30 & 120 & $\begin{array}{l}200,400,600 \\
800,1000\end{array}$ & $\begin{array}{l}4000,8000,10000 \\
15000,20000\end{array}$ & 500 \\
\hline 60 & 120 & $\begin{array}{l}200,400,600 \\
800,1000\end{array}$ & $\begin{array}{l}4000,8000,10000 \\
15000,20000\end{array}$ & 500 \\
\hline 100 & 120 & $\begin{array}{l}200,400,600 \\
800,1000\end{array}$ & $\begin{array}{l}4000,8000,10000 \\
15000,20000\end{array}$ & 500 \\
\hline 250 & 120 & $\begin{array}{l}200,400,600 \\
800,1000\end{array}$ & $\begin{array}{l}4000,8000,10000 \\
15000,20000\end{array}$ & 500 \\
\hline
\end{tabular}

Assumed temperature difference between coolant temperature and average stator and rotor conductor temperature was $300^{\circ} \mathrm{F}$ in all cases. These designs were obtained using the digital computer motor design program described in the next section. Because of their preliminary nature, input design parameters and material properties data were those used for the SNAP-50/SPUR Pump Motor Development Program.

Rough plots of each motor design (electrical weight versus efficiency) were made to select one promising design from each rating to run with the detailed temperature calculation subroutine. Each of the five designs selected above were run with coolant temperatures of 500,800 , and $1000^{\circ} \mathrm{F}$.

The main objectives in running these designs were to (1) reveal necessary modifications to the computer design program and (2) to help formulate an efficient method of attack to generate the parametric data outlined in former sections of this report.

Some necessary modifications were revealed and incorporated into the design techniques. Among them was the modified slot configuration mentioned in the previous section. Furthermore, a comprehensive step-by-step procedure was formulated for obtaining the parametric data. The tasks are summarized below. 
Task

1. Choose maximum speeds for $5,30,60,100,250 \mathrm{hp}$ ratings at coolant temperatures of $500^{\circ} \mathrm{F}, 800^{\circ} \mathrm{F}, 1100^{\circ} \mathrm{F}$ based on typical dimensions from preliminary designs.

2. Chose materials and material dimensions and fixed parameters including windage and friction losses $=\mathrm{f}(\mathrm{RPM}, \mathrm{Temp})$ and shaft diameter $=\mathrm{f}$ (size, rating).

3. Review choices of Task 2 to verify agreement with generator materials or to justify differences.

4. Run first-cycle frequency study designs using the following input parameters:

\section{Ratings \\ Volts \\ RPM}

Frequencies
$5,30,60,100,250 \mathrm{hp}$

$120 \mathrm{~L}-\mathrm{N}$

As chosen for each rating in Task 1 $200,400,600,800,1000$, $2000 \mathrm{cps}$ $500^{\circ} \mathrm{F}$

Use component temperatures obtained from preliminary designs.

5. Find actual ratings of designs from Task 4 by assuming rated torque $=1 / 2.25 \max$ torque .

6. Rerun designs of Task 4 as required to obtain the desired ratings within \pm 20 percent.

7. Compare designs from Tasks 4 and 6 in terms of $1 \mathrm{bs} / \mathrm{hp}$ and efficiency to obtain a best frequency for each rating.

8. Run detailed temperature calculations on best designs from Task 7.

9. Run first-cycle speed study using the following input parameters:

$\begin{array}{ll}\text { Ratings } & 5,30,60,100,250 \mathrm{hp} \\ \text { Volts } & 120 \mathrm{~L}-\mathrm{N} \\ \text { Frequencies } & \text { As chosen for each rating from } \\ & \text { Task } 7 \\ \text { Coolant Temp } & 500^{\circ} \mathrm{F}\end{array}$

Use component temperatures from Task 8.

10. Find actual ratings of designs from Task 9 by assuming rated torque $=1 / 2.25$ max torque.

11. Rerun designs of Task 9 as required to obtain desired ratings within \pm 20 percent. 
12. Compare designs from Tasks 9 and 11 to choose a best speed for each rating.

13. Run detailed temperature calculations on best designs from Task 12.

14. Run first cycle voltage study using the following input parameters:

Ratings
Frequencies
Speed

Ratings

Speed
$5,30,60,100,250 \mathrm{hp}$

As chosen for each rating from Task 7

As chosen for each rating from Task 12

15. Find actual ratings of designs from Task 14 by assuming rated torque $=1 / 2 / 25 \max$ torque.

16. Rerun designs of Task 14 as required to obtain the desired ratings within \pm 20 percent.

17. Compare designs from Tasks 14 and 16 in terms of $\mathrm{lbs} / \mathrm{hp}$ and efficiency to obtain best voltage for each rating.

18. Run detailed temperature calculations on best designs from Task 17.

19. Run second-cycle frequency study using the following input parameters:

$\begin{array}{ll}\text { Ratings } & 5,30,60,100,250 \mathrm{hp} \\ \text { Volts } & \text { Best from Task } 17 \\ \text { RPM } & \text { Best from Task } 12 \\ \text { Coolant Temp } & 500^{\circ} \mathrm{F}\end{array}$

Use component temperatures from Task 18, rerun designs as required to obtain desired ratings within \pm 20 percent, and compare designs in terms of lbs/hp and efficiency to choose best frequency for each rating.

20. Run detailed temperature calculations on best designs from Task 19.

21. Run second-cycle speed study using following input parameters:
Ratings
Volts
Frequencies
Coolant Temp

$5,30,60,100,250 \mathrm{hp}$

Best from Task 17

Best from Task 19

$500^{\circ} \mathrm{F}$

Use component temperatures from Task 20, rerun designs as required to obtain desired ratings within \pm 20 percent, and 
compare designs to choose best speed for each rating.

22. Run detailed temperature calculations on best designs from Task 21.

23. Run second-cycle voltage study using the following input parameters:

Ratings
Frequencies
Speed
Coolant Temp

$5,30,60,100,250 \mathrm{hp}$

Best from Task 19

Best from Task 21

$500^{\circ} \mathrm{F}$

Use component temperatures from Task 22 , rerun designs as required to obtain desired ratings within \pm 20 percent, and compare designs to choose best voltage for each rating.

24. Run detailed temperature calculations on best designs from Task 23.

Repeat preceding tasks at coolant temperatures of $800^{\circ} \mathrm{F}$ and $1100^{\circ} \mathrm{F}$.

(c) Computation Techniques. The motor design will be performed using a Westinghouse Aerospace Electrical Division developed digital computer program. A simplified flow chart of the program is shown in Figure 3.15. The program combines basic, fixed strap-wound motor design with temperature calculations. Provisions for calculating the effect of a metallic stator bore seal and rotor can are included in the program.

The electrical design portion of the program designs a motor using empirical and other basic formulas which have been developed at Westinghouse Aerospace Electrical Division and found to give good results. The original program has undergone some modification for use in applications such as this because of changes in materials and the extreme environments. For instance, the program was changed to give a trapezoidal bar in the rotor, to use an input diameter as the magnetic ID of the rotor, and to use all available a rea for slot space to obtain low-slip designs. Allowances for insulation were also changed and some of the empirical formulas were modified to give closer agreement with actual conditions because of the large air gap and extreme temperatures. Provisions were added to the program for calculating the losses in a stator and rotor can and the additional torque from the rotor can was included in the output.

The basic design provisions of the computer program start with minimum input data such as the outside diameter of the stator punchings, voltage, frequency, number of phases and poles, can thicknesses, friction and windage, and rated horsepower. The program then designs a motor using empirical formulas and standard materials. However, these empirical formulas are based on motors used in ordinary environments and do not give a suitable 

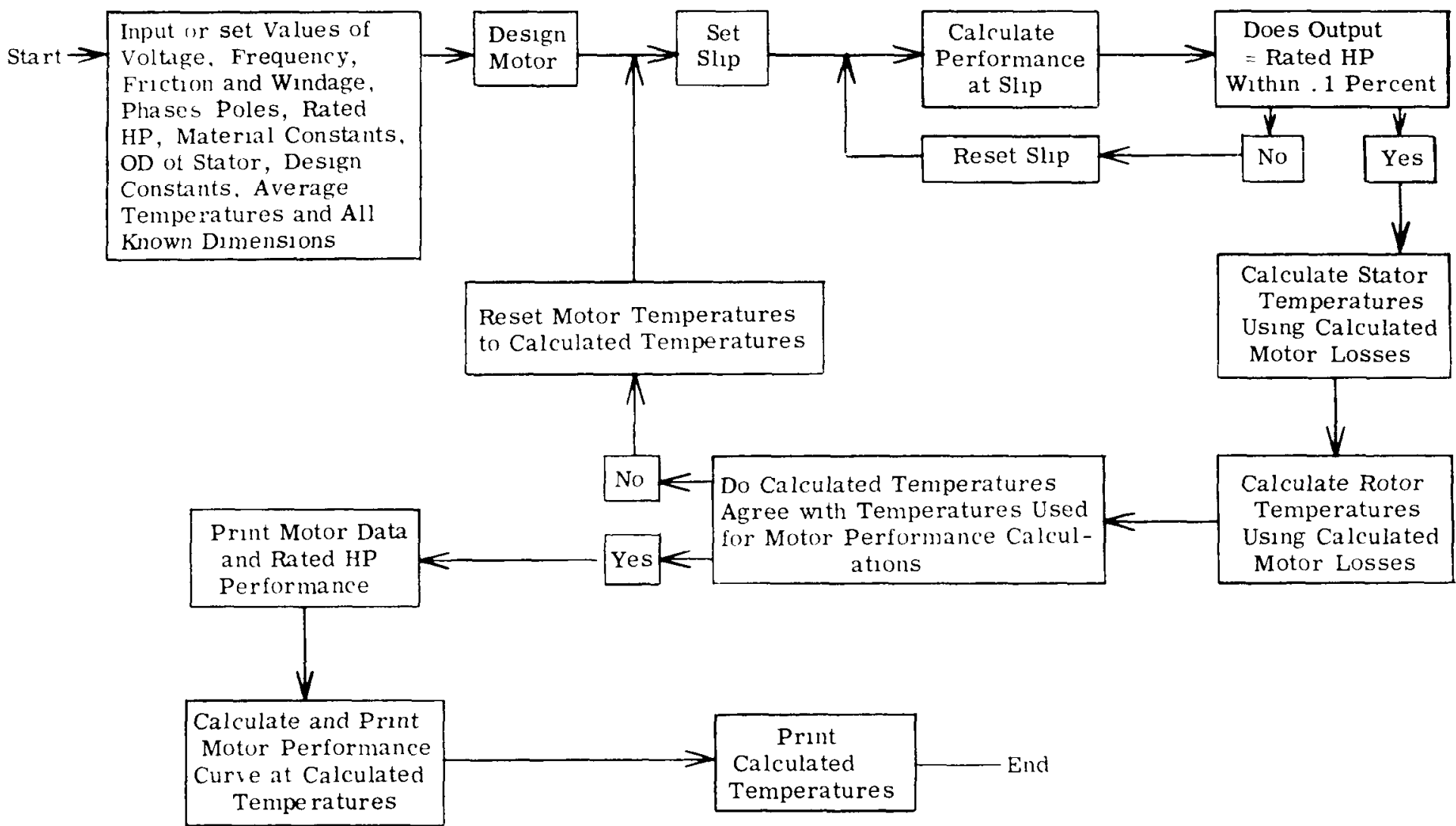

Figure 3.15 Simplified Flow Chart Strap Wound Induction Motor Design Computer Program 
motor design for extreme environments. Additional input data for the computer program must then be used for material constants and variations in clearances made necessary by the use of non-standard materials.

Other input data for the computer program allows the designer to fix any dimension of the motor at any compatible value. Other dimensions are then calculated with the input values fixed. Considerable versatility is thus built into the computer program allowing the designer to optimize a motor using any material for any environment.

The motor performance calculation is based on the per -phase equiva lent circuit shown in Figure 3.16. The terminology used agrees with the computer print-out sheet except that " $\mathrm{H}$ " is added to the symbols for stator and rotor resistance to indicate that the values are at temperature; the computer ordinarily prints out the value at $20^{\circ} \mathrm{C}$. The core loss resistance, RM1, is not printed out but may be calculated with the following formulas.

$$
\text { RM1 }=\frac{3(\text { VAG1 })^{2}}{\text { SCL }} \quad \text { (ohms) }
$$

where SCL $=$ total stator core loss.

The loss in the stator can is regarded as core loss and is represented in the circuit, in the same manner as the stator core loss.

The rotor can loss consists of two parts. The part which is due to the fundamental field is represented by the resistance RCANR. The rotor can, in relation to the fundamental field, acts as another rotor cage and provides useful torque. This component of the can loss is treated as another cage occurring prior to the rotor leakage reactance. The can resistance is divided by the slip in the same manner as the rotor cage and the torques from both branches are added to the output.

The other component of rotor can loss is due to the slot ripple. It acts like a load on the motor and hence is subtracted from the output similar to a friction or windage load. This component is not represented in the circuit. The computer symbol for this loss is RCANL.

The basic method for calculating can losses is derived from Reference 9. The stator can loss formula for the motor is:

$$
\mathrm{W}=\frac{15.5(\mathrm{~B})^{2}(\mathrm{n})^{2}(\mathrm{D})^{3}(\mathrm{~L})(\mathrm{t})\left(10^{-16}\right)(\mathrm{ks})}{\mathrm{P}}
$$

where $\mathrm{B}=$ Maximum gap density in lines per square inch

$\mathrm{N}=$ Speed of rotating field in revolutions per second

$\mathrm{D}=$ Diameter of can in inches

$\mathrm{L}=$ Length of stack in inches

$\mathrm{t}=$ Thickness of can in inches

$p=$ Electrical resistivity of can in ohm-inches

$\mathrm{ks}=$ Reduction factor for end effects (empirical)

$\mathrm{W}=$ Can loss in watts 


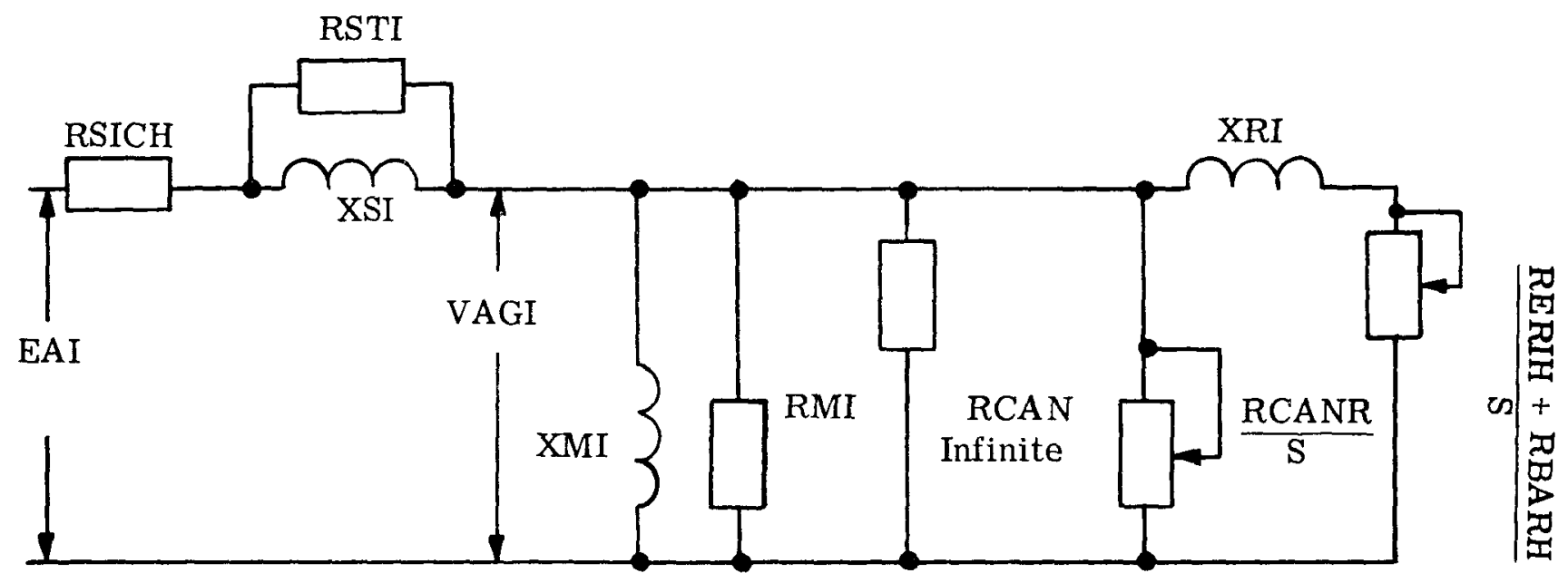

\footnotetext{
RSICH $=$ Hot stator per phase resistance

RSTI = Stray load loss resistor

$\mathrm{XSI}=$ Stator leakage reactance

$\mathrm{XMI}=$ Mutual reactance

RMI = Core loss resistance

RCAN = Stator bore seal resistance

RCANR = Rotor can resistance

$\mathrm{XRI}=$ Rotor leakage reactance

RERIH = Hot rotor ring resistance

$\mathrm{RBARH}=$ Hot rotor bar resistance

$\mathrm{S}=$ Slip

EAI = Input phase voltage - RMS

VAGI = Air-gap voltage - RMS
}

Figure 3.16 Per Phase Equivalent Circuit 
The formula for rotor can loss is:

$$
\text { Losses (watts) }=\frac{2.6(\mathrm{bt})(\mathrm{Kcc}-1)^{2.33}(\mathrm{Kr})(\mathrm{W})}{5.04(\mathrm{be})}
$$

where

$$
\begin{aligned}
\text { bt } & =\text { Stator tooth width } \\
\text { be } & =\text { Stator slot opening } \\
\mathrm{Kcc} & =\text { Carter's Coefficient } \\
\mathrm{W} & =\text { Losses as calculated by previous formula } \\
\mathbf{K r} & =\text { Reduction factor for mmf opposition in the rotor }
\end{aligned}
$$

This formula is based on the assumption that any rotor can losses would be due to slot ripple. The formula is mainly empirical but was basically derived from theoretically correct reasoning. The only basic change from the fundamental formulas in Reference 9 is that the expression containing Carter's Coefficient for rotor losses is raised to the 2.33 power instead of squared. This change was based on an investigation conducted by Westinghouse Aerospace Electrical Division (12).

The stray load loss resistor is calculated using an empirical method. The circuit is solved using the resistance as shown in the equivalent circuit except that the series equivalent resistance of the branch consisting of RSTI and XSI is multiplied by the square of the power factor.

The computer calculates and prints out total electrical weight. This includes everything in the motor from the stator OD to the rotor ID. It does not include cans, frame, seals, shaft, terminals, or leads.

The computer continually corrects for saturation of the magnetic steel. The constants and flux densities printed out are exact for the full load point only because of the change in flux densities with load. The actual design method using the computer program requires trial and error; an optimum design can only be obtained by varying parameters, noting the effect, and making further changes based on the effect. The optimizing procedure is influenced by inputs from material information and mechanical analysis. Design engineer judgement determines when the optimum design is achieved.

The temperature calculation-subroutine performs a steady -state, three-dimensional heat transfer and temperature distribution analysis. Variation with temperature of material properties, such as thermal conductivity and hardness is taken into account. During the calculation process, properties of material in the vicinity of nodal points are continually corrected to match the temperature calculated at the nodal points. The temperature of certain predominant heat generating motor components are fed back to the main electrical design computer program where they are reflected in determining the various electrical losses in the machine. Therefore, the heat transfer and temperature distribution subroutine not 
only provide a detailed calculated temperature profile for use in stress analysis and materials evaluation, but also extend the range of the conventional motor design program to elevated temperature ranges.

In addition to definition of heat path geometry and coolant information in the computer input sheets, equations of required material properties as a function of temperature must be supplied.

The temperature calculation-subroutine can be used only in conjunction with design of a liquid cooled motor utilizing various cooling passage arrangements at the stator OD and the rotor ID. However, an option of the overall design program permits the temperature calculations for the rotor, the stator, or both, to be disregarded by inputing certain key temperatures required by the electrical design program. This option allows use of the design program for design of performance calculations when steady-state temperatures are not desired as when different cooling methods are contemplated.

As indicated in the step-by-step procedure outlined in Section 3.2.2(b) preceding, the detailed temperature calculation subroutine will be used only at discrete times during generation of the data to check and correct average stator conductor, rotor bar, and rotor resistance end ring temperature estimates. These are required as input when the temperature calculation subroutine is not used. The reasons for this are:

1. The temperature calculation subroutine requires considerable specific design information, much of which can not be defined until subsequent conceptual design analyses are made. Examples of the required information are stator frame thickness, interface or interference fit pressures (stresses), and heat transfer coefficients. If assumptions are used for these figures, the significance of the detailed nature of the temperature calculation is reduced. For the parametric screening, it is considered just as accurate to make estimates of the average temperatures.

2. This reduces effort and associated elapsed time required to prepare computer input data.

\subsubsection{Plans for Coming Quarter}

It is expected that actual generation of the parametric data will be completed in the next quarter and the Topical Report summarizing the a-c motor study will be started. Conceptual design analyses will be started. 


\subsection{POWER CONDITIONING}

\section{ABSTRACT}

For the purposes of this report, the system power conditioning has been assumed to include transformers, rectifiers, frequency converters, component radiation damage effects, power transmission and power distribution. Parametric design comparisons are being made in all of these areas with the parameter ranges selected on the basis of adequately providing for subsequent system analysis and selection of such system parameters as voltage and frequency. These parametric comparisons will define the individual equipment weight/efficiency tradeoff and performance variations.

In making the parametric comparisons, only existing components are being used. This is defined to mean components which have been fabricated and tested to a sufficient degree to define performance; they are not required to be commercially available at this time. Although component parameters and power ratings could be extrapolated into the future beyond the laboratory, the selection of basic system parameters should not be based on these conjectures. Once the system parameters have been chosen, potential future developments will be evaluated to show potential improvements in system performance. This must necessarily occur at the conceptual design stage of the program.

High-temperature gas and vapor tubes will be included in the analysis of converters and rectifiers wherever they appear to be applicable. This applicability is being determined based on switching speed, voltage rating, and current rating. All variable parameter values (or data points) used in these analyses (including coolant temperatures) have been chosen to provide a common basis of analysis between all the power conditioning components and other components of the system. The parametric analyses being carried out in each equipment area are described below.

\subsubsection{Frequency Changer}

(a) Parametric Evaluation Approach. The primary application for frequency changers in space nuclear electric power systems is to drive liquid metal pumps. These may be either induction-motor-driven or electromagnetic pumps. Whereas the generator output will be a relatively high frequency to obtain low weight, the electromagnetic pumps require a relatively low frequency for efficient operation. The motor-driven pumps, if not operated at the generator frequency, will also require a reduced frequency to increase efficiency.

Previous studies (20), (21) of static frequency changer designs for frequency reduction at high power levels have shown the cycloconverter approach to have a much lower specific weight than the alternate method of using a d-c 
link. The d-c link approach rectifies the a-c input and then inverts to the desired output frequency. The cycloconverter on the other hand converts directly to the desired output frequency by properly gating controlled rectifie:s. The power circuit for a typical cycloconverter is shown in Figure 3.17.

In order to aid in the selection of power system configurations it is necessary to know the effects of the various frequency converter parameters on the load, the source, and the converter itself. The effects that are of primary concern are the weight and efficiency variations of each since these influence the overall system weight. A converter weight increase resulting from increased efficiency must be compared to the decrease in source weight in order to evaluate the overall effect on the system.

The parameters that affect the weight and efficiency include the rating, load power factor, voltage, frequency, coolant temperature, and input/output frequency ratio. Additional factors can include the input/output voltage relationship and the amount of required filtering. Obviously, to vary all of these parameters across the ranges of interest would require an extremely large number of designs with only a limited basis on which to select the system parameters. For this reason, a parametric evaluation approach has been developed to limit the number of variables in making the evaluation of each parameter. This approach makes separate evaluations of (1) rating and power factor, (2) input voltage, (3) input and output frequencies, (4) paralleling circuits, and (5) gas or vapor tube designs. In addition, all designs are assumed to include no voltage transformers or filters since transformer data will be available from a separate task and since the amount of required filtering may vary widely with load requirements.

For the separate evaluation of each parameter, weight and efficiency are being found as a function of the parameter of interest, with all other parameters held fixed at typical values. Paralleling evaluations are based on determining a weight penalty as a function of converter rating while gas or vapor tube converters are to be evaluated only on the basis of specified rating values.

(b) Pump Requirements Determination. The frequency changer perform ance requirements for supplying induction motor pumps can be based on meeting the input and output requirements of the generator and motor as discussed in Sections 3.1 and 3.2. Voltage variations can be met by means of transformers. To assure maximum usefulness of the converter parametric data merely requires that design comparisons include the parameter points and ranges specified for the motor and generator evaluation.

Electromagnetic pumps on the other hand present somewhat different output requirements. To aid in the parametric analysis of the frequency changer and its effect on the system when supplying electromagnetic pumps, the results of the pump research program carried out under NASA Contract NAS 3-2543 were evaluated. The a-c pumps must operate at a low frequency to keep the eddy-current losses at a low value. For most applications considered under this contract, the polyphase induction pump proved to be the most desirable from the standpoint of weight and efficiency. 
Frequency Changer

Power Circuit

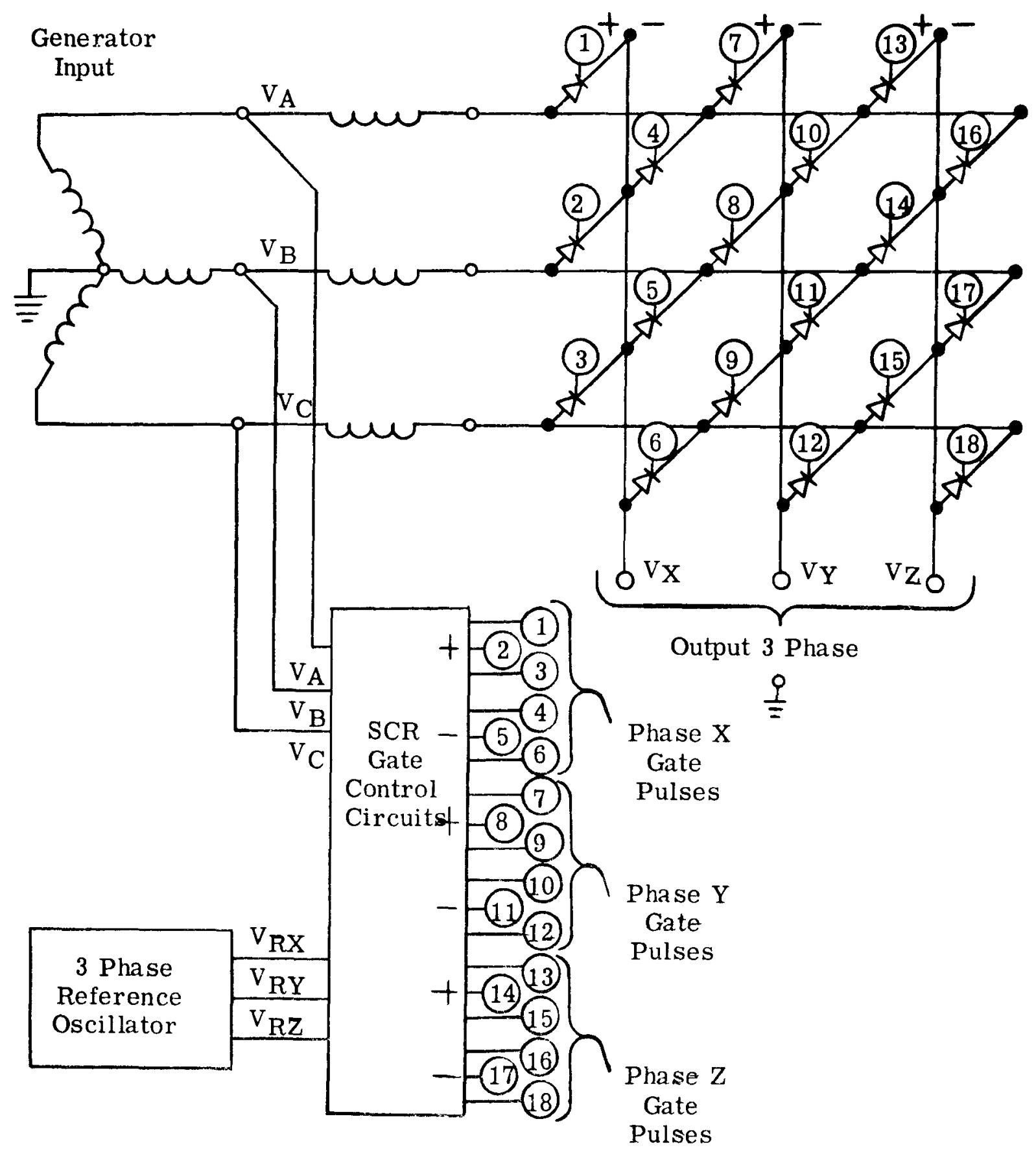

Figure 3.17 Power Circuit for a Typical Cycloconverter 
The pump research program showed that electrical efficiency increases as pump supply frequency decreases, with maximum pump efficiency, when designed for operation from a d-c supply. Although supply frequencies of $100-200 \mathrm{cps}$ are recommended as giving the best combination of efficiency and weight, the maximum efficiency available from a typical design at $50 \mathrm{cps}$ is shown to be almost 50 percent higher than for a design at $100 \mathrm{cps}$. Since this efficiency difference may prove significant as pump sizes become larger, the frequency converters in the current Design Study will be evaluated to as low as $50 \mathrm{cps}$.

DC pumps, although having the highest efficiencies, require power supplied at a voltage of approximately 1 volt; this, coupled with high current values, often results in an offsetting decreased efficiency in the supply. The a-c induction pumps in the referenced research program ranged between 0.1 and $100 \mathrm{KW}$ input power rating with those designs selected as best for each application requiring input voltages of 75 to 200 volts line-to-line at frequencies below $200 \mathrm{cps}$. Since no data was presented to show the relationship of the voltage and frequency, it is required that the output voltage levels for the frequency changer parametric study cover the required ranges.

The effects of harmonic distortion on pump performance were ignored in the pump study program. As long as the input-to-output frequency ratio is large, this assumption should provide a reasonably accurate basis of analysis.

(c) Ranges of Parameters. The parameter ranges selected for evaluation must be compatible with the power source and load to permit an accurate system evaluation. The contract requires the rating evaluation to include a range of 5 to $250 \mathrm{KVA}$ output. The range chosen for study however is 5-500 KVA to permit driving a pump motor delivering 250 horsepower to its load. The input frequency range of 800 to $3200 \mathrm{cps}$ is compatible with the output range of the generator evaluation and similar data points are being used. The required input voltage range of up to 1500 volts will include the required 1000 volts and also insure compatibility with generator data. Voltages lower than the generated voltage will be obtained by means of input or output transformers when required. Transformer data for the system evaluation will be obtained from the transformer parametric evaluation task of this program.

To perform the separate parametric evaluations, fixed values will be selected for those parameters not being evaluated under each separate task. These values will represent typical values within the range specified for that parameter. The data points selected for each evaluation are listed in Table 3.3. Some of the frequency-value combinations may result in harmonic distortion unsuitable for the application but all values are initially listed for completeness. 
Table 3. 3 Parameter Ranges and Data Points for Frequency Changer Parameter Evaluations

A. Rating and Power Factor Parametric Evaluation

Ratings - 5, 25, 50, 100, 250, $500 \mathrm{KVA}$

Load Power Factor - 0.7 lagging and 0.5 lagging

Input Frequency - $2000 \mathrm{cps}$

Output Frequency -- $400 \mathrm{cps}$

Input Voltage - - 200 volts $\mathrm{L}-\mathrm{N}$

Output Voltage -- 160 volts $\mathrm{L}-\mathrm{N}$ nominal (no transformer)

B. Voltage Parametric Evaluation

Input Voltage -- 200,500,1000, 1500 volts

Output Voltage -- Natural output (no transformer)

Rating -- $50 \mathrm{KVA}$

Load Power Factor -- 0.7 lagging

Input Frequency -- $2000 \mathrm{cps}$

Output Frequency -- $400 \mathrm{cps}$

C. Frequency Parametric Evaluation

Rating -- $50 \mathrm{KVA}$

Load Power Factor -- 0.7 lagging

Input Voltage -- 200 volts L-N

Output Voltage -- 160 volts $\mathrm{L}-\mathrm{N}$ nominal (no transformer)

Input Frequency

$800 \mathrm{cps}$

$1200 \mathrm{cps}$

$2000 \mathrm{cps}$

$3200 \mathrm{cps}$

\section{Output Frequencies}

$50,100,200,400 \mathrm{cps}$

$50,100,200,400,800 \mathrm{cps}$

$50,100,200,400,800,1000 \mathrm{cps}$

$50,100,200,400,800,1000,2000 \mathrm{cps}$

(d) Performance Assumptions. It has been assumed that the frequency changers in the parametric study are cycloconverters having the same basic circuits for all ratings. There will be circuit variations, or course, since it is necessary to use thyristors in parallel or series arrangements to obtain the required ratings.

The designs will not include either an input or an output transformer. Thus the output voltage will be fixed by the input voltage. The cycloconver ter circuit will produce half-wave conversion. Although it would produce a better output waveform, full-wave conversion requires either an output transformer or isolated output phases. 
The source is assumed to be a 3 -phase infinite bus. Commutation inductors are thus included in the design to limit the rate of change of current in the thyristors during commutation.

The load is assumed to consist of motors or other inductive load, such that filtering is not required. The output will, the refore, be non-filtered. No voltage regulator will be included, thus the output voltage will vary with input voltage variations. The output voltage will be essentially sinusoidal with high frequency ripple superimposed. Current is limited to 1.25 per unit in all designs.

(c) Progress to Date and Plans for The Coming Quarter. An approach has been developed to provide meaningful frequency changer parametric data and the required parameter ranges and data points have been determined. However, the parametric equipment design effort was initiated during the last month of the reporting period and the refore only limited preliminary results have been obtained. The selected circuit design approach is basically the same as that reported in SNAP-50/SPUR Frequency Changer Preliminary Design and Specification (20). Initial effort has resulted in the development of general design equations to cover the specified ranges.

Designs are being made using available materials and components. The ratings required by the study demand the use of thyristors operated in parallel and/or in series because of limited available ratings. Methods of properly controlling series and paralleled thyristors are being investigated. Study of the electrical characteristics of thyristors is under way so that losses may be accurately evaluated.

Future effort will be directed toward completion of design equations necessary to cover the required parameter ranges. Parts are to be selected for each design. Circuit variations will be made to cover the range of ratings using available thryistors. Once the electrical design parameters have been established, mechanical layouts will be made. Heat rejection calculations and mechanical design will then determine the weight of each design.

\subsubsection{Transformers}

(a) Parametric Evaluation Approach. The evaluation of the transformer and its effect on the system design requires that the relationship of weight and efficiency be known as well as the effect on this relationship caused by varying the other transformer parameters. This relationship is greatly af fected by the ability to cool the transformer since increased operating temperatures result in increased losses; increased magnetic material and conductor sizes reduce these losses but increase weight. It is obvious, therefore, that a complete analysis of the transformers requires a rather detailed evaluation of the method of cooling.

The transformer parameters affecting the performance, weight, and efficiency of a given design include the rating, coolant temperature, frequency, input voltage and output voltage. In order to make parametric designs of all 
possible combinations of data points within the ranges specified would obviously require a relatively large number of designs. In order to limit the number of designs to a manageable level and still provide a complete analysis, it has been necessary to develop an approach to perform separate evaluations of the major parameters.

The parameters selected for individual evaluation for both the singlephase and three-phase transformers are the input voltage, output voltage, rating, and coolant temperature. These particular parameters were selected because they are relatively independent in their effect on the transformer and they a re important system parameters. The analysis of typical loads from the Power Uses and Missions Task has shown that a large amount of the power to be transformed will then be rectified to certain specified voltage levels. Therefore, it is necessary that transformer output voltage data points be compatible with rectifier input needs to meet these typical voltages.

In order to provide realistic values for the transformer design, transient voltages and overload values must be assumed. These represent the actual sizes and ratings that would be needed to meet the chosen application. For the purpose of making the analysis, transient voltages of 160 percent rated value and overloads of 300 percent for 5 seconds have been assumed.

(b) Selection of Ranges. The investigation of load requirements (Section 4.1) has shown that the amount of power required to be transformed at any one particular voltage level in a 0.25 to 10 megawatt nuclear electric space power system may vary from below 25 KVA up to almost the total source output. Therefore, 3-phase transformers are being evaluated in the range of $25 \mathrm{KVA}$ to $10,000 \mathrm{KVA}$. It is unlikely that single-phase transformers would be used at the multimegawatt level because of their larger size and the characteristics of the load. Therefore, the range being evaluated for these is $10 \mathrm{KVA}$ to $1,000 \mathrm{KVA}$. Below $10 \mathrm{KVA}$ the variations in transformer weight and efficiency do not, in general, represent a sufficiently significant effect to influence the selection of system parameters.

Coolant temperatures of $500^{\circ} \mathrm{F}$ to $1100^{\circ} \mathrm{F}$ have been selected for the evaluation to include the specified range of up to $1000^{\circ} \mathrm{F}$ and also to give representative values for the state-of-the-art in transformer materials. The data points selected are compatible with those of the other items of high temperature electrical apparatus being evaluated as a part of the system.

The Power Uses and Mission analyses have also indicated that load voltage requirements will vary from as low as 20 volts up to as high as 20 kilovolts. Somewhat higher voltages may also be desirable for power transmission use. Another factor influencing the transformer evaluation is that large blocks of power up to $250 \mathrm{KW}$ will probably be required at voltages as low as 20 volts $d-c$. Thus, designs are necessary to carry relatively large values of current. The much larger blocks of power in the order of 5 to 10 megawatts will be required to be supplied at several kilovolts. 
The output voltage data-points selected for evaluating the 3-phase transformers have been selected to be compatible with the required rectifier output values. Intermediate values may be found by data interpolation. For threephase transformer designs this means that the phase voltage must be equal to 42.8 percent of the required rectifier output. Thus, a transformer output of approximately 52 volts line-to-neutral will result in a rectifier output of 120 volts. The maximum voltage included in the evaluation is 12,840 volts line-toneutral which will result in a line-to-line voltage of 22,200 volts and a rectifier output of 30,000 volts d-c. The input voltage and frequency values used in the analysis are equivalent to the output values used in the generator analysis. This will assure the direct applicability of the data for evaluation of the system.

To evaluate the effect of the various transformer parameters, it is neces sary to hold certain parameters fixed while others are varied. For each of the evaluations, the parameters that are held constant represent typical values within the specified range. The range of values, the data points being used, and the information being generated are listed in Table 3.4. For each of the parameters being considered, the weight versus efficiency relationship as a function of frequency is being determined. In addition, for the coolant-temperature evaluations, the coolant flow rate as a function of losses is being determined for each temperature value. This cooling penalty will be coupled with the source weight penalty to provide a more accurate system basis for evaluating the weight/efficiency tradeoff.

(c) Electrical Design Approach. An existing computer transformer design program is being revised to use high temperature materials and liquid potassium cooling with temperatures ranging from $500^{\circ} \mathrm{F}$ to $1100^{\circ} \mathrm{F}$. This computer program will then permit the design of the single-phase and three-phase transformers of this study. The criteria for the transformer computer designs is minimum weight while meeting specified performance levels and, therefore, will use the transformer materials at their maximum safe operating temperature. For the ratings and power frequencies of the transformers of this study, minimum weight can usually be obtained by an equality of transformer conductor weights to core weights and of conductor losses to core losses (23).

The electrical portion of the computer program is being prepared to accept the properties and characteristics of different conductors, core materials, and insulations depending upon the system coolant temperature. Trans former computer input data will consist of power rating, frequency, input and output voltage, coolant temperature, and material properties. Assuming values of conductor current density and core flux density, as well as a cooling duct configuration, a transformer design will be calculated. If the cooling design is inadequate, such that the material temperature limits would be exceeded, a change in cooling configuration is made and a new transformer design is calculated. If the cooling design is more than adequate such that the materials are not being worked to their safe maximum limits, then a change in conductor 
Table 3.4 Parameter Ranges and Data Points for Transformer Parameter Evaluations

I. Three-Phase Transformer

A. Input Voltage Parametric Evaluation

Frequency values: $400,800,2000,3200 \mathrm{cps}$

Output voltage: 428 volts $\mathrm{L}-\mathrm{N}$ (full-load)

Data points for power rating, input voltage, and average coolant temperature are:

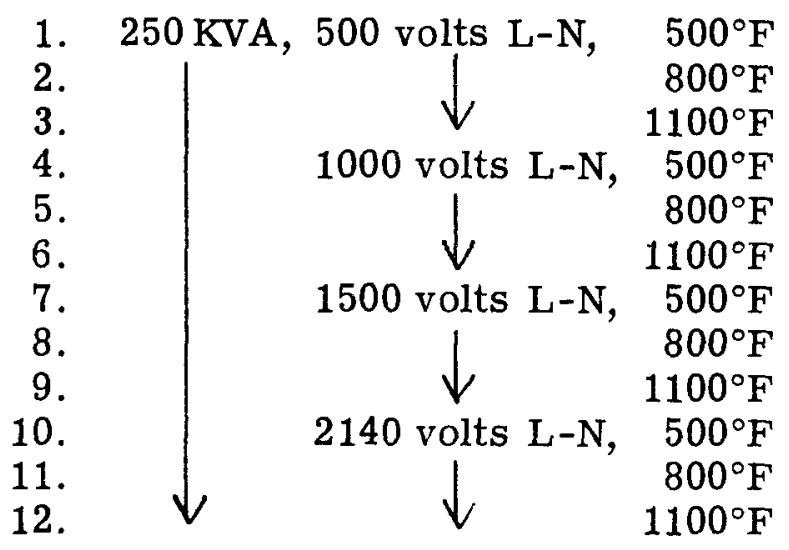

B. Output Voltage Parametric Evaluation

Frequency values: $400,800,2000,3200 \mathrm{cps}$ Input voltage: 1000 volts $\mathrm{L}-\mathrm{N}$

Data points for output rating, full-load output voltage, and average coolant temperature are:
1. $250 \mathrm{KVA}$,
2.
3.
4.
5.
6.
7.
8.
9.
10.
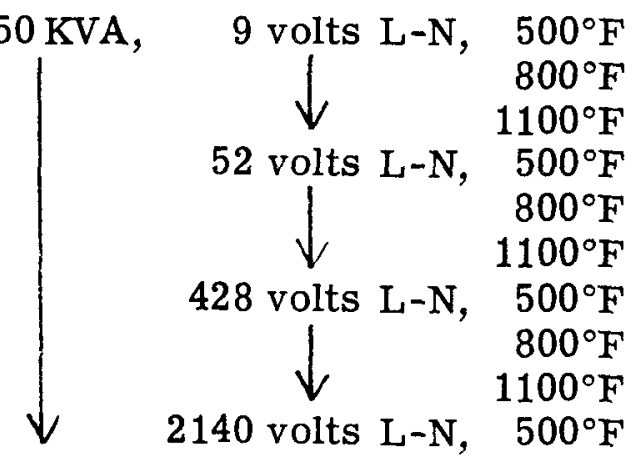
Table 3.4 Parameter Ranges and Data Points for Transformer Parameter Evaluations (continued)

11. $250 \mathrm{KVA}, 2140$ volts $\mathrm{L}-\mathrm{N}, 800^{\circ} \mathrm{F}$

12. $\downarrow \forall \vee 1100^{\circ} \mathrm{F}$

13. $1000 \mathrm{KVA}, 2140$ volts $\mathrm{L}-\mathrm{N}, 500^{\circ} \mathrm{F}$

14.

15.

16.

17.

18.

19.

20.

21.

22.

23.

24.

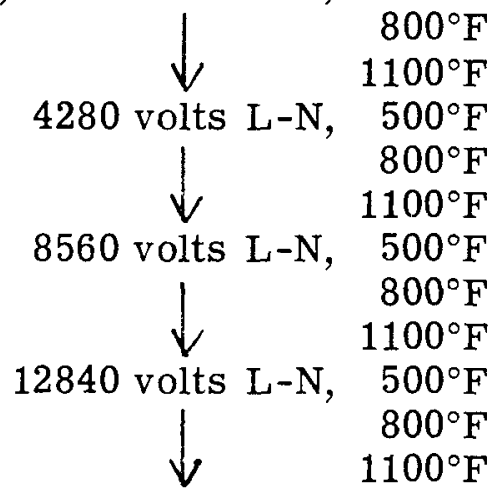

C. Rating and Coolant Temperature Parametric Evaluation

Frequency values: $400,800,2000,3200 \mathrm{cps}$

Input voltage: 100 volts $\mathrm{L}-\mathrm{N}$

Data points for output rating, full-load output voltage and average coolant temperature are:

1. $25 \mathrm{KVA}, \quad 52$ volts $\mathrm{L}-\mathrm{N}, \quad 500^{\circ} \mathrm{F}$

2. $\begin{aligned} & \text { 3. } \downarrow \\ & 4\end{aligned} \begin{array}{r}800^{\circ} \mathrm{F} \\ 1100^{\circ} \mathrm{F}\end{array}$

4. $\quad 75 \mathrm{KVA}, \quad 52$ volts $\mathrm{L}-\mathrm{N}, \quad 500^{\circ} \mathrm{F}$

$\begin{array}{ll}5 . \downarrow \downarrow & \downarrow \\ 6 . & 800^{\circ} \mathrm{F}\end{array}$

7. $250 \mathrm{KVA}, \quad 52$ volts $\mathrm{L}-\mathrm{N}, \quad 500^{\circ} \mathrm{F}$

9. $\downarrow \downarrow \begin{array}{r}800^{\circ} \mathrm{F} \\ 1100^{\circ} \mathrm{F}\end{array}$

10. $500 \mathrm{KVA}, 2140$ volts $\mathrm{L}-\mathrm{N}, 500^{\circ} \mathrm{F}$

11. $\downarrow$ 12. $\downarrow \quad \begin{array}{r}800^{\circ} \mathrm{F} \\ 1100^{\circ} \mathrm{F}\end{array}$

13. $1000 \mathrm{KVA}, 2140$ volts $\mathrm{L}-\mathrm{N}, 500^{\circ} \mathrm{F}$

$14 . \downarrow$
$15 . \downarrow \downarrow$ $\begin{array}{r}800^{\circ} \mathrm{F} \\ 1100^{\circ} \mathrm{F}\end{array}$ 
Table 3.4 Parameter Ranges and Data Points for Transformer Parameter Evaluations (continued)

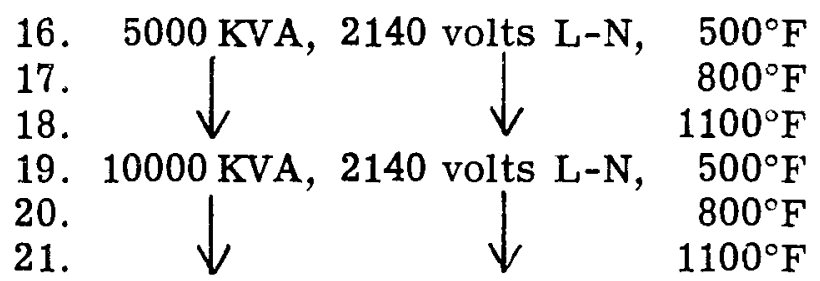

II. Single-Phase Transformers

A. Input Voltage Parametric Evaluation

Frequency values: $400,800,2000,3200$ cps

Output voltage: 120 volts (full-load)

Data points for power rating, input voltage, and average coolant temperature are:

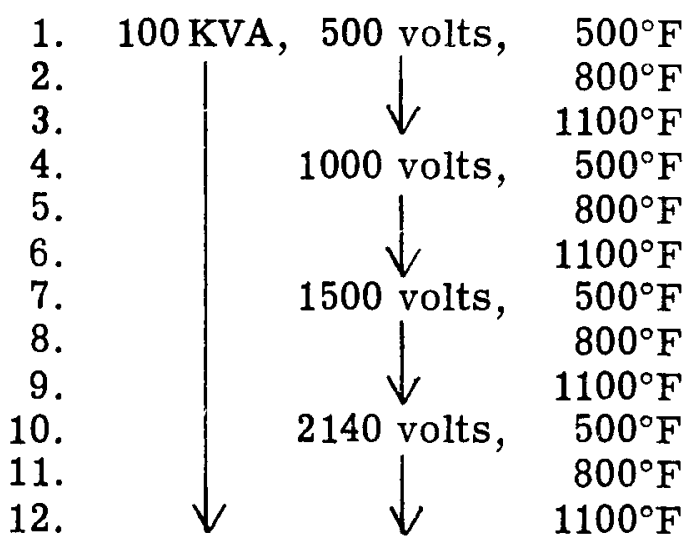

B. Output Voltage Parametric Evaluation

Frequency values: $400,800,2000,3200 \mathrm{cps}$ Input voltages: 1000 volts

Data points for power rating full load output voltage, and average coolant temperature are:

1. $100 \mathrm{KVA}, 30$ volts, $500^{\circ} \mathrm{F}$

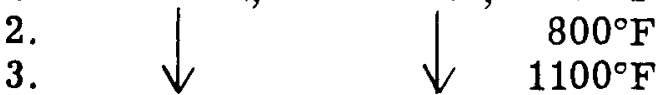


Table 3.4 Parameter Ranges and Data Points for Transformer Parameter Evaluations

(continued)

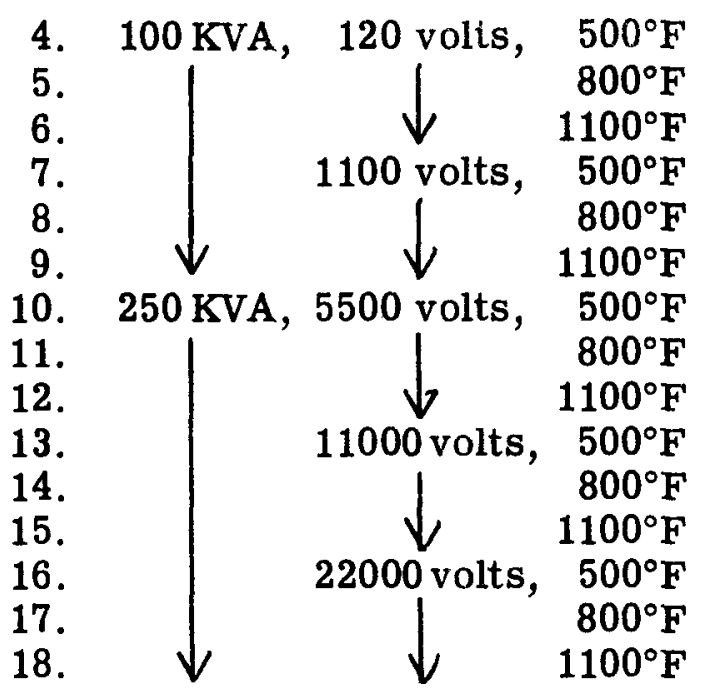

C. Rating and Coolant Temperature Parametric Evaluation

Plot weight versus efficiency as a function of frequency for the following designs:

Frequency values: $400,800,2000,3200 \mathrm{cps}$ Input voltage: 1000 volts

Data points for output rating, full-load output voltage and average coolant temperature are:
1. $10 \mathrm{KVA}, 120$ volts, $500^{\circ} \mathrm{F}$
2. $\quad 800^{\circ} \mathrm{F}$
3. $\downarrow \checkmark 1100^{\circ} \mathrm{F}$
4. $50 \mathrm{KVA}, 120$ volts, $500^{\circ} \mathrm{F}$
5. $\downarrow \downarrow \downarrow \quad{ }^{800^{\circ} \mathrm{F}}$
7. $100 \mathrm{KVA}, 120$ volts, $500^{\circ} \mathrm{F}$ (See part II. B)
8.
$9 . \downarrow$$\quad \downarrow \quad \begin{array}{r}800^{\circ} \mathrm{F} \text { (See part II. B) } \\ 1100^{\circ} \mathrm{F} \text { (See part II. B) }\end{array}$
10. $500 \mathrm{KVA}, 11000$ volts, $500^{\circ} \mathrm{F}$
11. $800^{\circ} \mathrm{F}$
12. $\downarrow$
$1100^{\circ} \mathrm{F}$
13. $1000 \mathrm{KVA}, 11000$ volts $500^{\circ} \mathrm{F}$
14.
15.

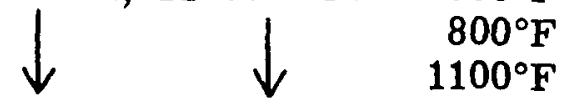


cur rent density and core flux density is made and the transformer design is repeated. The results of the computer program will be plotted to compare transformer weight to transformer efficiency as a function of rating, frequency, input and output voltage, and coolant temperature. The planned approach is to machine-process the computer output data directly to graphical representation.

(d) Cooling Design Approach. Cooling of high-temperature transformers is most effective when the coolant is passed through the coils. For multi-section wound coils this should be accomplished by passing cooling ducts through the coils between layers of conductors as shown in Figure 3.18. For pancake sectioned coils, coolant ducts should be placed between the coils as in Figure 3.19. The arrangement of pancake coils with sandwiched cooling ducts was selected as the most desirable method of transformer cooling for the following reasons:

1. Sample transformer designs were made which indicated that the coils will be either strip or strap wound; therefore, thermal paths to the edges of the coil will provide better heat conduction than the thermal paths from layer to layer.

2. Pancake section coils would not require special winding techniques, as would be necessary with multi-section coils with through-the-coil cooling.

3. Fewer coolant ducts will be required and all coolant flow paths will be parallel, thereby reducing the amount of duct manifolding required.

Potting compound is used between the coils and coolant ducts to provide sufficient thermal contact. Cooling of the core is by cold plates thermally attached to the exposed edges of the tape-wound core. The evaluation of transformer cooling is based on the following assumptions:

1. Liquid potassium will be the coolant.

2. Cooling will be by conduction.

3. The average coolant temperatures will be $500^{\circ} \mathrm{F}, 800^{\circ} \mathrm{F}$, and $1100^{\circ} \mathrm{F}$.

4. The coolant temperature rise will be $100^{\circ} \mathrm{F}$ in all cores.

5. Operating temperature will be the maximum allowable operating temperature of the transformer materials.

6. Cooling weight considerations will be limited to only the coolant weight, weight of coolant ducts, cold plates, and the associated insulation and potting compound. 


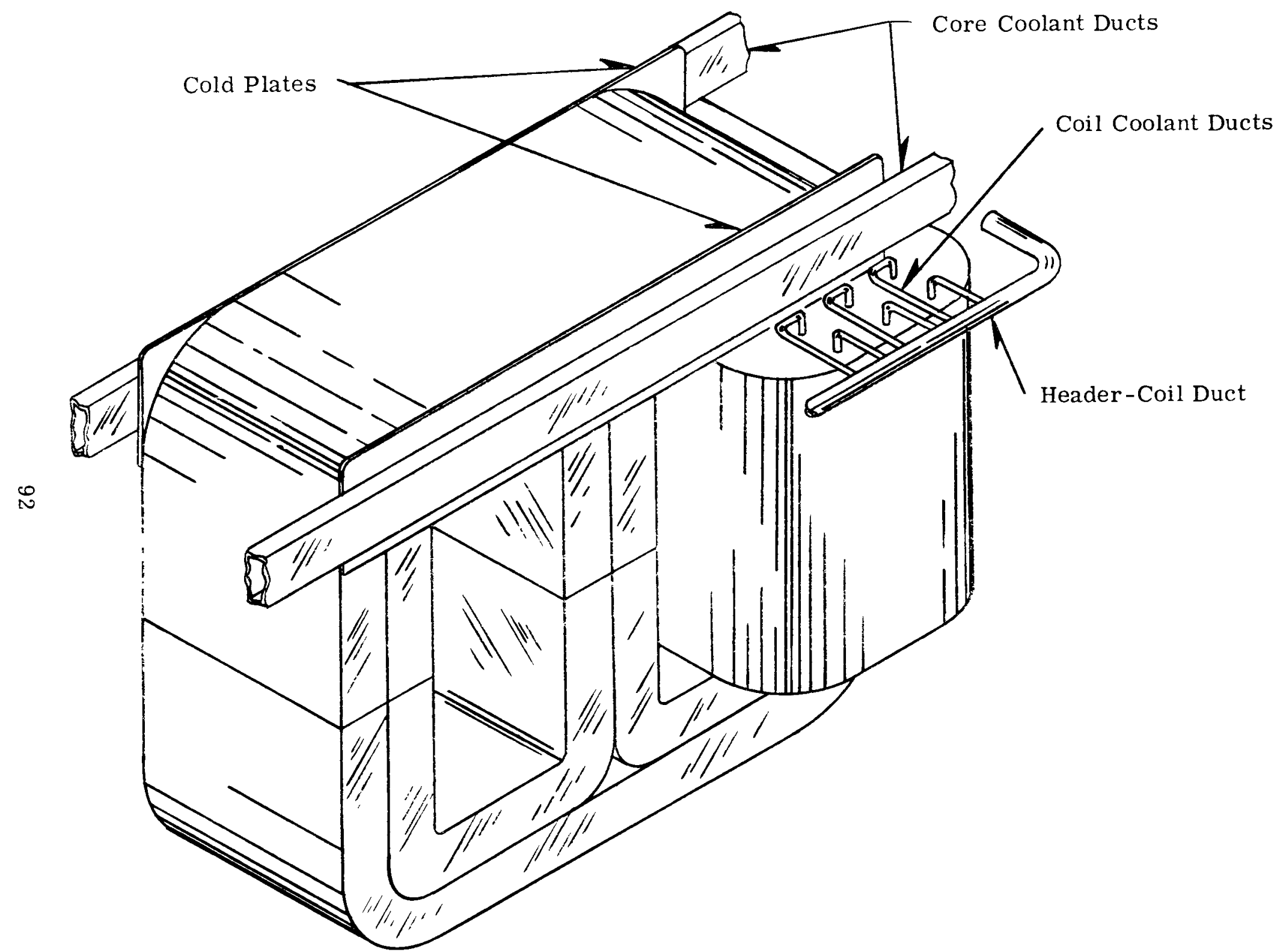

Figure 3.18 Through the Coil Cooling 


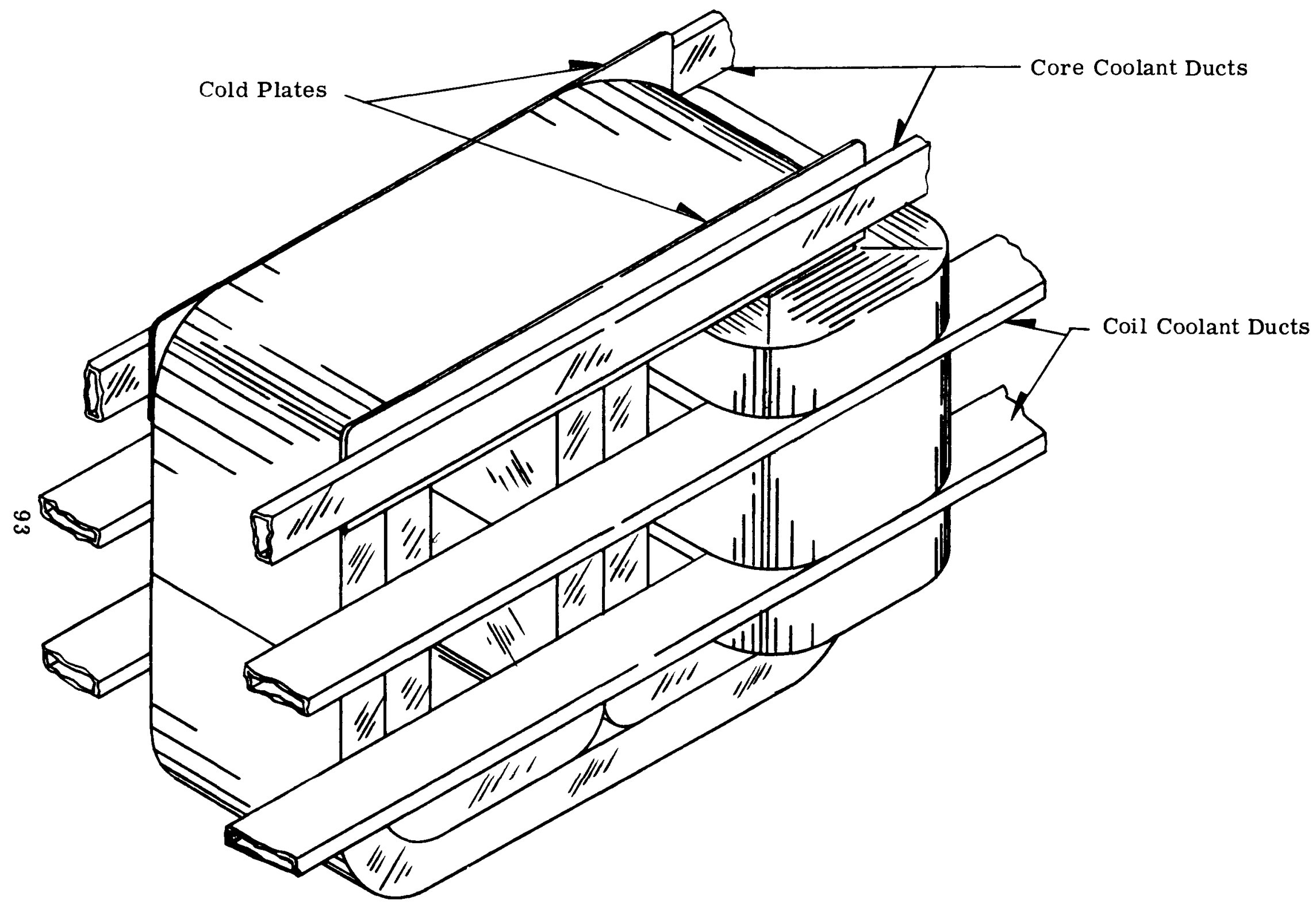

Figure 3.19 Between the Coils Cooling 
(e) Plans for the Coming Quarter. Effort will be directed to completing the electrical and cooling design equations to permit the completion of computer programming. Material properties and characteristics and their variations as a function of temperature, will be made an integral part of the computer program. After a computer debugging phase, the parametric transformer design data will be generated and presented in the form of curves relating the various parameters.

\subsubsection{Rectifiers}

(a) Parametric Evaluation Approach. Although a certain amount of the d-c load demands may be supplied directly by rectification of the generator output, the great majority of these loads must be supplied at some voltage other than that which is generated. Thus, a parametric evaluation of the rectifiers for such a system must consider their integral operation with the transformers. As in the other power conversion and distribution components, the parameters that are of primary interest in performing a system evaluation are the weight and efficiency, and the effect on these two caused by varying the other major parameters. The weight and efficiency are primarily affected by the rating and operating voltage. Coolant temperature is set at the maximum permissible value in order to obtain the lowest radiator and cooling system weight.

In order to evaluate the various system parameters, an approach has been selected to compute the weight and losses of three-phase rectifiers as a function of the rectifier rating. This is being done for each of the required voltage values. These voltage values are based on the Power Uses and Mission analysis. From this data the relationship of weight as a function of rating, weight as a function of voltage, and efficiency as a function of rating will be determined. The weight evaluation includes an allowance for cooling structure. The required coolant flow rate is to be determined for each design.

(b) Ranges of Parameters. In analyzing the power uses and missions, the $\mathrm{d}-\mathrm{c}$ loads in the system were found to require voltages ranging between 20 volts and 30,000 volts $d-c$. The individual loads, in turn, may vary from below 25 $\mathrm{KW}$ to almost the total generator output of $10,000 \mathrm{KW}$. Although some loads at a particular voltage may go below $25 \mathrm{KW}$, they begin to have a negligible effect on the selection of system parameters for generated system outputs of $250 \mathrm{KW}$ and higher since, at a maximum, they still represent less than 10 percent of the load.

The load analyses has also shown that voltages as low as 20 volts will be needed up to as high as $250 \mathrm{KW}$. This requires relatively large values of current just as in the transformer. At the very high power levels of 1,000 to $10,000 \mathrm{KW}$ the power will be required at multi-kilovolt levels, thus permitting a limited current value. The data points representing the voltage and power levels chosen for evaluation are presented in Table 3.5. 
Table 3.5 Data Points for Evaluation of Three-Phase Rectifiers

Data points defining rating and nominal $d-c$ output voltage are as follows:

1.a.

b.

c.

2.a. 120 volts

b.

c.

d.

3.a. 1000 volts

b.

c.

d.

4.a. 5000 volts

b.

c.

d.

e.

f.

5.a. 10000 volts

b.

c.

d.

6.a. 20000 volts

b.

c.

d.

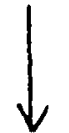

7.a. 30000 volts

b.

c.

d.<smiles>C1CC1</smiles>

$25 \mathrm{KW}$

$75 \mathrm{KW}$

$250 \mathrm{KW}$

$25 \mathrm{KW}$

$75 \mathrm{KW}$

$250 \mathrm{KW}$

$500 \mathrm{KW}$

$25 \mathrm{KW}$

$75 \mathrm{KW}$

$250 \mathrm{KW}$

$500 \mathrm{KW}$

$25 \mathrm{KW}$

$75 \mathrm{KW}$

$250 \mathrm{KW}$

$500 \mathrm{KW}$

$1000 \mathrm{KW}$

$5000 \mathrm{KW}$

$500 \mathrm{KW}$

$1000 \mathrm{KW}$

$5000 \mathrm{KW}$

$10000 \mathrm{KW}$

$500 \mathrm{KW}$

$1000 \mathrm{KW}$

$5000 \mathrm{KW}$

$10000 \mathrm{KW}$

$500 \mathrm{KW}$

$1000 \mathrm{KW}$

$5000 \mathrm{KW}$

$10000 \mathrm{KW}$ 
(c) Design Approach. During this reporting period parametric designs have been made for the kilovolt $d-c$ bus rectifier systems specified in Table 3.5. Although the configuration chosen for this voltage level will most likely not apply to all voltage levels, it serves to demonstrate the design procedure and the selection and availability of the required components.

The configuration selected for the 5 kilovolt rectifier systems is the threephase full-wave bridge. This configuration requires the least number of series silicon diodes per rectifier leg to withstand the reverse voltage resulting from the system voltage and also provides the highest rectifier efficiency of the rectifier circuits studied. This circuit permits the associated transformer to operate with a high utilization factor resulting in relatively lower weight than with other rectificr transformers. The detailed considerations applied in selecting the three-phase full-wave bridge for the kilovolt d-c rectifier bus systems of this study are presented in Appendix B. The work represented by the discussion in this Appendix was performed by the Westinghouse Aerospace Electrical Division on NASA Contract NAS 5-1234(2).

The individual silicon diode voltage and current ratings presently available for the parametric designs of this study were found to be individually incompatible with the system requirements. It is necessary, therefore, for these individual diodes to be connected in series and parallel, respectively. To obtain the rectifier voltage capability to withstand the peak inverse steady-state and transient system voltages it was determined to be necessary to force voltage division across the series diodes by shunting each diode with a resistor-capacitor network. To provide the required current capacity parallel diodes which have matched forward voltage and current characteristics with respect to temperature are used. Additional details on the discussion of series and parallel diodes, in rectifier operation, is presented in Appendix B.

The evaluation of rectifier cooling is being based on the following assumptions.

1. Monoisopropyl Biphenyl (MIPB) will be the coolant

2. Cooling will be by conduction. The cold plate method will be employed.

3. Cooling weight penalty considerations included in the rectifier total weight will be limited to only the coolant weight, weight of coolant ducts, cold plates, and the associated component insulation.

4. Rectifier and voltage balancing components will operate at temperatures in the range of $185^{\circ} \mathrm{F}$ to $230^{\circ} \mathrm{F}$.

(d) Progress To Date and Plans for the Coming Quarter. The threephase full-wave bridge rectifier is a conventional circuit which has been presented in detail in the literature and has been briefly described in Appendix B. Further discussion of basic circuit operation, therefore, will not be made here.

The schematic representation of a bridge circuit with series diodes in the rectifier legs is shown in Figure 3.20. A series-parallel rectifier bridge 
3-Phase AC Input

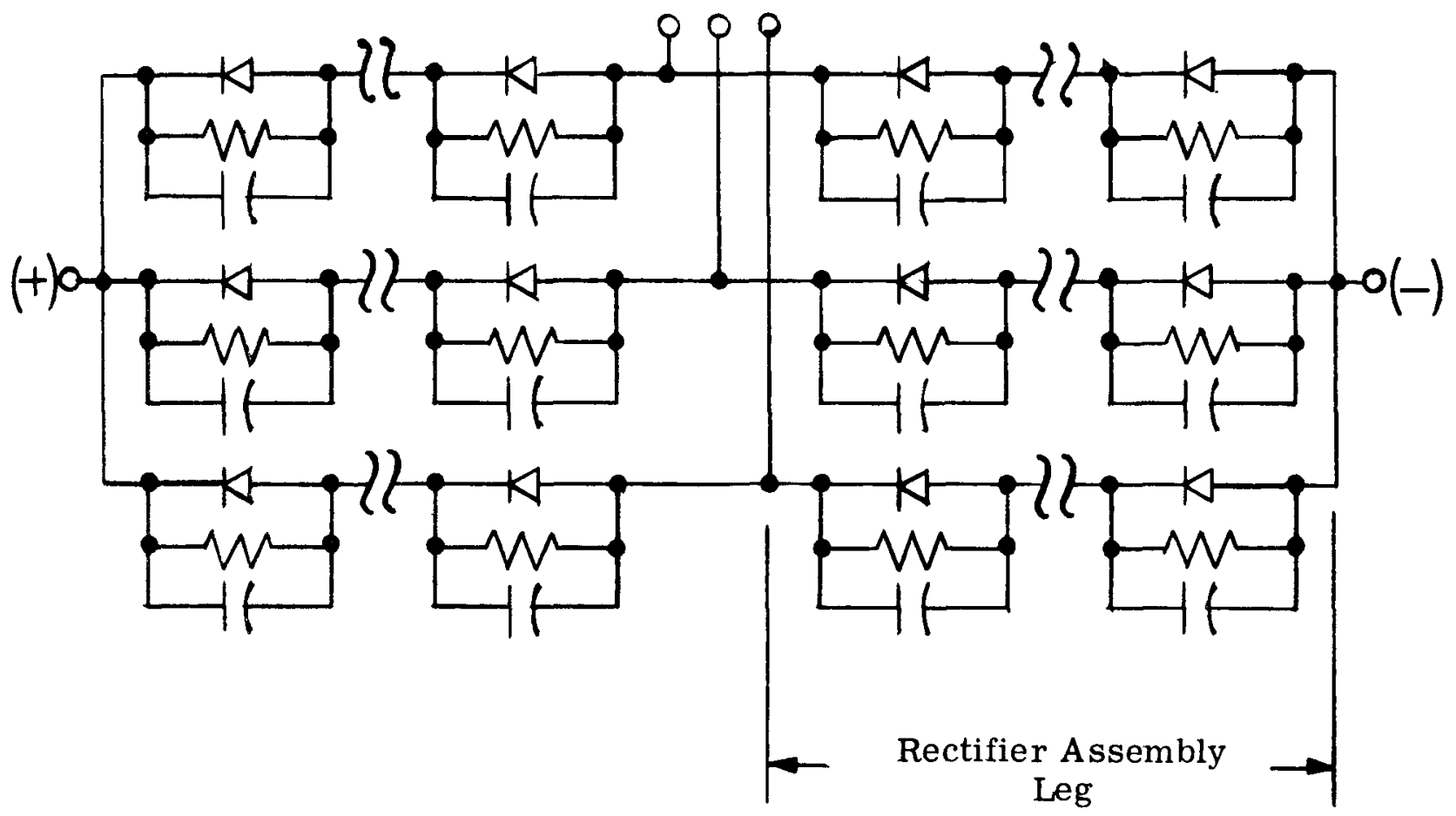

Figure 3.20 Three-Phase, Rectifier-Bridge Assembly with Series Diodes in the Rectifier Legs 
assembly is similar to Figure 3-20 except additional strings of series diodes are paralleled in each rectifier leg, as necessary, to increase the assembly current capacity. Table 3.6 lists the calculated electrical quantities, weight, power losses, and rectifier conversion efficiency for the 5 kilovolt $d-c$ bus systems. It is seen that the 5 kilovolt, 5000 kilowatt rectifier assembly uses four strings of parallel diodes per rectifier leg, with five series diodes in each string. The transformer design for the 5000 kilowatt rectifier assembly of Table 3.6 will require only a single secondary winding. If, because of other considerations, four transformer secondaries are required, the rectifier system would consist of four separate three-phase full-wave bridges. The tabulated rectifier data, however, would still be applicable

Table 3.6 shows that, in the range being considered, frequency has little effect on total weight and losses. To calculate the data for this table the following design guide lines and/or basic assumptions were made:

1. The number of series diodes per rectifier bridge was established by specifying the rectifier leg peak inverse voltage (PIV) rating to be at least 2.25 times the system inverse voltage under normal operation. A factor of 2.25 allows for an estimated system voltage transient of 1.6 , unbalance between the diodes and the voltage balancing components, and an adequate derating for long life.

2. The current rating of the diodes was determined by requiring a minimum overload capacity of 300 percent for 5 seconds. This is an estimated system current overload requirement.

3. Diode manufacturers have indicated that diode losses are essentially unaffected by operating frequencies below 5 kilocycles per second. Frequency, therefore, was not considered in the computation of rectifier losses. Diode losses were calculated for reverse and forward conduction only, on the basis of a minimum of 25 percent derating from the manufacturer's maximum junction temperature rating.

4. The resistor power-dissipating capability has been derated by a minimum of 75 percent when operating at normal system conditions at body temperatures identical to the established diode case temperature limit. The manufacturer's maximum recommended rms operating voltage is at least two times that seen by the resistors during normal system operation.

5. The capacitor voltage rating is at least equal to the individual diode PIV rating at a temperature identical to the diode case temperatures. This voltage, therefore, is at least 2.25 times greater than the peak working voltage seen by each capacitor under normal system operation.

6. All of the components selected for this study are those on which electrical characteristics have been demonstrated by component manufacturers. 
Table 3.6 5 Kilovolt DC Silicon Diode Rectifier Assembly Systems

DC Bus Power (kw)

AC System Freq. (cps)

DC Bus Current (amps)

Qty. Rectifier Assy's

Diode:

Type

Amps/3 Phase Bridge

Amps/Bridge Leg

Peak Amps

Avg. Amps

PIV (volts)

Series Diodes/Rect. Leg

Parallel Diodes/ Rect. Leg

Total Qty. Diodes

Total Losses (watts) $\frac{\text { Capacitor: }}{\text { Type }}$

Capacitance (ufd)

Total Qty. Capacitors

Total Losses (watts)

Total Weight (lbs)

Total Losses (watts)

Rect. Conversion Eff. (\%)

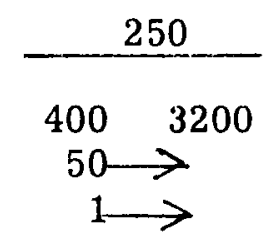

JEDEC $1 \mathrm{~N} 1190$

$$
\begin{aligned}
& 50 \longrightarrow \\
& 50 \longrightarrow \\
& 16.7 \rightarrow \\
& 600 \longrightarrow \\
& 20 \longrightarrow
\end{aligned}
$$

None

$120 \rightarrow$

$2480 \rightarrow$

4.877

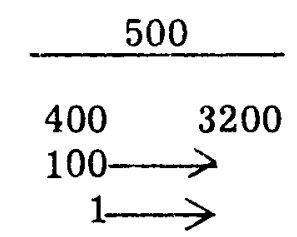

JEDEC $1 \mathrm{~N} 1403$
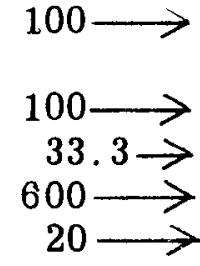

None

$120 \longrightarrow$

$4440 \longrightarrow$

$22.5 \rightarrow$

Bendix E-200

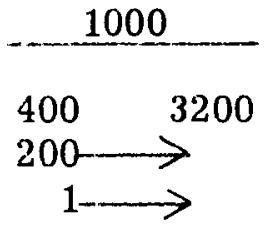

(W) Type 790

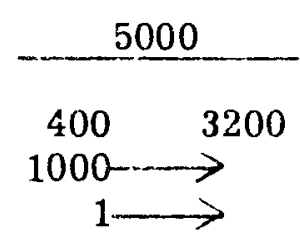

(W) 'Type 790 $1000 \longrightarrow$

$$
\begin{array}{r}
200 \longrightarrow \\
66.6 \longrightarrow \\
2400 \longrightarrow \\
5 \longrightarrow \\
\text { None } \\
30 \longrightarrow \longrightarrow \\
2970 \longrightarrow \\
18.8 \rightarrow
\end{array}
$$

$$
\begin{array}{r}
1000 \longrightarrow \\
333.3 \longrightarrow \\
2400 \longrightarrow \\
5 \longrightarrow \\
4 \longrightarrow \\
120 \longrightarrow \\
15000 \longrightarrow \\
75 \longrightarrow
\end{array}
$$

DALE RH-25

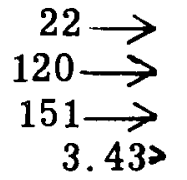

Tubular

\section{DA LE RH-25}

$$
\begin{array}{r}
15 \longrightarrow \\
120 \longrightarrow
\end{array}
$$

Tubular

Bendix E-200
$0.01>$
$120 \longrightarrow$
$0.36 \quad 6.48$
$2.23 \rightarrow$
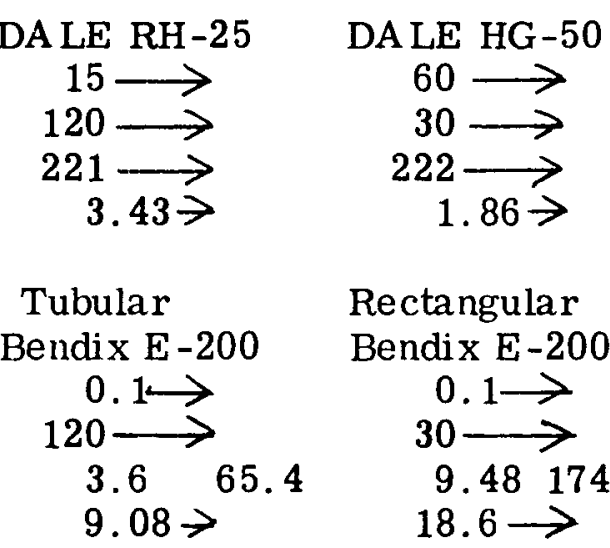

Rectangular

Bendix E-200

$$
\begin{aligned}
& 0.1 \longrightarrow \\
& 30 \longrightarrow \\
& 9.48174 \\
& 18.6 \longrightarrow
\end{aligned}
$$

$$
\begin{gathered}
\text { DA LE HG-50 } \\
60 \longrightarrow \\
120 \longrightarrow \\
888 \longrightarrow \\
7.44 \longrightarrow
\end{gathered}
$$

Rectangular Bendix E-200

$$
\begin{gathered}
0.1 \longrightarrow \\
120 \stackrel{\rightarrow}{37.9} 696 \\
74.5 \rightarrow
\end{gathered}
$$

$2631.42637 .5 \quad 4664.6 \quad 4726.4 \quad 3201.5 \quad 3366$ $\begin{array}{llll}98.95 & 98.95 & 99.07 & 99.06\end{array}$
$99.68 \quad 99.66$

$15926 \quad 16584$

$99.9 \quad 99.7$


(e) Plans for Coming Quarter. In addition to preparing the cooling design for the 5 kilovolt rectifier systems, effort in the coming quarter will be directed to initiating and completing the remaining silicon diode rectifier electrical designs for the points specified in Table 3.5. High temperature gas and vapor tube diodes are presently being studied and developed by General Electric on NASA Contract NAS 3-9423 and NAS 3-8525. Tube characteristics for these devices have been requested from General Electric. Electrical and cooling designs will be completed for applicable rectifier systems.

Rectifier cooling evaluation will consist of determining the coolant average temperature, coolant temperature rise, coolant flow rate, and cooling system weight tor all rectifier assemblies.

\subsubsection{Transmission and Distribution}

(a) Parametric Evaluation Approach. The effect of the power transmission and distribution on the system parameters of any large electric power system can be quite large. Unfortunately, because of the complexity of dealing with these aspects of the system, they are often treated in insufficient detail to establish the actual value of this effect. Transmission lines a re typical of this complexity since they produce a complex interdependence of the various parameters. For example, close spacing is desired to keep the inductive reactance low. High voltage is also desired to decrease the required current carrying capability and therefore the conductor size. However, the insulation for the high voltage may tend to increase the required spacing, again raising the reactance. Aluminum conductors may prove lighter than copper but they also have a lower maximum temperature capability. Thus the variation of a given parameter in a particular direction may not always prove desirable.

Other variables include the frequency of operation for a-c lines which will determine the skin effect and, along with the length, also influences the voltage drop. Increased operating temperature reduces conductor size but may also increase the losses. Added to these are such variables as solid or hollow, round or rectangular, paralleled or nonparalleled conductors.

An approach to the parametric study was desired which would aid the recommendation of the system parameters, rather than one that would merely present design techniques and equations as has been done in past studies. Investigation showed that certain assumptions could be made to separate the evaluation into several independent tasks to limit the parameters that must be considered. These separate tasks are (1) an electrical parameter evaluation, (2) a configuration evaluation, and (3) a cooling evaluation.

For the electrical parameter evaluation, the configuration and temperature parameters can be assumed constant at typical values. Thus hollow, round, copper conductors have been assumed operating at $500^{\circ} \mathrm{F}$. A radius ratio providing good performance is being chosen to meet each data point. Then, assuming 1000 volts line-to-neutral and a close, equidistant conductor 
spacing the relationship of weight and losses as a function of frequency is being determined. In addition, the variation of voltage drop per unit length with current as a function of frequency is also being determined. This evaluation will aid in the selection of the system voltage, frequency, and conductor size to meet a required power rating and transmission length.

For the configuration comparison, electrical and thermal parameters may be held constant. Typical values are selected as follows: $500^{\circ} \mathrm{F}, 3-$ phase, $2000 \mathrm{cps}$, 100 amperes, 1000 volts, line-to-neutral. Once the system electrical parameters have been selected, this configuration comparison will show any weight or performance gains that can be obtained at the selected values by varying the configuration. At the above design point, comparisons are to be made of copper versus aluminum (hollow, round) conductors, and hollow, round versus hollow, flat (copper) conductors. These comparisons are to be made by determining weight as a function of losses. The configuration comparison is also to determine insulation thickness, minimum spacing, and insulation weight penalty as a function of voltage for the above design point.

For the cooling evaluation, a cooling approach is being selected based on hollow, round copper conductors carrying 100 amperes at 500 volts lineto-neutral, $2000 \mathrm{cps}$. The weight will be determined as a function of losses for maximum conductor temperatures of $500^{\circ} \mathrm{F}, 800^{\circ} \mathrm{F}$ and $1100^{\circ} \mathrm{F}$. Cooling weight penalties will also be determined.

Only limited parametric studies have been made of circuit breakers or contactors for multimegawatt nuclear space power systems. Since these contactors will be required in any such system, the primary objective of a parametric evaluation is to determine the relative effects of varying the applicable parameters rather than comparing basic design approaches. To accomplish this, it is necessary to assume a "ba seline" design and relate the effects of parameter variations to this design.

A base line design is to be selected for the a-c and also for the d-c contactors. Each will be rated at one megawatt, 1000 volts with a coolant temperature of $500^{\circ} \mathrm{F}$. In addition the a-c design will be based on threephase operation at $2000 \mathrm{cps}$. Weight and losses will then be determined to supply a range of ratings from $100 \mathrm{KW}$ to $1000 \mathrm{KW}$. Similar data is to be found for ratings of $1000 \mathrm{KW}$ to $10,000 \mathrm{KW}$ at 500 volts. Using the weight and losses as a function of rating, the effect of variations in frequency, voltage and coolant temperature will be determined.

(b) Ranges of Parameters. The range of parameters considered for the contactors and transmission lines must be sufficient to evaluate their use in all portions of the system. This includes operation at the outputs of the generator, transformers, rectifiers, and frequency converters. The ranges of parameters and data points were selected to be compatible with other tasks of this study and are presented in Table 3.7. These points represent values to be used for computations when a parameter is varied as well as when it is held fixed in the evaluation. 
Table 3.7 Parameter Ranges and Data Points for Transmission and Distribution Evaluation

\begin{tabular}{|c|c|}
\hline Frequency & $\begin{array}{l}0,50,100,200,400,800,1600 \\
2000,3200 \mathrm{cps} \text {. }\end{array}$ \\
\hline AC Voltage & $\begin{array}{l}120,240,500,1000,2000,5000 \\
10,000,20,000 \text { volts, } 3 \text {-phase } \\
\text { line-to-neutral }\end{array}$ \\
\hline DC Voltage & $\begin{array}{l}100,200,500,1000,2000,5000 \\
10,000,20,000 \text { and } 30,000 \text { volts }\end{array}$ \\
\hline $\begin{array}{l}\text { Transmission } \\
\text { Distance }\end{array}$ & $25,50,100,200,300,500$ feet \\
\hline Current & $50,100,200,300,400,500$ amperes \\
\hline $\begin{array}{l}\text { Temperature } \\
\text { (coolant or con }\end{array}$ & $500^{\circ} \mathrm{F}, 800^{\circ} \mathrm{F}, 1100^{\circ} \mathrm{F}$ \\
\hline
\end{tabular}

(c) Progress to Date and Plans for the Coming Quarter. During the past quarter, a review of applicable transmission and distribution studies (2), (24), (25) demonstrated that, whereas these past analyses had been concerned principally with presenting design information, and approach was needed to provide for recommending certain parameters to meet the system requirements. Although the relationship of the transmission and distribution parameters is quite complex, an approach was developed to provide for separate evaluations in which the number of varying parameters is limited.

The ranges of parameters and data points, required to carry out the evaluations, have also been established. Parametric design effort for these evaluations was initiated during the last month of the reporting period and, therefore, results and trends have not been established. During the coming quarter, effort will be directed toward carrying out the evaluation by developing the applicable mathematical relationships. Baseline contactor designs will be made based on the results of past studies and the effects of varying the specified parameters will be determined. The resulting data will be presented in the form of curves relating the various parameters. 


\subsubsection{Radiation Damage Effects}

(a) Damage Effects Evaluation Approach. The compilation and evalua tion of nuclear radiation damage effects to components of a space nuclear power system covers a broad range of component types and parameter ranges. There has been a large amount of laboratory investigation of damage effects to various components but much of this information is either uncoordinated or has limited value for the design engineer.

In general, the resultant information will state that a particular component will be permanently damaged at some level of integrated neutron and/ or gamma radiation or that up to some maximum tested radiation it did not fail. It is often not clear as to what definition of a failure was used. In the case of parameter changes, a failure in one application might not constitute a failure in another.

In those instances where the mechanism or mode of change or failure are defined, it is often in terms of qualitative rather than quantitative values. For example, a statement that the leakage current on a diode has "increased substantially" is of limited help to the circuit designer who must allow for the increased leakage in his design. The equipment designer needs relative data to show that with a given design at a specified radiation level, the circuit will meet required tolerances for a determinable period of operation.

Although it can be argued that the damage effects will be different for identical components with the same radiation levels, certainly all devices will fall into a specifiable range or into a statistical distribution. Relative effects on various types of similar components will also permit the designer to modify a circuit, substitute components, or make other changes to improve the equipment performance in a specified ambient radiation.

The approach chosen for the damage effects evaluation is the determina tion of the availability and applicability of the desired information on the primary components of the system. This approach proves to be of more general value than analyzing several typical components in great detail when their mode of application in the system may not be well defined.

(b) Scope of Effort. To provide the most meaningful data, the radiation damage effects evaluation is being limited to a literature search to determine the availability of damage effects information that is useful to the designer. As a minimum of specific information, the damage threshold and mode of failure will be determined for each component wherever possible. No attempt is being made to compile all the damage effects information for the various components. In general, the greatest emphasis will be placed on components designed for large power-handling capability since these are the most difficult to shield and usually represent the components most easily damaged. For the materials to be considered, primary emphasis will be on those capable of operation at high temperature. 
(c) Selection of Components and Parameters for Evaluation. The components and materials that are being investigated within the specified scope of effort and the parameters that are of interest are as follows:

(1) Electrical Components

a. Silicon Transistors (Classified by structure, voltage rating, current rating, and switching speed).

Parameters of interest are:

1. DC current gain

2. Collector saturation voltage drop

3. Collector characteristics (collector current versus collector voltage)

4. Emitter-Base voltage versus base current

5. Collector-emitter leakage currents

6. Collector-emitter breakdown voltage $\left(\mathrm{BV}_{\mathrm{cEo}}, \mathrm{BV}_{\mathrm{ces}}\right)$

7. Turn-on time $\left(t_{d}+t_{r}\right)$

8. Turn-off time $\left(t_{S}+t_{f}\right)$

9. Cut-off frequency

10. Collector - base breakdown voltage $\left(\mathrm{BV}_{\mathrm{CBO}}\right)$

11. Thermal Resistance

b. Silicon Controlled Rectifiers (classified by voltage and current rating).

Parameters of interest are:

1. Maximum gate voltage to fire

2. Minimum gate voltage to fire

3. Maximum gate current to fire

4. Forward voltage drop

5. Forward leakage current

6. Minimum forward breakover voltage

7. Maximum reverse leakage current

8. Maximum reverse voltage

9. Turn-on time

10. Turn-off time

11. Maximum holding current

12. Thermal resistance 
c. Silicon Semiconductor Diodes (classified by voltage and current rating)

Parameters of interest are:

1. Maximum peak reverse voltage

2. Reverse leakage current

3. Forward voltage drop

4. Forward voltage drop versus forward current

5. Recovery time

6. Thermal resistance

d. Semiconductor Zener Diodes (classified by function, voltage rating, and current rating)

Parameters of interest are:

1. Zener voltage

2. Dynamic resistance at specified current

3. Temperature coefficient

4. Voltage reference volts at specified bias current Minimum volts

Average volts

Maximum volts

5. Voltage reference dynamic resistance at specified bias current

Minimum ohms

Average ohms

Maximum ohms

6. Thermal resistance

e. High Tempe rature Vapor and Gas Tube Thyratrons (classified by type, power level, and current rating).

Parameters of interest are similar to the siliconcontrolled rectifier and should include:

1. Filament power (steady-state or momentary)

2. Filament voltage

f. High Temperature Vapor and Gas Tube Diodes (classified as in No. e. above)

Parameters of interest are as for the semiconductor diodes as well as: 
1. Filament power

2. Filament voltage

g. Resistors (classified by type and power rating)

Parameters of interest are:

1. Resistance value

2. Dielectric strength

3. Stability

4. Temperature coefficient

5. Maximum working voltage

6. Resistance variation with frequency

h. Capacitors (classified by type, capacitance, and voltage rating)

Parameters of interest are:

1. Insulation resistance

2. Capacitance as a function of frequency and temperature

3. Dissipation factor as a function of frequency and temperature

4. RC product (megohms-microfarads)

5. Breakdown voltage

6. Dielectric strength (terminal to case)

7. Measurement of corona effects

8. Quality of hermetic seal

i. Microelectronic Circuits (classified by function)

Evaluate relative changes in:

1. Output versus input

2. Stability

(2) Mechanical and Other Components. For these components the various properties of interest as applicable to each function are as follows:

a. Magnetic Properties

1. Hysteresis Loop

2. Permeability

3. Core Losses

4. Saturation flux density 
b. Electrical Conductivity

c. Thermal Properties

1. Thermal conductivity

2. Emissivity

3. Coefficient of thermal expansion

d. Physical Properties

1. Hardness

2. Density

c. Mechanical Properties

1. Strength (tensile, compressive, and yield)

2. Young's modulus

3. Modulus of rigidity

4. Poisson's ratio

5. Creep

6. Elongation

(d) Results of Initial Investigation. Recent studies (20), (26), (27), (28) have documented the general nuclear radiation effects data for many components including the parameters that are affected and the level of radiation to cause a failure. Although the mode of failure is usually not well defined and the parameter range where the information is applicable may vary, this information has been summarized and is presented below to serve as a base of reference for further evaluation.

In this discussion, nvt will be used to indicate the integrated dose of fast neutron flux while $R$ will represent the integrated gamma ray dose in Roentgens. Each type of component will be considered individually as to the parameters affected and the amount of radiation required for permanent damage.

(1) Transistors - Radiation of transistors results in decreased gain and degradation of the other parameters. Little specific information is given for transistors as a group. Lower power devices are more radiation resistant. Damage threshold is about $10^{13}$ nvt and $10^{8} \mathrm{R}$.

(2) Semiconductor Diodes - Semiconductor diodes are more radiation resistant than transistors. Relative values are not stated. Damage results in an increased forward voltage drop and reverse leakage current. Damage threshold reaches as high as $10^{14}$ nvt and $10^{8} \mathrm{R}$.

(3) Silicon Controlled Rectifiers - Radiation damage to SCR's results in increased saturation voltage drop breakover voltage, and required holding current. Damage threshold is $10^{13}$ nvt and $10^{7} \mathrm{R}$ for low power units. Few tests have been run on high power units but their radiation damage resistance is estimated to be lower. 
(4) Tubes

a. Glass tubes are permanently damaged at roughly $10^{18} \mathrm{nvt}$ and $109 \mathrm{R}$.

b. Ceramic tubes are permanently damaged at $10^{19}$ nvt and $10^{11} \mathrm{R}$.

Damage modes are not well defined.

(5) Resistors

a. Wire wound damage threshold is above the tested value of 3 x 1017 nvt.

b. Metal film are also not damaged at $3 \times 10^{17}$ nvt.

c. Carbon composition a re damaged at $2 \times 105$ nvt.

d. Deposited film are damaged at $2 \times 105$ nvt.

Damage modes and parameter changes are not well defined.

(6) Capacitors

a. Ceramic capacitors are undamaged at test levels of $2 \times 10^{15} \mathrm{nvt}$ and $3 \times 10^{8} \mathrm{R}$.

b. Mica Capacitors exhibited less than 5 percent capacitance decrease up to a tested maximum of $1 \times 1015$ nvt and $3 \times 108$ R.

c. Plastic capacitors showed 10-14 percent capacitance change and 3 percent increase in dissipation factor. Permanent damage occurred at $1 \times 10^{15}$ nvt and $3 \times 10^{8} \mathrm{R}$.

d. Tantalum capacitors had 11 percent capacitance change and 40 percent change in dissipation factor. Permanent damage occurred near $1 \times 10^{17} \mathrm{nvt}$ and $7 \times 10^{8} \mathrm{R}$.

e. Paper capacitors show 20-30 percent change in capacitance and a small change in dissipation factor. Damage threshold is about $1 \times 1015$ nvt and $3 \times 108 \mathrm{R}$.

Information on other components is similarly not specific. Available reports usually offer the designer only a radiation level that shouldn't be exceeded. He is likewise cautioned to use judicious judgement in component selection and to follow design practices that allow for variation of the important parameters. The amount of damage is usually stated to be a function of electrical biasing, operating and ambient temperatures, and the ambient atmosphere with little guidance for the designer as to what these effects might be. 
(e) Plans for the Coming Quarter. The literature search of nuclear radiation damage effects will result in a bibliography of radiation-effects documents useful to the nuclear space power system equipment designer. All information will be organized in a manner to show where information is not available or is lacking in scope or direct applicability.

The effect of ambient or operating temperatures on the degree of damage will be determined. The relative radiation damage resistance of electrically operating versus non-operating components will also be determined. This will include cyclic operation such as semiconductors operated in a switching mode.

Approximate methods for extrapolating damage effects data to higher component power levels will be determined if possible. Where permanent damage to a component is incurred by radiation exposure, the requirements for a failure as well as the mode of failure will be well defined. 
page blank 


\section{SYSTHM DEFINITIONS}

\section{1 ELECTRICAL, LOAD DEFINITION}

\subsubsection{Results of Initial Investigations}

Several types of missions have been investigated to determine the typical load requirements for a space nuclear power system. In order to specify the Power Uses and Missions, the power range, frequency and voltage requirements have been evaluated as well as the relative amounts of $a-c$ and $d-c$. The missions being investigated are based on reference missions specified to be used as a guide by the contracting office (29). The specified missions are as follows:

(a) Interplanetary Mission (electrical propulsion)

(1) Unmanned Scientific Mission - One megawatt reference system to be based on Table 5-1 of "Research on Spacecraft and Powerplant Integration Problems," Third and Fourth Quarterly Report, 26 October 1963 to 26 April 1964; G. E. Document 64SD700, Contract NAS 3-2533.

(2) Manned Mars Mission - Eight megawatt reference system to be based on General Electric Document 66SD2026, "Study of Low Acceleration Space Transportation Systems"; Contract NAS 8-11423.

(b) Manned Orbiting Space Station - Typical net power values are:

1. AC 35 percent of total power -- 120 volts, 3-phase, $400 \mathrm{cps} \pm 1$ percent.

2. DC (Regulated) -- 40 percent of total power -- $28 \pm 2$ percent volts.

3. DC (Unregulated) -- 25 percent of total power -- 30-40 volts.

(c) Lunar Base - Load types and division similar to the manned orbiting station can be used for the lunar base requirements.

Initial investigations have been aimed at providing guideline information for the component parametric tasks of this study. Thus, initial concern has been primarily with determining the ranges of the various parameters such as power level, voltage level and also frequency level for a-c. This may be contrasted to the information that will be generated for the conceptual design comparisons in which the types, duty cycle, and performance of the loads becomes a critical factor. In the evaluation of the reports 
mentioned above one should keep in mind that many of the system parameters that are being evaluated as part of this study were simply assumed at fixed values in past studies. Such assumption affect the mode of operation of the various loads as well as the system itself. By replacing these assumptions with values verified through parametric evaluations, this study will assure a system more closely approaching the optimum configurations.

Evaluation of these reports has shown that voltage variations from approximately 20 volts to 20 kilovolts will be required by the loads. Both a -c and d-c are required at the lower values but usually only $d-c$ at the higher voltage levels. However, in obtaining the high d-c voltages, high a-c voltage must be rectified.

In evaluating the various missions, it was found that there are fixed amounts of control and communication loads requiring a-c (very likely at 400 cps) and d-c voltages ranging between 20 and 120 volts. However, these loads represent typically $30 \mathrm{KW}$ which is a small portion of a 0.25 to 10 megawatt system. The next largest portion of the load is provided to the alkali-metal pumps at between 100 and 200 volts a-c. Required frequencies would normally fall between 100 and $400 \mathrm{cps}$. These pumps require from 10 to 15 percent of the total available power and, therefore, total load demand varies with system capacity.

The remaining portions of the load are normally required at low $d-c$ voltages of about 20 volts or high d-c voltages above 5 kilovolts. For the unmanned interplanetary mission above, it is shown that for a nominal one megawatt system, ion source power in the electrical thrusters requires 20 volts at over $200 \mathrm{KW}$. The loads above 5 kilovolts, however, represent a combined total of over $1400 \mathrm{KW}$ although duty cycles of each load would maintain the instantaneous demand below $1000 \mathrm{KW}$. Of this $1400 \mathrm{KW}$, nearly $900 \mathrm{KW}$ is provided to the thrusters while the remaining portion is for radar and communications.

For system power demands above a nominal one megawatt, the highvoltage thruster and the radar or communications loads represent by far the greatest portion of the increase over one megawatt. Therefore, the power conditioning evaluation must provide for low d-c voltages near 20 volts for power levels up to at least $250 \mathrm{KW}$ and high d-c voltages above several kilovolts are needed from near one megawatt to almost 10 megawatts.

Mission power demands of under a megawatt are representative of demands for a lunar base or orbiting space station where there is not a need for electric thrusters and a more limited need for high voltage radar. Therefore, the selection of system parameters at the se power levels will be governed by more conventional power quality demands such as those specified under (b) above. Although high voltages will be required in these systems, they are of secondary concern in the selection of the parameters; as a result, power conditioning evaluation for the high voltages may be concentrated at the higher power levels. 
Since large values of power are needed at high voltages, the transmission and distribution analysis must cover the complete range of voltages. This will aid in the decision of whether most of the power should be transmitted at high voltages or only that which will be used at the transmitted voltage level. Transmission voltages of up to 30,000 volts must be considered.

\subsubsection{Plans for the Coming Quarter.}

Having defined the loads in sufficient detail to direct the efforts of the power conditioning parametric evaluation, effort will now be directed towa rd defining the load demands as required for the conceptual design evaluation. This requires primarily that the load power-quality flexibility be determined. Thus, the ability of particular loads to operate at selected voltage levels will be determined. Effects of voltage and frequency tolerances will be analyzed as well as the effect of harmonics in the a-c sine wave.

Additional investigation will be made in the area of the lunar base and manned space station to define the exact nature of the load requirements. Assumptions in the area of generated voltage or frequency will be avoided to provide an unbiased parametric system analysis.

\subsection{NUCLEAR MECHANICAL SYSTEM DEFINITION}

\subsubsection{Results of Initial Investigations}

Like the electrical load definitions, the effort on the nuclear-mechanical system definitions has been aimed at providing guideline information for the component parametric tasks of the design study. Initial concern has been to determine what the basic design guidelines should be; this is in contrast to the definitive data to be tabulated for the conceptual design analyses as summarized in Section 2.1.2. Some of the pertinent design guidelines established thus far are:

1. The high temperature components which include the generator motors, transformers, etc., will probably be located in a hermetically sealed, insulated can close up behind the reactor and shield in the rocket nose cone. The can provides for uniform pre-heat, soaking and operating temperatures as well as providing for meteroid protection. The low temperature components which include generator control, frequency changers, rectifiers, payload, etc. are isolated further away for minimal radiation and are connected by electrical bus to the generator, motors, etc. 
2. The high temperature components will undergo ground preheat, checkout and shut down; pre-heat will be maintained for orbital startup not less than about 4 hours after launch. The orbital startup will be a series of part speed/power holds to check out the system prior to going on to final operating conditions. Auxiliary power is supplied to aid the system to reach one of the initial holds; control is then switched to the main power source. The system will probably undergo a number of shutdown/coast periods over its lifetime; control coolant systems, etc., must account for this.

3. Electrical component cooling configurations will probably utilize heat exchanger loops connected to a single auxiliary radiator; parallel flow paths may exist in the radiator, however, for reliability/redundancy purposes. The high and low temperature components each have their own radiators.

A part of the past quarter effort on this task was devoted to estimating the electrical system cooling loads and corresponding flow requirements for the four ratings specified in the generator discussions, Section 3.1.1 (e). The high temperature coolant was considered to be liquid potassium; the low temperature coolant was MIPB fluid (monoisopropyl Biphenyl). The losses determined are not to be considered final in any way (the actual design study will determine final losses); they should only be considered to be order -of magnitude numbers for purposes of selecting ranges of radiator sizes, specific weights, etc. The values determined are tabulated on Tables 4.1 and 4. 2 .

The minimum coolant flow was arbitrarily limited to one pound/sec; the maximum temperature rise of the fluid through the components was limited to $100^{\circ} \mathrm{F}$ and $50^{\circ} \mathrm{F}$ respectively for the high and low temperature coolants in accordance with past design practices. These are not hard and fast rules and may be altered as required during the design study. The $100^{\circ} \mathrm{F}$ temper ature rise through the high-temperature electrical loads was arbitrarily assumed.

The generator losses were estimated from the calculated losses of the previous 1-10 megawatt study, contract NAS 5-1234(2). The other losses were estimated using data from General Electric's third and fourth quarterly reports on contract NAS 3-2533(25) which defined an unmanned system of one megawatt nominal load. The following assumptions were used in analyzing and defining the resulting representative system loads and losses.

1. All four missions were unmanned, scientific space probes with similar types of loads.

2. The generator output voltage was approximately equal to the pump-motor input voltage. 
Table 4.1 Summary of Estimated Electrical System Losses

\section{Components}

1. Generator losses 500 to $1100^{\circ} \mathrm{F}$ coolant

2. AC Motor losses 500 to $1100^{\circ} \mathrm{F}$ coolant
System Electrical Rating

$\frac{0.35 \mathrm{mwe}}{40 \mathrm{kw}} \frac{1.0 \mathrm{mwe}}{75 \mathrm{kw}} \frac{5.0 \mathrm{mwe}}{275 \mathrm{kw}} \frac{10.0 \mathrm{mwe}}{570 \mathrm{kw}}$

$5.5 \mathrm{kw} \quad 27.8 \mathrm{kw} \quad 163 \mathrm{kw} \quad 334 \mathrm{kw}$

$5.9 \mathrm{kw} \quad 17.5 \mathrm{kw} \quad 88 \mathrm{kw} \quad 168 \mathrm{kw}$

3. High temperature power conditioning - 500 to $1100^{\circ} \mathrm{F}$ coolant

Subtotal - High temp. coolant losses

4. Low temperature power conditioning - 150 to $200^{\circ} \mathrm{F}$ coolant

Total - Electrical

System losses

5. High temperature elec. 228 kw $\quad 658 \quad \mathrm{kw} \quad 3139 \mathrm{kw} \quad 6245 \mathrm{kw}$ loads utilizing 500 to $800^{\circ} \mathrm{F}$ coolants
$8.9 \mathrm{kw} \quad 22.4 \mathrm{kw} \quad 129 \mathrm{kw} \quad 246 \mathrm{kw}$

$60.3 \mathrm{kw}$ $142.7 \mathrm{kw}$

$655 \mathrm{kw} \quad 1318 \mathrm{kw}$ 
Table 4.2 Summary of Estimated Electrical System Coolant Flows

Components

1. Generator coolant 500 to $1100^{\circ} \mathrm{F}$, maxi mum allowable $\Delta \mathrm{T}=100^{\circ} \mathrm{F}$

2. AC Motor coolant 500 to $1100^{\circ} \mathrm{F}$, maxi mum allowable

$\Delta \mathrm{T}=100^{\circ} \mathrm{F}$

3. High temperature power conditioning coolant - 500 to $1100^{\circ} \mathrm{F}$, maximum allowable $\Delta \mathrm{T}=100^{\circ} \mathrm{F}$

Subtotal - High temp. coolant

4. Low temperature power conditioning coolant -150 to $200^{\circ} \mathrm{F}$, maximum allowable $\Delta \mathrm{T}=50^{\circ} \mathrm{F}$

5. High temperature elec. loads utilizing 500 to $800^{\circ} \mathrm{F}$ coolants, maxi mum allowable $\Delta \mathrm{T}=100^{\circ} \mathrm{F}$ (assumed)

System Electrical Rating

\begin{tabular}{|c|}
\hline 0.35 \\
\hline
\end{tabular}

2.1

3.9

14.2

29.4

$\mathrm{lb} / \mathrm{sec}$

$\mathrm{lb} / \mathrm{sec}$

$\mathrm{lb} / \mathrm{sec}$

$\mathrm{lb} / \mathrm{sec}$

1

$\mathrm{lb} / \mathrm{sec}$

1.4

$\mathrm{lb} / \mathrm{sec}$
8.4

$\mathrm{lb} / \mathrm{sec}$

17.3
$b / \sec$

17.3
$\mathrm{lb} / \mathrm{sec}$

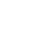


3. The amount of control and electronic load was the same for all missions. All remaining power is distributed to electric thrusters, pumping loads, and high voltage transmitters according to the same ratios as defined for the one megawatt system.

4. Full-load power conditioning efficiencies were assumed to be as follows:
a. Transformers
98 percent
b. Frequency changers
93 percent
c. High-voltage rectifiers
99 percent
d. Low-voltage rectifiers
95 percent

Additional data was gathered on the a-c motor losses as a function of horsepower rating and are given below. These were determined independent of the losses shown in Table 4.1 and were calculated for the purpose of better defining the total pump motor losses after the pumping requirements for the four power systems have been separately defined.

\begin{tabular}{|c|c|c|}
\hline $\begin{array}{l}\text { AC Motor } \\
\text { Rating }\end{array}$ & $\begin{array}{c}\text { Estimated } \\
\text { Motor Losses }\end{array}$ & $\begin{array}{r}\text { Coolant Flow, } \\
\Delta \mathrm{T}=100^{\circ} \mathrm{F} \max \end{array}$ \\
\hline $5 \mathrm{hp}$ & 2.2 to $3.3 \mathrm{kw}$ & $1 \mathrm{lb} / \mathrm{sec}$ \\
\hline $30 \mathrm{hp}$ & 3.0 to $4.3 \mathrm{kw}$ & $1 \mathrm{lb} / \mathrm{sec}$ \\
\hline $60 \mathrm{hp}$ & 4.5 to $6.2 \mathrm{kw}$ & $1 \mathrm{lb} / \mathrm{sec}$ \\
\hline $100 \mathrm{hp}$ & 9.7 to $19.1 \mathrm{kw}$ & $1 \mathrm{lb} / \mathrm{sec}$ \\
\hline $250 \mathrm{hp}$ & 19.0 to $25.0 \mathrm{kw}$ & 1 to $1.3 \mathrm{lb} / \mathrm{sec}$ \\
\hline
\end{tabular}

Note that on Table 4.1, the electrical component losses amount to about 10 to 15 percent of the rating for the high temperature coolant and about 2.5 percent of the rating for the low temperature coolant. The high temper ature electrical loads amount to about 64 percent of the electrical rating of the system.

\subsubsection{Plans for the Coming Quarter}

Effort will now be directed toward defining and tabulating the data, facts, configurations, etc., representative of the four system ratings $-0.35,1.0$, 5 and $10 \mathrm{mw}_{\mathrm{e}}$. The specific data will include items 1 through 8 discussed in Section 2.1.2. Additional investigations will be made to define the mechanical design guidelines to be followed during the parametric design analyses in the following quarter. 
page blank 


\section{EXPERIMENTAL VERIFICATION}

Early in 1965, the design of a 467-kva potassium-cooled generator was completed (1) and the fabrication of two sets of components was initiated. The design details are shown in Figure 5.1. The generator design was based largely on analytical considerations with only a minimum of experimental data. Mechanically speaking, the generator represented the technology developed since the initiation of the SNAP-50/SPUR program in late 1960. For example, the bearings and seals used were developed on data from the $50-\mathrm{KW}$ (LMCD-II) generator $(30)$, rotor fluid dynamic tests (1), and in-house developments (5), (31), (32). In addition, the generator incorporated the features necessary to cool the rotor and to scavenge and maintain rotor cavity pressure below 0.02 psia. These features were developed on data from rotor fluid dynamic tests. Electrically speaking, the only experimental data available was that extrapolated from apparatus that differed considerably from this application in rating, speed, operating environment, and the type of material used in construction. Accordingly, in some design areas, an acute need existed for pertinent experimental data that would facilitate the accurate prediction of generator performance and operating characteristics.

This generator was designated the Experimental Generator and the two sets of components to be built were intended to:

1. Obtain experience and test data on the fabrication and performance of the machine, and

2. to define problem areas peculiar to this type of machine.

Initial tests were to be performed using Stoddard solvent at low speeds and at no load. Complete electrical and mechanical tests, using potassium as the coolant and lubricant, were to be used to verify the feasibility of the design concepts. Before the testing was started, the program was redirected and the hardware was diverted to a component technology test program on AF Contract AF33(615)-2326. At the conclusion of the 2326 contract, the status of the generator hardware was as follows:

1. The No. 1 Stator was completed except for electrical winding and procurement of a bore seal. 


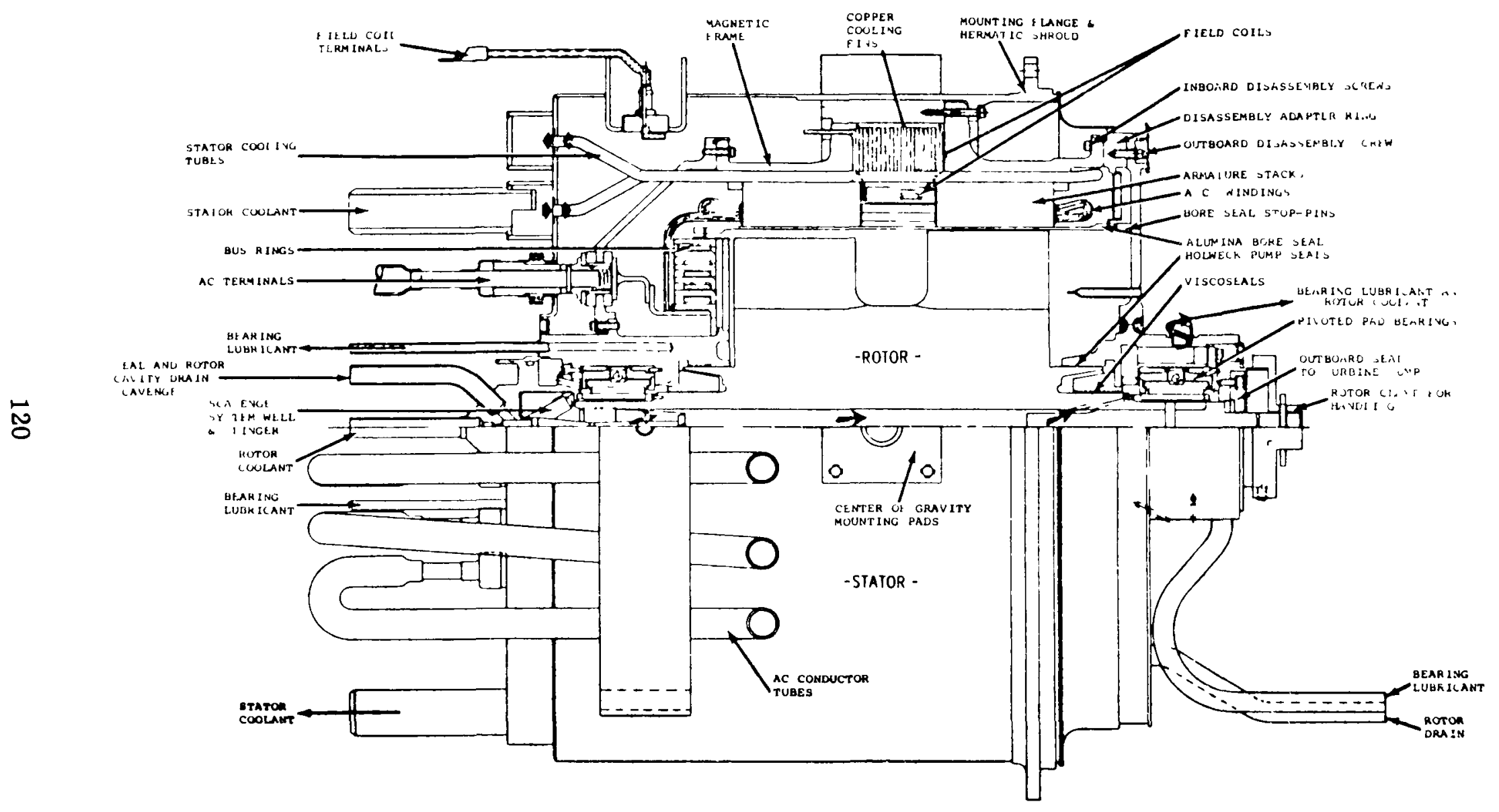

Figure 5.1 467 KVA Experimental Generator 
2. The No. 1 Rotor was completed except for slotting the pole faces and final polishing and balancing operations. (The pole face slotting technique was fully developed on separate development pieces.)

3. A special rotor fluid dynamic-test assembly was completed on which fluid-dynamic tests had been conducted and completed.

4. A portion of the No. 2 set of parts was started.

The present program again diverts the existing hardware for use in three important verification test areas:

1. Magnetic Unbalance and Flux Distribution Tests

2. No Load Loss Tests, and

3. Additional Rotor Fluid Dynamic Tests.

\subsection{MAGNETIC UNBALANCE AND FLUX DISTRIBUTION}

\subsubsection{Background}

(a) Magnetic Unbalance Tests. Any eccentricity of the cylinder circumscribed by the rotor pole face surfaces with that of the stator bore will produce an unbalanced force on the rotor. The magnitude of this force for any given amount of eccentricity is dependent on the degree of field excitation. Further, any misalignment between rotor and stator will similarly produce a force couple or torque. These forces must be carried by the rotor support bearings, and, as these may be a significant portion of the total bearing load, their magnitude and direction must be known and verified with that which can be obtained by present calculation methods. Since the bearings may be limited as to permissible total load, these data will help define dimensional limits of bea ring size and alignment must be maintained.

(b) Magnetic Flux Distribution Tests. The generator output voltage at any given speed is a function of the magnitude of the change in magnetic flux cutting the stator conductors. This flux can therefore be considered the useful flux, while the difference between this useful flux and the total flux is considered leakage flux. An important step in the initial design of any generator is to compute the values of both useful flux and leakage flux. It is necessary to experimentally verify these flux distribution calculations so that: (1) accurate predictions of generator performance and operating characteristics can be made well in advance of development testing, and (2) pertinent flux leakage data can be established for large inductor generators suitable for nuclear space electric power systems. Determination of this data now will improve the design accuracy of later generator configurations required by such programs. 


\subsubsection{Test Description}

The essential requirements of these tests are: (1) to duplicate the full range of generator excitation, eccentricity, and misalignment that may be imposed on the 467-kva Experimental Generator, and (2) to accurately measure the resultant flux distribution and the forces imposed on the rotor. To accomplish this, the No. 1 467-kva Experimental Generator stator (with the a-c windings and the bore seal assembly deleted) is fitted with a total of 8 search coils. The No. 1 generator rotor is fitted with a total of 10 search coils. The rotor is mounted to the stator through anti-friction bearings, load cells, and adjustable linkage, while the stator in turn is mounted in a fixture as shown in Figure 5.2.

Anti-friction bearings are provided to facilitate the use of dial indicators which will be mounted on the rotor to measure eccentricity and misalignment. The load cells are provided to measure the forces imposed on the rotor by reason of the magnetic unbalance caused by the rotor eccentricity and/or misalignment. Adjustable linkage is provided to accurately adjust the eccentricity and/or misalignment of the rotor relative to the stator bore. All mounting fixtures and adapters are constructed of non-magnetic stainless steel to avoid any distortion of the generator flux distribution.

Generator flux level is controlled by excitation of the generator field through a d-c power source over a range of from zero to 125 percent of rated excitation current. The output of each search coil is measured by sensitive flux meters. To minimize the number of flux readings that must be obtained at the same instant and also to reduce the number of flux meters required, the test is divided into four segments. Thus, each test segment will require only a maximum of five flux meter readings to be taken at any one time rather than 18. The flux meters are calibrated at the beginning of each test run with standard flux meter calibration equipment, the flux density range of which envelopes the flux range to be measured. The load cells are similarly calibrated by calibration resistors provided by the manufacturer.

\subsubsection{Past Quarter Accomplishments}

The Magnetic Force and Flux Distribution test assembly was completed and all instrumentation was installed. Testing began the last week of November.

(a) Hardware. The stator outer field coil was wound and all interconnections were brazed in an inert gas atmosphere. Figure 5.3 shows the stator with the field coil in place and insulated. Three of the search coils are shown wound over the outer field coil. The field housing cap was then installed and the laminated stator stacks were ground to size. While the stator was mounted in the grinding machine, the inside diameters of the stator locking rings were also machined to obtain excellent concentricity of these diameters with respect to the stator stacks. Concentricity of the ring diameters with respect to the stator stack diameters was verified to be less than 0.0002 inches total indicator reading. The continuous ring diameters will, therefore, be used as an indicating surface when determining rotor eccentricity. 


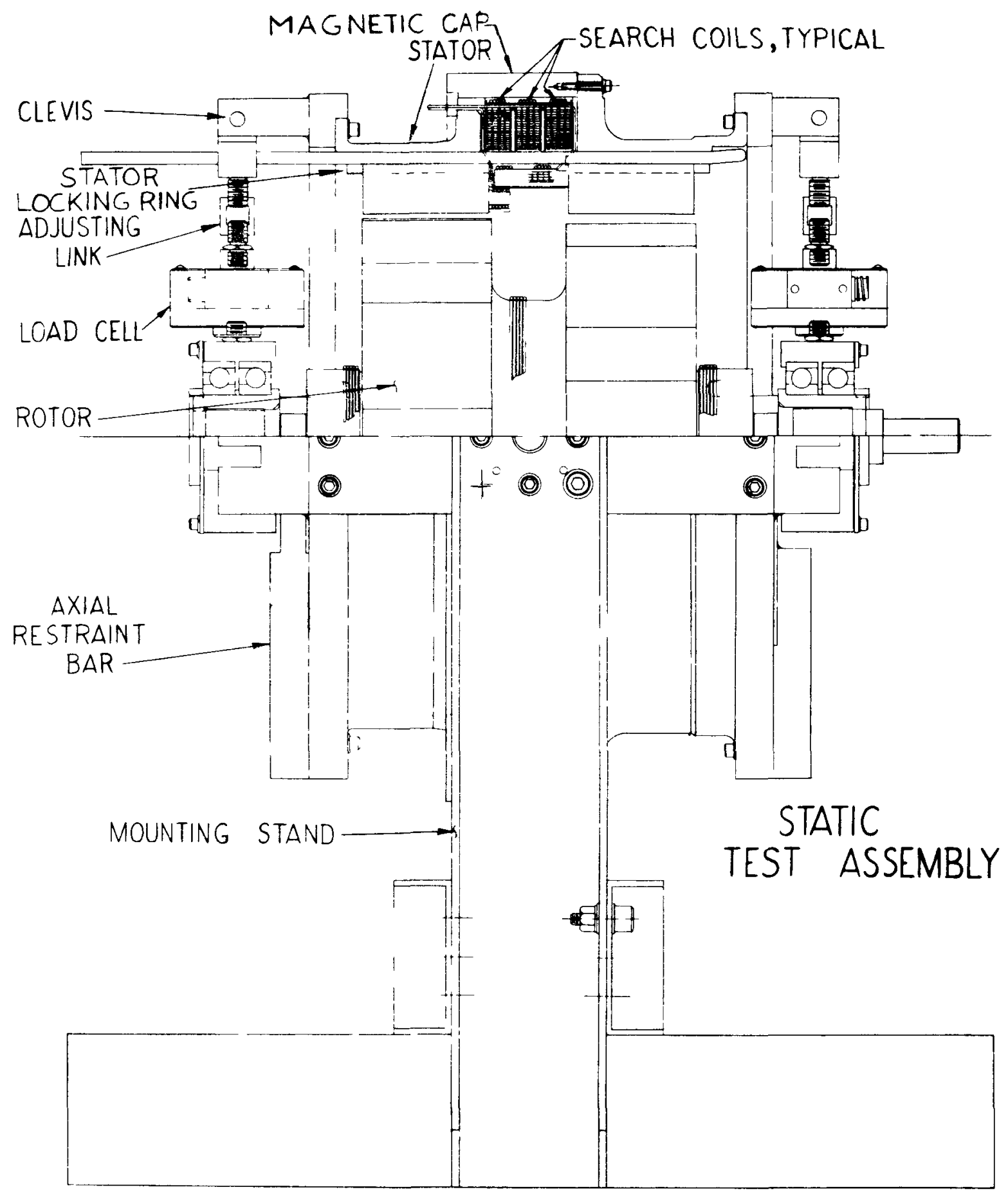

Figure 5.2 Stator Test Fixture 


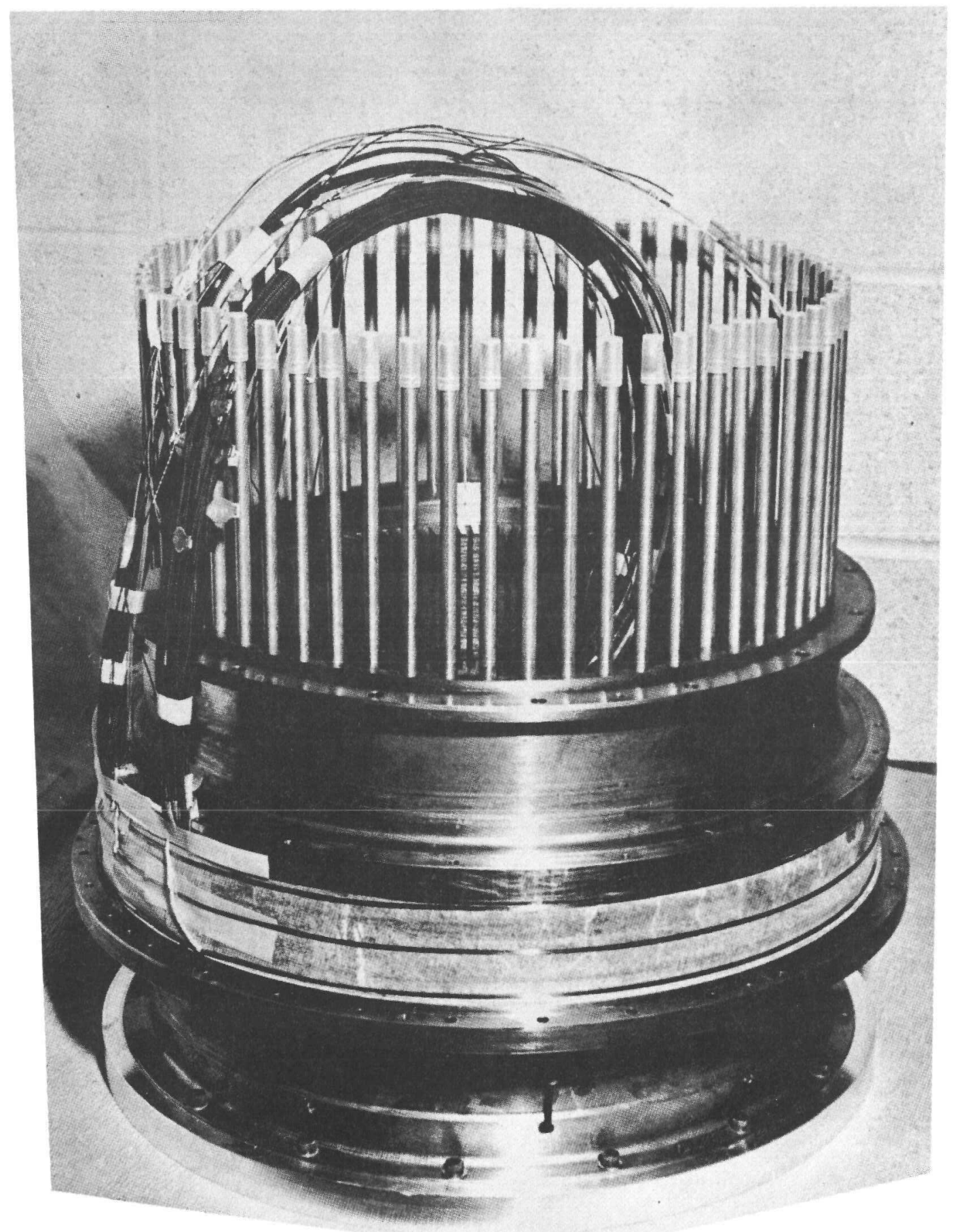

Figure 5.3 No. 1 Stator 
Figures 5.4 and 5.5 show the completed rotor with bearings and bearing housings installed. The two figures also indicate the location of all rotor search coils.

Figure 5.6 is the completed test assembly with the cooling tubes connected to the inlet and outlet manifolds.

(b) Test Instrumentation. Figure 5.7 shows the Magnetic Force and Flux Distribution Test Assembly with instrumentation connected. Precision dial indicators ( 0.0001 inch per division) are clamped to the rotor poles at each end of the rotor with the pointer bearing on the stator locking ring diameter. Initial values of rotor eccentricity are measured by these indicators. Since some indicator components are magnetic, the indicators must be removed from the rotor prior to energizing the stator field coil. Under field excitation, the additional elastic deflection of the load cells and associated support linkage plus that in the small diameter ends of the rotor will be measured by indicators mounted to special non-magnetic extensions. These extensions were designed to allow the indicators to be located about eight inches from the magnetized components. The magnetic field at this location does not affect indicator operation. These extensions were verified and found to be accurate except for 0.001 inches backlash in the indicator -extension combination. The backlash presents no problem to accurate measurement.

The load cells are strain gage type cells manufactured by the Lebow Instrument Co. and are used with an Ellis Associates, Model BAM-1 bridge amplifier meter. The cells were calibrated on a tensile test machine and calibrated to $\pm 3 / 4$ percent accuracy. Only at the high load values (400 to 500 pounds) did load call readings deviate from machine readings; at 400 to 500 pounds, deviation was 1 percent. Calibration of the load cells using the calibration resistors supplied by the manufacturer was also verified on the tensile test machine. The calibration resistors will be used periodically during the course of the tests to check and recalibrate the cells.

\subsubsection{Plans for Next Quarter}

During the next quarter the Magnetic Force and Flux Distribution tests will be completed. 


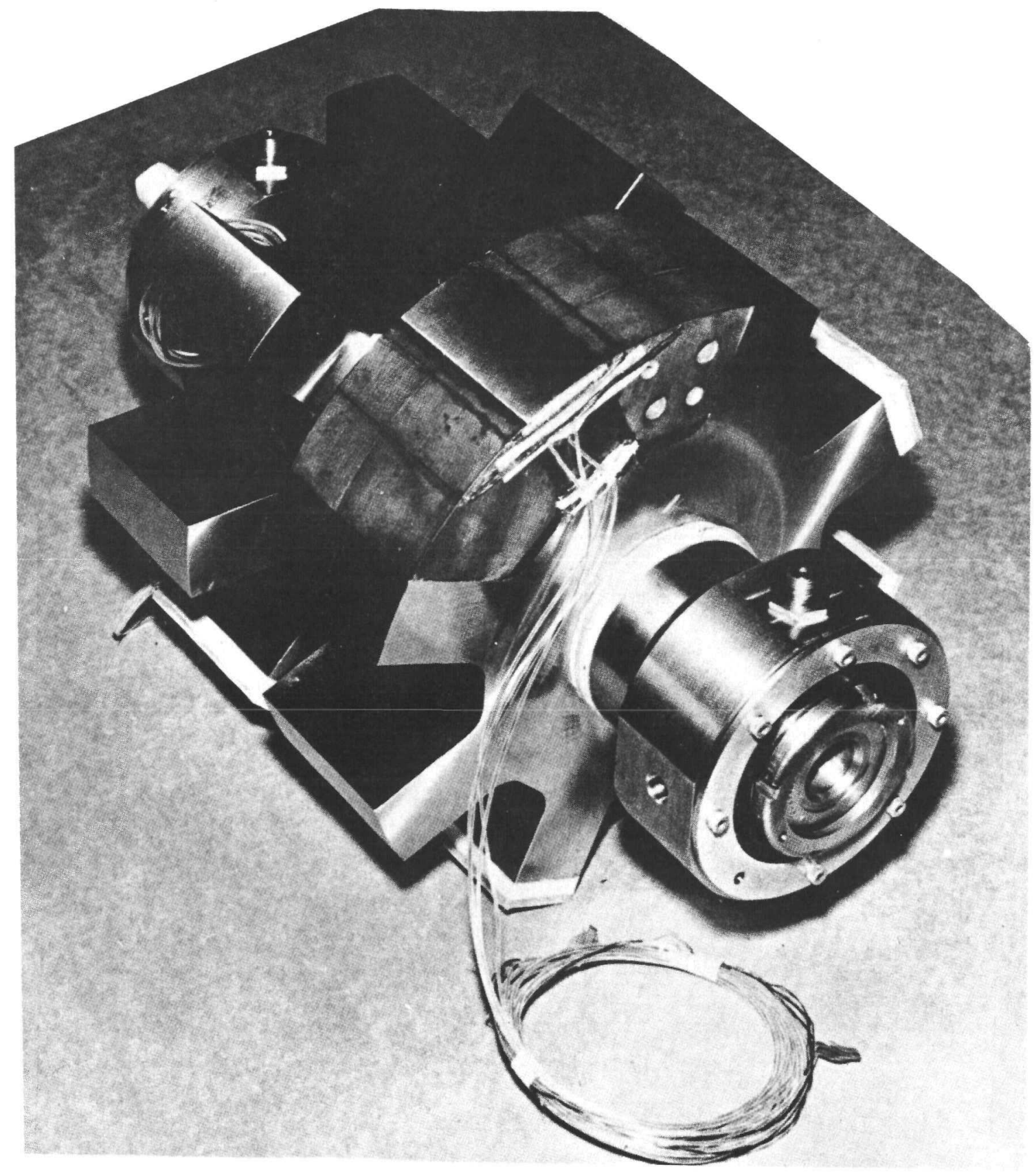

Figure 5.4 No. 1 Rotor 


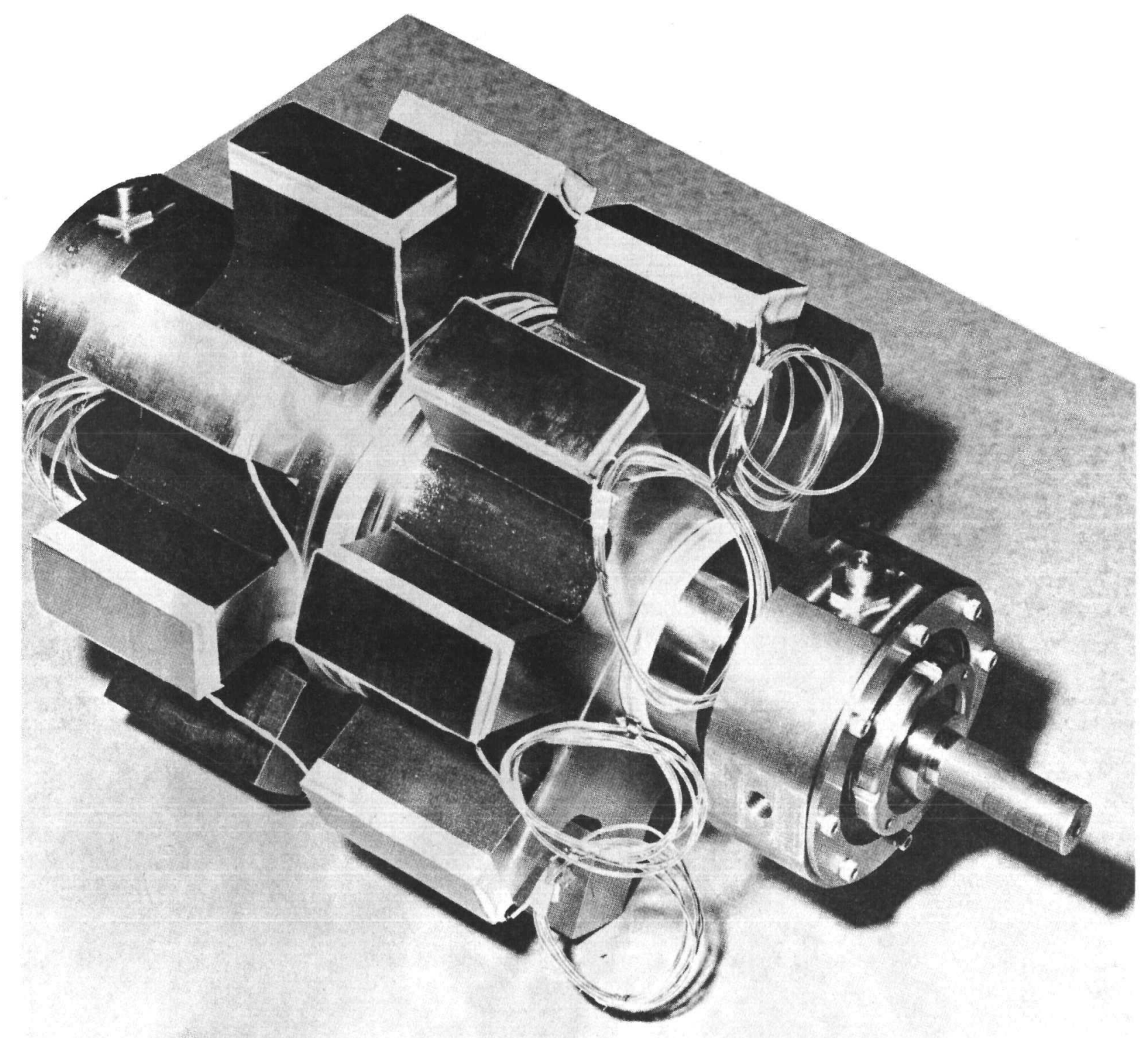

Figure 5.5 No. 1 Rotor 


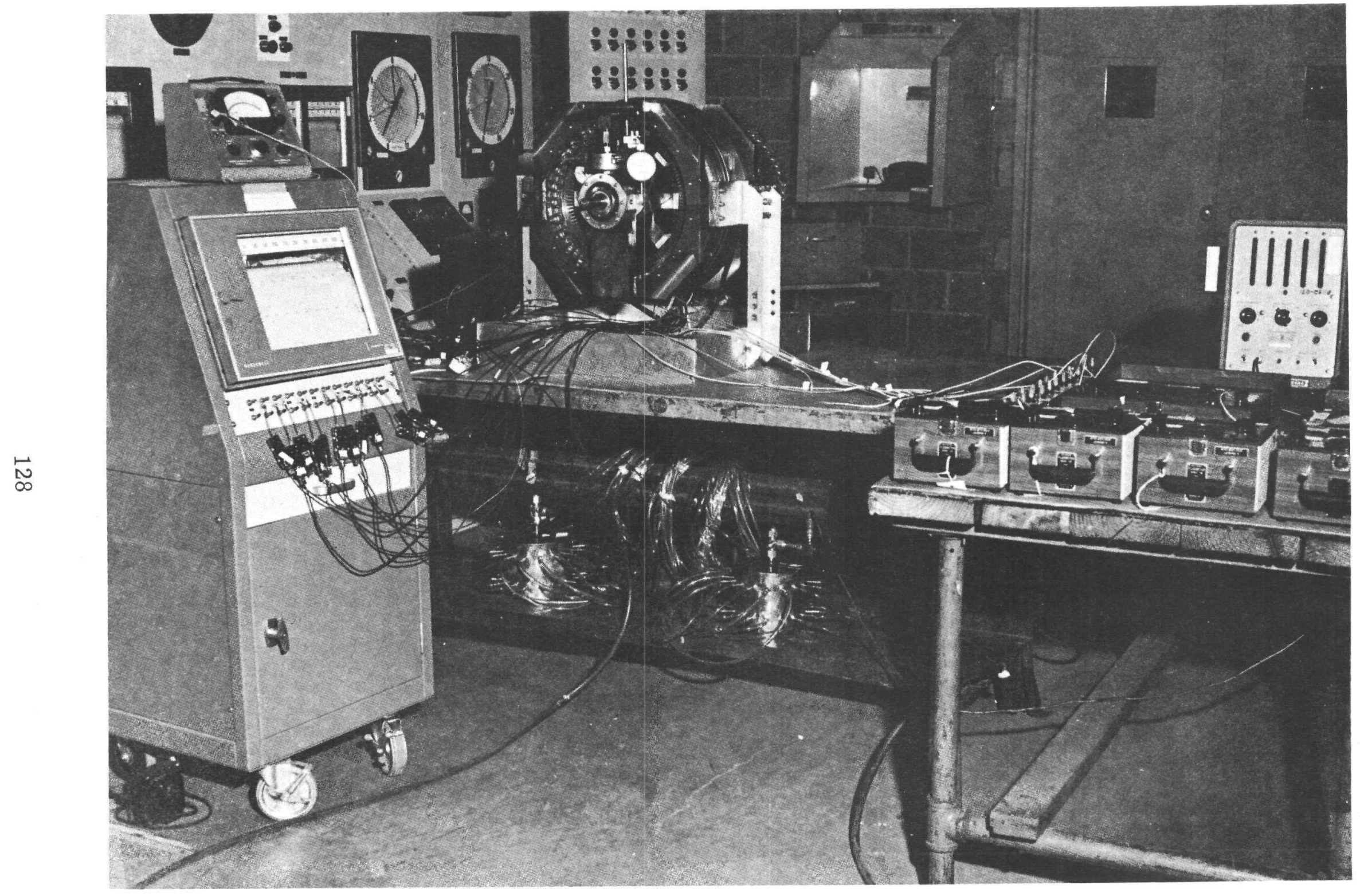

Figure 5.6 Static Test Set-Up 


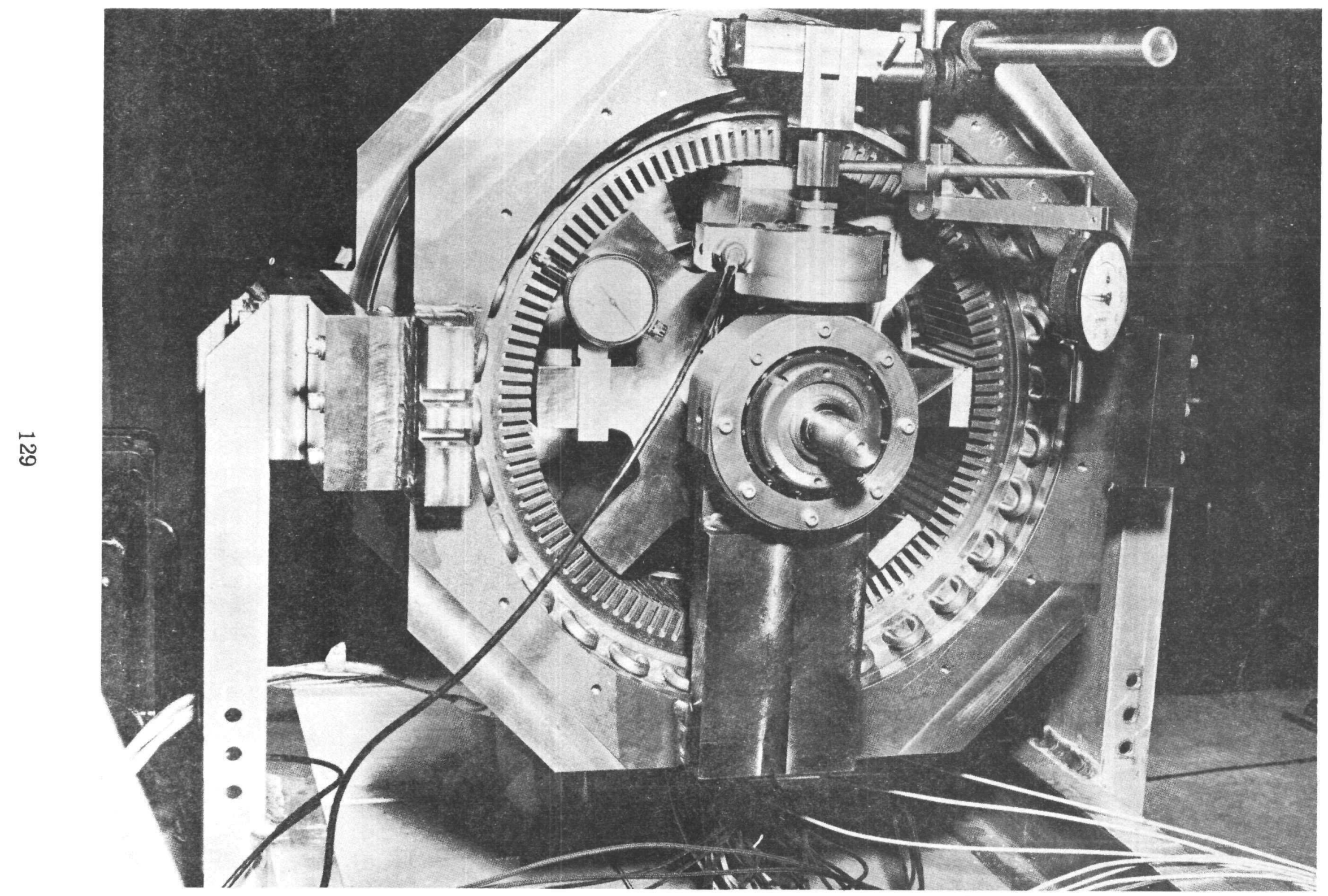

Figure 5.7 Static Test Assembly and Instrumentation 


\subsection{MAGNETIC NO-LOAD LOSS TESTS}

\subsubsection{Background}

A major portion of the total generator losses are the iron losses produced in the magnetic path. These losses are primarily dependent upon the flux density throughout the generator. Theoretically, these can be calculated from the flux distribution. However, the influence of such assembly requirements as cooling slots, shrink fits, mechanical fasteners, etc., may cause substantially higher losses. Because of the dissimilarity between the 467-kva Experimental Generator and existing machines, there are no valid empirical factors which can be used to predict these effects. Accordingly, experimental data are needed to determine actual iron losses over the ranges of generator excitation and speed of interest. These data will define the temperature distribution that will exist within the generator magnetic path as well as the generator cooling requirements.

\subsubsection{Test Description}

The No. 1 stator and rotor from the previous test will be used for the No-Load Loss Tests. The rotor will be reworked to remove the search coils and to have the pole faces slotted (0.004 inch wide and 0.070 inch deep). In addition, rotor modification will include incorporating the necessary components to cool with water. Oil jet lubricated anti-friction bearings will support the rotor and a face type shaft seal will be used to separate the water coolant from the bearing lubricant. The stator will be essentially the same config uration as was required for the previous tests but will include end bells and other stator components required to accomodate the bearings and shaft seals. Neither a-c windings nor a bore seal will be included in the stator. A single a-c winding will be included, however, so that the generated no-load voltage can be measured. A water system will be provided for both rotor and stator cooling. The rotor will be driven by a $60-\mathrm{kva}$ aircraft generator operating as a motor through a gear box and a precision torque meter. The entire assembly will be enclosed and sealed by a hermetic protective cover. Tests will be performed at approximately 1 psia in a helium atmosphere to minimize the effect of windage. The combined no-load losses (pole face, magnetic, and field coil) of the machine will be measured at three constant speeds. These losses will be measured for increments of field current starting at zero. The flux level will be measured for each increment of current and the temperature distribution of the machine will be recorded for each steady-state condition. Figure 5.8 illustrates the No-Load Loss test assembly configuration. 


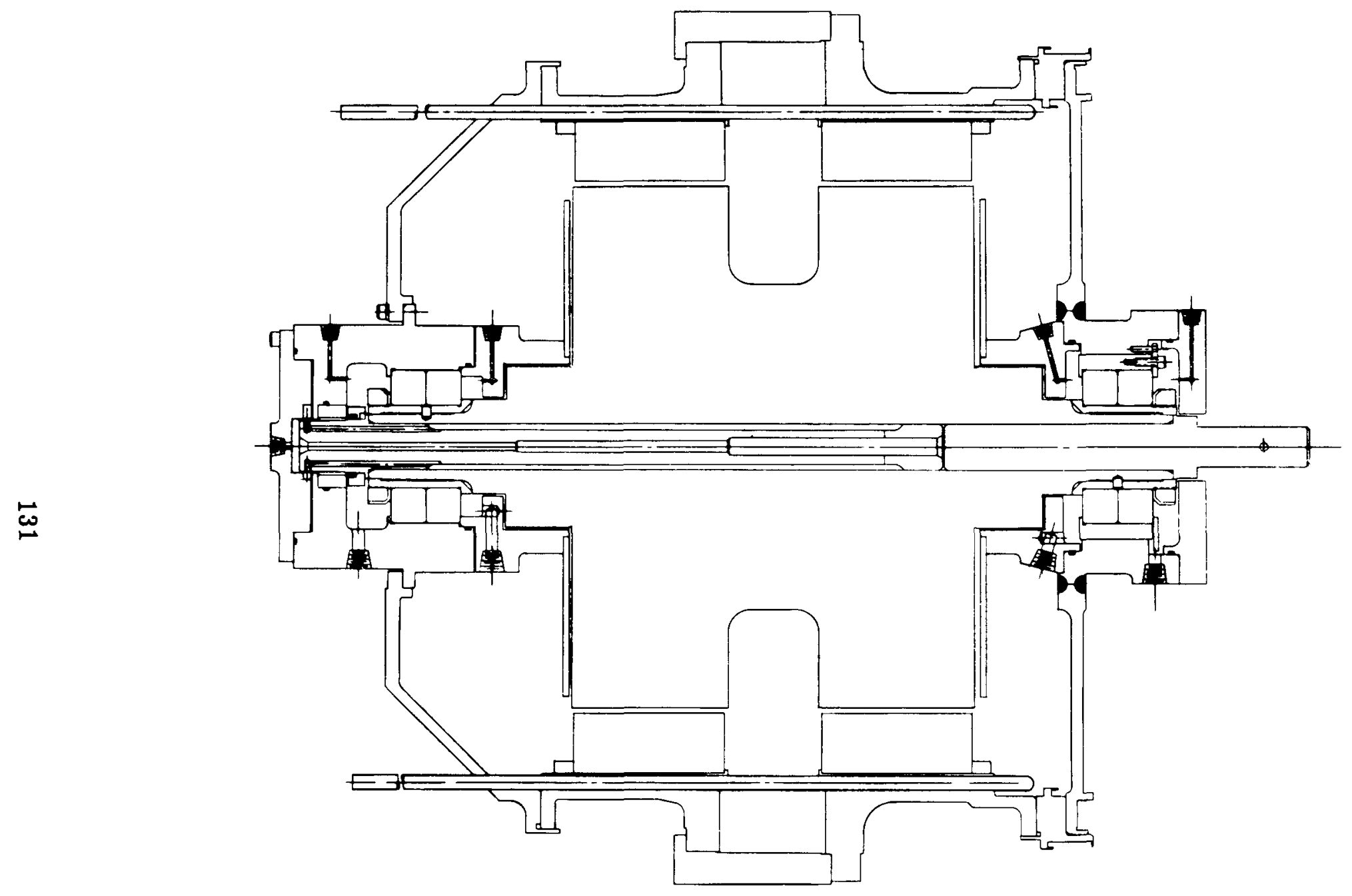

Figure 5.8 No-Load Dynamic Test Rig 


\subsubsection{Past Quarter Accomplishments}

A preliminary layout of the No-Load Loss test assembly was completed and detail drawings were started. Bearings and shaft seals were placed on order. Where possible, new components were designed to be manufactured from materials procured on earlier phases of the program, thereby reducing material procurement problems.

\subsubsection{Plans for Next Quarter}

Drawings will be completed and all necessary components will be completed including rework of the No. 1 rotor. Assembly of the No-Load Loss test assembly is also scheduled for completion during the next quarter.

\section{3 ROTOR COOLING CONCEPTS}

\subsubsection{Background}

The energy losses in the pole faces can be removed efficiently by diverting rotor coolant outward into the body of the rotor. This cooling scheme reduces the heat conduction path between the source and the sink; thus, the maximum temperatures within the rotor will be almost equal to the temperature of the coolant. Since the core or the central portion of the rotor is inherently subjected to the greatest stress, a scheme which produces low temperatures in this portion of the rotor will also increase the integrity and life of the rotor. A cooling scheme with the coolant passage diverted radially outward provides this feature.

\subsubsection{Problem}

When the coolant within the rotor flows radially or perpendicular to the axis of rotation, Coriolis forces are produced upon the fluid. These forces produce secondary flows if a velocity gradient exists within the main flow.*

*Reference - Westinghouse proprietary memo on the "Secondary Flow in a Rotating Duct" by R. W. Detra and J. L. McCabria, Report No. AGT $2126,9 / 30 / 55$. Although this report was released for the use of Westinghouse personnel only, pertinent parts of it shall be issued in the Final Report which will cover the experimental verification of the rotor cooling concept under investigation. 
The secondary flows can be thought of as perturbations superimposed upon the main flow within the passage. In this interpretation, the secondary flow consists of velocities acting in a cross sectional plane which is perpendicular to the axis of rotation. The effect of these velocities is to affect a transport of the fluid particles, resulting in a deformation of axial velocity distribution and an increase of the frictional forces.

The phenomenon of secondary flows in a passage rotating about an axis perpendicular to the longitudinal axis of the passage is similar to the phenomenon of secondary flow in stationary curved pipes. In curved pipe flow, centrifugal forces are produced upon the fluid and these forces produce secondary flows if a velocity gradient exists within the main flow. The increase in resistance to turbulent flow which is produced by curvature was investigated by C. M. White and others, References 33 and 34 . C. M. White's equation for turbulent flow in curved pipe is:

$$
\frac{\lambda}{\lambda_{o}}=1+0.075\left(\frac{\mathrm{PvR}}{\mu}\right)^{1 / 4}\left(\frac{\mathrm{R}}{\mathrm{r}}\right)^{1 / 2}
$$

where

$$
\begin{aligned}
r & =\text { Radius of curvature of pipe } \\
R & =\text { Radius of the cross-section } \\
v & =\text { Main flow velocity } \\
\lambda & =\text { Resistance coefficient for curved pipe flow } \\
\lambda_{o} & =\text { Resistance coefficient for straight pipe flow } \\
\mu & =\text { Absolute viscosity of fluid } \\
P & =\text { Density of fluid }
\end{aligned}
$$

Unfortunately, equivalent equations for the increase in resistance to flow in rotating pipes do not exist. However, it can be shown that the dimensionless variable, $R / r$, in $C$. $M$. White's equation can be replaced with an equivalent dimensionless variable. The equivalent variable in terms of the parameters associated with a rotating duct is $\mathrm{RW} / \mathrm{v}$ where w equals the angular velocity of the duct. The derivation* of this dimensionless variable is based upon the conditions that will produce Coriolis forces in a rotating duct which are equal to the centrifugal forces in a curved duct as illustrated below:

\footnotetext{
*The author is indebted to Dr. O.G. Smith of the Aerospace Electrical Division, Westinghouse Electric Corporation, for this derivation.
} 


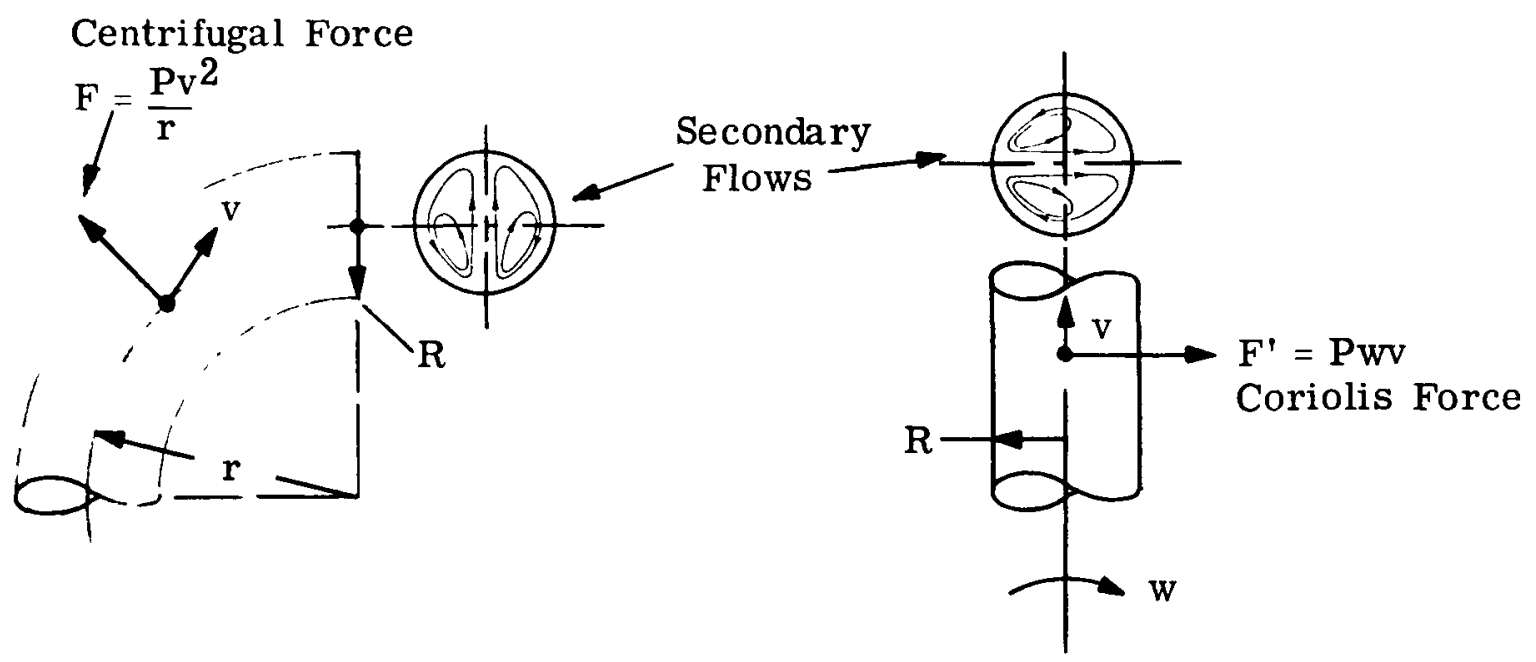

with

$$
\begin{aligned}
& \mathrm{F}=\mathrm{F}^{\prime}=\frac{\mathrm{Pv}^{2}}{\mathrm{r}}=\mathrm{Pwv} \\
& \mathrm{r}=\frac{\mathrm{v}}{\mathrm{w}}
\end{aligned}
$$

and

$$
\frac{\mathrm{R}}{\mathrm{r}}=\frac{\mathrm{Rw}}{\mathrm{V}}
$$

Thus, White's equation for rotating dust becomes:

$$
\frac{\lambda}{\lambda_{o}} \approx 1+0.075\left(\frac{\mathrm{PvR}}{\mu}\right)^{1 / 4}\left(\frac{\mathrm{Rw}}{\mathrm{v}}\right)^{1 / 2}
$$

It should be noted that these dimensionless parameters only give an approximate estimate for the increase in resistance to flow in a rotating pipe. It was assumed that the change in the radius of curvature throughout the cross sectional planes associated with White's experiments had a negligible influence upon the centrifugal forces on the fluids. 
In general, it was assumed that the secondary flows were produced by a variation of centrifugal forces due to a variation of velocity caused by viscous drag. Nevertheless, it is reasonable to expect that the modified equation will give a good estimate for the increased resistance provided that the dimensionless variable $\mathrm{Rw} / \mathrm{v}$ is small compared with unity and within the range of $R / r$ that is represented empirically by White's equation.

Typical values of the variables for a high speed rotor with $500^{\circ} \mathrm{F}$ potassium coolant are:

$$
\begin{aligned}
\mathrm{w} & =800 \pi \mathrm{radians} / \mathrm{sec} \\
\mathrm{R} & =0.048 \mathrm{inch}=0.004 \mathrm{ft} \\
\mathrm{v} & =25 \text { feet } / \mathrm{sec} \\
\frac{\mathrm{Rw}}{\mathrm{v}} & =0.402 \\
& =5.47 \times 10^{-6} \mathrm{Lb}_{\mathrm{f}} \mathrm{sec} / \mathrm{ft}^{2} \\
\mathrm{P} & =47 \mathrm{~b}_{\mathrm{m}} / \mathrm{ft}^{3} \\
\frac{\mathrm{PvR}}{\mu} & =26,600 \\
\text { and } \quad \frac{\lambda}{\lambda_{\mathrm{o}}} & =1.0+0.075(26,600)^{1 / 4}(0.402)^{1 / 2}=1.61
\end{aligned}
$$

The calculations, even though they are not exact, indicate that the increase of flow resistance due to Coriolis forces acting upon the potassium will not be a critical problem.

\subsubsection{Experimental Verification}

The test fixture which was used to verify the fluid dynamic performance of the rotor assembly and related components in the 467-kva SNAP-50/SPUR experimental generator are being modified to accomodate a new rotor assembly. A cross-sectional view of the new fixture is given in Figure 5.9. In general, the shaft seals, bearings, and scavenge system are same as used in the original test fixture. A description and the fluid dynamic performance of these components is given in the final report on the SNAP-50/SPUR generator design program (1) (presently being published). The coolant flow path through the new rotor has several features described below.

(a) Coolant Inlet Section. The coolant enters the rotor along the axis of rotation through a central hole 0.25 -inch in diameter. The flow is then diverted in a radial direction through four vanes. The radial vanes will 


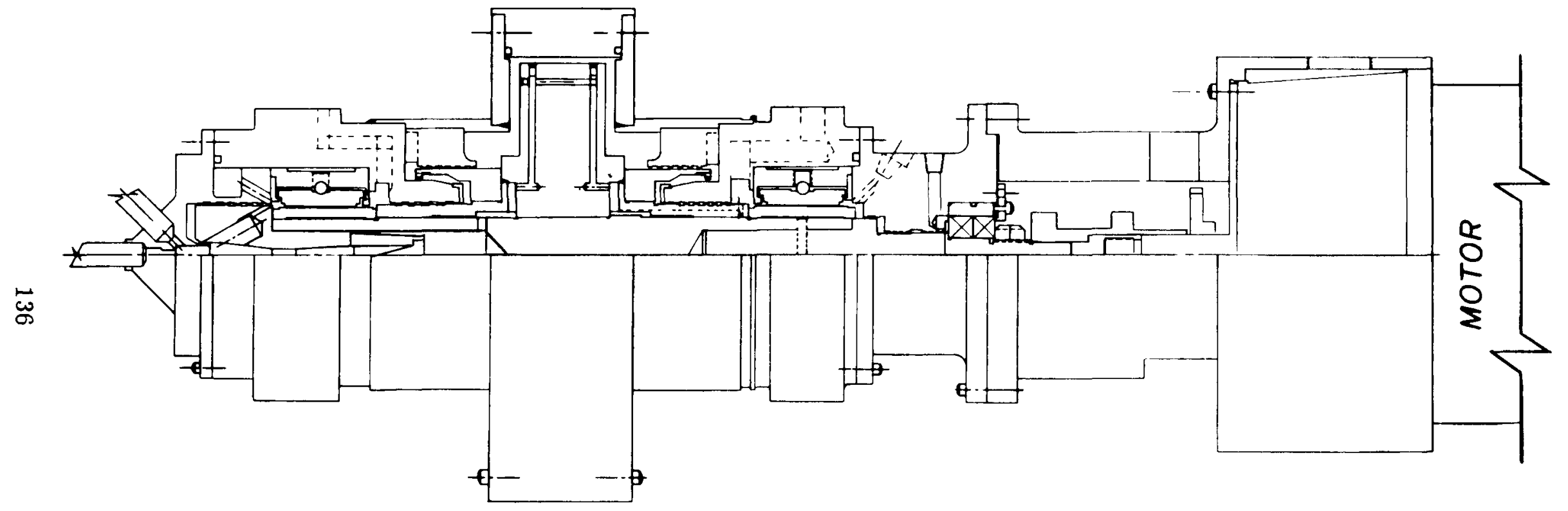

Figure 5.9 Fluid Dynamic Test Rig 
decrease the drag on the rotor since it is more efficient to increase the tangential velocity ( 102.5 feet per second at $24,000 \mathrm{rpm}$ ) without slippage than to increase the velocity by viscous action along the wall of the central passage.

(b) Manifold on Inlet Side of Rotor. The coolant flows through the shaft extension and into a manifold which serves as a distribution duct for the eight parallel coolant passages in the body of the rotor. The manifold also forms the rotating portion of the liquid seal and provides a support for the rotating portion of the vapor seal. Radial vanes within the manifold will provide the Coriolis reaction necessary to accelerate the coolant up to the tangential velocitv of the coolant passage within the body of the rotor.

(c) Rotor Coolant Passages. The rotor has eight equally spaced passages which divert the coolant radially outward and inward from a diameter of 2.75 inches to a diameter of 7.0 inches and back again. The pressure within the passage at the 7.0 -inch diameter will be approximately 3,370 psia at 24,000 rpm due to centrifugal forces on the fluid.

(d) Manifold on Outlet Side of Rotor. The manifold on the outlet side of the rotor will be similar to the inlet manifold except that it will contain flow passages to divert the fluid into the drive-end bearing discharge chambers. The discharge chamber will contain a volute type diffuser which will convert part of the tangential velocity of the fluid into static pressure.

The distinct advantage of rotor cooling concept illustrated in Figure 5.9 is that it contains all of the features of a centrifugal pump with an impeller diameter of 2.0 inches; the flow enters along the axis of rotation and leaves the rotor at a diameter of 2.0 inches. Thus, at $24,000 \mathrm{rpm}$, the pressure head across the rotor would have to reach approximately 290 psi before the flow would stop. While the Coriolis forces acting upon fluid will produce secondary flows and cause an increase of the flow resistance, it is not expected that the required pressure head will approach 290 psi at $24,000 \mathrm{rpm}$.

A second advantage of this rotor cooling scheme is that it can be used in conjunction with a rotor cavity and seal scavenge system which has been experimentally verified; the scavenge system produced pressures as low as $0.2 \mathrm{psia}$ without the use of any external vacuum pumps, Reference 1.

Manufacture of components for the modified test fixture was started in November and this phase of the task is approximately half-way complete.

\subsubsection{Plans for Coming Quarter}

Modifications to the fluid dynamic test rig are to be completed. The tests should be completed by the end of the next reporting period also. 
page blank 


\section{REFERENCES}

1. Work on the SNAP-50/SPUR Generator covered a period from 1960 to 1966 and was carried out under U.S.A.F. Contracts A F33(616)7379 and -8322, A F33(657)-8954 and -10922, and AF33(615)-1551 and -2326 . Final reports on this program are presently being published. Progress reports covering A F33(657)-8954, A F33(615)-1551 and AF33(615)-2326 were utilized extensively in selecting design parameters and background for this study.

2. Work on Contract NAS 5-1234 was reported in six volumes:

Vol. I, II, II I and IV as Westinghouse Aerospace Electrical Division Report No. D-709533, December 1962.

One volume as Westinghouse Aerospace Electrical Division Report No. WAED 63.11E, December 1963.

One volume, unnumbered, by Westinghouse Aerospace Electrical Division on 250 and $500 \mathrm{KW}$ designs on an extension of NAS 5-1234.

Official NASA contractor report numbers were not applied to these reports.

3. Magnetic Materials Topical Report, NASA Lewis Research Center Report, NASA-CR-54091, September, 1964. Prepared by Westinghouse Aerospace Electrical Division.

4. Electrical Conductor and Electrical Insulation Materials Topical Report, NASA Lewis Research Center Report, NASA-CR-54092, October, 1964. Prepared by Westinghouse Aerospace Electrical Division.

5. R.W. Briggs \& F.X. Dobler, "Development of Potassium-Cooled Generators for Space Application". Presented at AIAA Summer Meeting, June $17-20,1963$.

6. Investigation and Design of an Alte rnate SPUR Turbogenerator, Report No. APL-TDR-64-38, June 30, 1964 (Confidential). Prepared by General Electric Co. for U.S.A. F. Systems Command on Contract A F33(657)-11425. 
7. Research on Spacecraft and Powerplant Integration Problems, Final Report, NASA Lewis Research Center Report, NASA-CR-54159, July, 1964. Prepared by General Electric Co.

8. Advanced Nuclear Electric Power Generator System Study, Rankine Cycle Nuclear Spare Powerplant, Pratt and Whitney Aircraft Co., Report No. PWA-2232, August, 1963.

9. Robinson, R. C., I. Rowe, and L. E. Donelan, "Calculations of Can Losses in Canned Motors," AIEE Transactions, Part III, Power Apparatus and Systems, pp. 312-315, June 1957.

10. W.J. Gibbs, "Tooth Ripple Losses in Unwound Pole Shoes, "IEE Journal, Vol. 94, Part 2, February, 1947

11. Final Report, SNAP-50 Primary Pump Motor Design Study, Contract No. AEC (30-1)2789, Westinghouse Aerospace Electrical Division D-Spec No. D-709635, August 9, 1963.

12. Final Report, Task 2, SNAP-50 Pump Motors Design Study, Contract No. AEC (30-1)2789, Task 2, Westinghouse Aerospace Electrical Division Report No. 63.15, December 10, 1963.

13. Supplement to Final Report, Task 2, SNAP-50 Pump Motors Design Study, Contract No. AEC (30-1)2789, Task 2, Westinghouse Aerospace Electrical Division Report No. 63.15, December 10, 1963.

14. Reference Motor Design, SNAP-50/SPUR Pump Motor Development Program, Pratt \& Whitney Aircraft Division - CANE L Report No. 469, PWAC Contract AT(30-1)2789 prepared by Westinghouse Aerospace Electrical Division under agreement 65-9, September 3, 1965.

15. Summary Report, SNAP -50/SPUR Pump Motor Development Program, Pratt \& Whitney Aircraft Division - CANEL Report No. 470, PWAC Contract AT(30-1)2789, prepared by Westinghouse Aerospace Electrical Division under agreement 65-9, September 3, 1965.

16. Bore Seal Technology Topical Report, NASA Lewis Research Center Report No. NASA-CR-54093, December, 1964. Prepared by Westinghouse Aerospace Electrical Division.

17. T.N. Cetinkale and M.F. Fishendon, "Thermal Conductance of Metal Surfaces in Contact, " International Conference on Heat Transfer, The Institution of Mechanical Engineers, London, 1951. 
18. H. Fenech and W.M. Rohsenow, "Prediction of Thermal Conductance of Metallic Surfaces in Contact, " Journal of Heat Transfer, Transactions of the ASME, Vol. 85, Series C, No. 1, 1963, pp. 15-24.

19. W.J. Graff, "Thermal Conductance Across Metal Joints," Machine Design, Vol. 33, pp. 166-172, September 15, 1960.

20. Doughman, C. L., Jessee, R.D., and Knauer, P., SNAP-50/SPUR Frequency Changer Preliminary Design and Specification, Technical Report AFAPL-TR-65-98, Air Force Aero Propulsion Laboratory, December 15, 1965.

21. Haugen, E., Spender, L. C., et. al., SNAP-50/SPUR Frequency Converter Preliminary Design and Specification, Technical Report AFAPL-TR-65-119, Air Force Aero Propulsion Laboratory, January, 1966.

22. Verkamp, J.P. and Rhudy, R.G., Electromagnetic Alkali Metal Pump Research Program, NASA Report NASA CR 380, National Aeronautics and Space Administration, February, 1966.

23. Garbarino, H. L., "Some Properties of Optimum Power Transformer Design", AIEE Transactions, Volume 73, 1954, pp. 675-682.

24. Westinghouse Astronuclear Laboratory, Engineering Study of Nuclear Power Plant, Lunar Exploration Systems for Apollo, Report WANLPR(S)-009A, Pittsburgh, Pa., October 1, 1964. Contract DA 49-129ENG(NASA)-1A.

25. General Electric Missile and Space Division, Research on Spacecraft and Powerplant Integration Problems, Third and Fourth Quarterly Report, Report 64SD700, Philadelphia, Pa, 26 April 1964. Contract NAS 3-2533.

26. Kircher, J. and Bowman, R.E., Effects of Radiation on Materials and Components, Reinhold Publishing Co., New York, 1964.

27. Lockheed Missiles and Space Co., Space Materials Handbook, Addison-Wesley Publishing Co., Inc., Palo Alto, California, 1965.

28. Drenan, J. F. and Hamman, D. J., Space Radiation Damage to Electronic Components and Materials, Radiation Effects Information Center Report $\$ 39$, Battelle Memorial Institute, Columbus, Ohio, January 31, 1966. 
29. Private Communication from AEC to Westinghouse dated September 15, 1966.

30. Scheffler, P.H., Development of a 50 KVA Model SNAP-50/SPUR Inductor Generator, Technical Report AFAPL-TR-66-26, Air Force Aero Propulsion Laboratory, September 1, 1966.

31. King, A. E., "Screw Type Shaft Seals for Potassium Lubricated Gener ators, "Supplement to IEEE Transactions on Aerospace, Vol. AS-3, No. 2, June, 1965.

32. Dnt,ier, F. X., "Development of Pivoted-Pact Journal Bearings for Potassium Lubricated Space Electric Power Generators, "Supplement to IEEE Transactions on Aerospace, Vol. AS-3, No. 2, June, 1965.

33. R.W. Detra, "The Secondary Flow in Curved Pipes, "Reports of the Aero Inst. of the E. T. H., Zurich, No. 20 (1953)

34. C.M. White, "Fluid Friction and its Relation to Heat Transfer", Trans-Inst. Chem. Engrg., Vol. 10, No. 66 (1932)

35. "Contract for Development and Evaluating Magnetic and Electrical Materials Capable of Operating in the Temperature Range from $800^{\circ} \mathrm{F}$ to $1600^{\circ} \mathrm{F}$." Currently in progress at Westinghouse Aerospace Electrical Division for NASA Lewis Laboratories. Contract No. NAS 3-6465. 


\section{APPENDIX A \\ DERIVATION OF POLE FACE LOSSES}

In reference to the discussions in Section 3.1.1(b), the derivation of eddy current pole face losses in Reference 6 resulted in unusually low losses which lead to the subsequent conclusion that the rotor configuration of the axial gap generator shown is applicable to the SNAP-50/SPUR design requirements. However, the derivation is in error which, when corrected, results in considerably greater losses and marginal cooling configurations. The equation used in Reference 6 is stated as Gibb's $(10)$ and is shown as:

$$
\mathrm{P}_{\mathrm{e}}=\frac{1.57}{10^{3}} \frac{\left(\mathrm{D} \mathrm{B}_{2} \mathrm{~B}_{\mathrm{m}}\right)^{3}}{\mathrm{P} \mathrm{N}_{\mathrm{a}}}\left(\frac{\mathrm{n}}{1000}\right)^{2} \quad \text { watts } / \mathrm{in}^{2}
$$

where $\quad \mathrm{D}=$ diameter, inches $=15.75$ (mean diameter)

$\mathrm{B}_{2}=$ flux oscillation factor $=0.015$ based on an air gap of 0.11 inch, a slot opening of 0.06 inch, a mean slot pitch of 0.344 inch and Figure 3 in Reference 10.

$\mathrm{B}_{\mathrm{m}}=$ average flux density in pole face, kilolines $/ \mathrm{in}^{2}=64$

$\mathbf{P}=$ resistivity, microhm $-\mathrm{cm}=120$

$\mathrm{N}_{\mathrm{a}}=$ number of slots $=144$

$\mathrm{n}=$ rotor speed, $\mathrm{rpm}=24,000$

Substitution of the above parameters into equation (A-1) gives:

$$
\mathrm{P}_{\mathrm{e}}=0.182 \text { watts } / \mathrm{in}^{2}
$$

The area of the poles faces is 78 square inches so the total eddy-current pole face losses are calculated to be 14.2 watts (which is still only an approximation since both equation (A-1) and the total losses should be determined by integrating radially over the pole face surface for axial gap generators). However, close examination of equation (A -1) shows that it is not Gibb's equation; Gibbs' original equation is presented in the form (10)

$$
\begin{aligned}
& \mathrm{P}_{\mathrm{ec}}=5.9 \lambda_{\mathrm{c}} \mathrm{B} 2 \mathrm{BmcnNa} \mathrm{H}_{\mathrm{c}} \times 10^{-10} \text { watts } / \mathrm{cm}^{2} \\
& \text { and } \mathrm{H}_{\mathrm{c}} \sqrt{\rho^{\mu} \mathrm{c}^{\mu}}=1.81 \lambda_{\mathrm{c}} \mathrm{B}_{2} \mathrm{Bm}_{2}\left(\mathrm{n} \mathrm{Na}^{1 / 2} \times 10^{-6}\right.
\end{aligned}
$$


where

$$
\begin{aligned}
\lambda_{\mathrm{c}} & =\text { armature slot pitch }=\pi \mathrm{D}_{\mathrm{c}} / \mathrm{N}_{\mathrm{a}}, \mathrm{cm} \\
\mathrm{B}_{2} & =\text { flux oscillation factor } \\
\mathrm{B}_{\mathrm{mc}} & =\text { average flux density in pole face, gauss } \\
\mathrm{n} & =\text { rotor rpm } \\
\mathrm{N}_{\mathrm{a}} & =\text { number of stator slots } \\
\mathrm{H}_{\mathrm{c}} & =\text { magnetic field strength, oersteds } \\
\rho_{\mathrm{c}} & =\text { resistivity, ohm }-\mathrm{cm} \\
\mu & =\text { permeability, c.g. s. system } \\
\mathrm{D}_{\mathrm{c}} & =\text { diameter at stator slot opening, } \mathrm{cm} .
\end{aligned}
$$

Substituting $\lambda_{c}$ and $\mathrm{H}_{\mathrm{c}}$ into $(\mathrm{A}-3)$ gives

$$
\mathrm{P}_{\mathrm{ec}}=\frac{10.56\left(\mathrm{D}_{\mathrm{c}} \mathrm{B}_{2} \mathrm{~B}_{\mathrm{mc}}\right)^{2}(\mathrm{n})^{3 / 2} \times 10^{-16}}{\sqrt{\mu \rho_{\mathrm{c}} \mathrm{N}_{\mathrm{a}}}} \quad \text { watts } / \mathrm{cm}^{2} \quad(\mathrm{~A}-5)
$$

which, when converted to the following units,

$$
\begin{aligned}
\mathrm{Pe}_{\mathrm{e}} & =\text { watts } / \mathrm{in}^{2} \\
\mathrm{~B}_{\mathrm{m}} & =\text { kilolines } / \mathrm{in}^{2} \\
\mathrm{D} & =\text { inches } \\
\mathrm{P} & =\text { microhm }-\mathrm{cm}
\end{aligned}
$$

gives,

$$
\mathrm{P}_{\mathrm{e}}=\frac{0.334\left(\mathrm{D} \mathrm{B}_{2} \mathrm{~B}_{\mathrm{m}}\right)^{2}}{\sqrt{\mu} \sqrt{\mathrm{PNa}_{\mathrm{a}}}}\left(\frac{\mathrm{n}}{1000}\right)^{3 / 2} \quad \text { watts } / \mathrm{in}^{2}
$$

In order for one to compare equations $(A-1)$ and $(A-6)$, the permeability must be substituted into equation $(A-6)$. Since the value used in $(A-1)$ was not published in Reference 6 , a check was made of the value required to give the same constant $\left(1.57 \times 10^{-3}\right)$ in both equations ignoring the fact that the exponents are in disagreement; it was found to be 45,400. Assuming that this were possible, the resulting equation below should have been used (as Gibbs') instead of the one represented as (A-1).

$$
\mathrm{P}_{\mathrm{e}}=\frac{1.57}{10^{3}} \frac{\left(\mathrm{D} \mathrm{B}_{2} \mathrm{~B}_{\mathrm{m}}\right)^{2}}{\sqrt{\mathrm{P} \mathrm{Na}_{\mathrm{a}}}}\left(\frac{\mathrm{n}}{1000}\right)^{3 / 2} \quad \text { watts } / \mathrm{in}^{2}
$$

or, for the conditions before,

$$
\mathrm{P}_{\mathrm{e}}=0.320 \mathrm{watts} / \mathrm{in}^{2}
$$

instead of 0.182 watts $/ \mathrm{in}^{2}$. 
Pole face loss tests at Westinghouse indicate that, for $\mathrm{H}-11$ steel, the applicable value of permeability is only about 11; using this value in place of the 45,400 gives pole face losses of

$$
\begin{aligned}
P_{e} & =0.320\left(\frac{45,400}{11}\right)^{1 / 2}=20.55 \frac{\text { watts }}{\text { in }^{2}} \\
& =(20.55)(78)=1600 \text { watts }
\end{aligned}
$$

Combining these with the published load loss of 431 watts* gives total pole face losses of approximately 2030 watts, considerably more than the 500 watts used in designing the rotor coolant configuration. Superimposing this loss on the best cooling configuration selected for the rotor $(6)$ results in an average, calculated rotor core temperature of about 810 to $1045^{\circ} \mathrm{F}$, depending on the amount of rotor surface area considered to be radiating heat; the lower temperature considers the entire rotor surface area, the upper temperature only considers the pole tips. Both of these temperatures are well above the maximum safe design temperature of $750^{\circ} \mathrm{F}$ called out in Reference 6 . Of course, there are a number of steps which can be taken to decrease the pole face losses, all of which result in design compromises in other areas of the generator especially if losses must be reduced to one-fourth of their original values.

It should also be pointed out that pole face loss studies at Westinghouse have indicated Gibbs' equations to be in error in their derivation and in their conversion to conventional units. However, the corrected equations give nearly the same results so conclusions drawn as a result of equation (A -9) remain applicable also. An improved method for determining toothripple pole face losses has been developed at Westinghouse and is being published as part of the final reports on the SNAP-50/SPUR studies.

*The accuracy of these losses in Reference 6 were not checked as part of this analysis. 
page blank 


\section{APPENDIX B}

\section{SELECTION AND DESIGN OF RECTIFIER CIRCUITS}

\section{A. Selection of Basic Rectifier Circuit Configuration \\ 1. Design Criteria Affecting Circuit Selection}

Multi-phase, alternating-current sources are usually employed in rectifier circuits where a good voltage waveform is required. The source voltage is usually at a level different from that required by the $d-c$ bus. A transformer is, therefore, necessary for voltage transformation. To select the proper transformer-rectifier configuration for an application, several factors must be considered. These factors, not necessarily listed in order of importance, are:

a. Wave Shape of the Direct Voltage and Current

As the number of transformer secondary phases is increased, the output characteristics of the direct voltage and current approach the ideal straight line. The extent to which this ideal condition is approached is dictated by the load requirements. The undulations of the voltage wave (voltage ripple) in the load circuit may affect the operating characteristics of the load as well as produce interference in communication circuits. Theoretical output ripple voltage is a function of the number of rectifier phases. The minimum value is determined by the fundamental of the ripple voltage frequency and single rectifier conduction in the rectifier commutating groups.

b. Direct Voltage Regulation

A certain voltage regulation curve designed to suit the load conditions is often desirable. The transformer-rectifier assembly has an inherent drooping voltage characteristic. The amount of droop is mainly dependent upon the type of transformer connection and the number of phases. The no-load to full-load voltage regulation characteristic is complicated by conflicting conditions. For minimum regulation, it is desirable to have many phases operating in 
parallel with each phase conducting for a maximum period of time. The method of obtaining low regulation is with a transformer configuration which changes its mode of operation (phase conduction period). Unfortunately, this type of circuit has a no-load voltage rise dependent upon the number of mode changes. A twelve-phase circuit which changes its mode of operation from twelve-phase (30-degree-phase conduction), to six-phase (60-degree-phase conduction), to three-phase (120-degree-phase conduction) as the load current increases has a no-load voltage rise of about 20 percent. Depending on interphase transformer design, the critical load current where desired operation results is 0.5 to 5 percent of the rated load current.

\section{c. Efficiency}

The rectifier voltage drop and losses are influenced by the type of rectifying element and the shape of the anode currents resulting from the different transformer configurations. The influence of the rectifier voltage drop on the overall efficiency of the transfor mer-rectifier is particularly noticeable for low direct voltage outputs; therefore, the choice of the transformation circuit for these systems is particularly important.

\section{d. Transformer Utilization}

The utilization factor is a measure of the degree to which the transformer is capable of utilizing and transforming the energy supplied to it. The size of the transformer (kva rating) varies appreciably with different transformation circuits. As the number of phases increase for equal d-c power output, the utilization factor will, generally, increase. This factor must be weighed against overall electrical performance.

\section{e. Simplicity of Transformer Connections}

In general, it is desirable to have transformer connections as simple as possible. Simple connections give maximum reliability by avoiding insulation and mechanical problem areas. Complexity increases with the number of phases, especially when interphase transformers are used to improve transformer utilization. With increasing phases the actual increase in size and weight may be considerably greater than theoretically expected because of the bulk factor related to complex interconnections and their related insulation systems. It may be simply stated that as the number of phases increase the electrical performance improves at the expense of mechanical complexity. 


\section{f. Power Factor}

The power factor at the primary terminals of the transformer is dependent on the number of phases and transformer configuration. Since the power factor is about 0.95 to 0.98 for typical six-phase and twelve-phase circuits, respectively, power factor is not weighed too heavily unless the rectifier load constitutes a relatively large portion of the total load.

\section{Circuit Evaluation}

Electrical performance requirements immediately restrict the minimum number of rectifier phases to six, and mechanical considerations restrict the maximum number of rectifier-phases to twelve. The characteristics of several transformer-rectifier configurations a re summarized in Table B. 1. All table values are related to the power (P), current (I), and voltage $(E)$ of the load bus. Five assumptions were made to find a common base for analyzing and comparing each of the rectifier circuits of Table B. 1. These assumptions are:

(1) The direct-current wave is assumed to be a straight line.

(2) The rectifier voltage drop is assumed to be constant at all loads.

(3) The rectifier transformer ratio is assumed to be $1: 1$.

(4) The magnetizing current of the transformer is neglected.

(5) The resistance and reactance of the transformer and feeders are neglected.

a. Wye, Six-Phase Fork (Star)

With this circuit, the secondary voltages from transformer neutral to the rectifier anode terminal are displaced from each other by 60 degrees forming six rectifier phases. Each rectifier and branch winding of the transformer secondary carries the full value of the direct current (I) for 60 degress, and each of the star windings carries the current for 120 degrees.

This circuit and the wye, six-phase, delta, double-way (bridge) circuit have an advantage over the others because a no-load voltage rise does not occur. Though the over-all regulation of this circuit may be less, the regulation under load is worse than any 
Table B. 1 Rectifier Circuit Configurations and Characteristics

\begin{tabular}{|c|c|c|c|c|c|c|}
\hline \multicolumn{2}{|c|}{ CIRCUIT NAME (ASA) } & $\begin{array}{l}\text { Wye, 6-phase, } \\
\text { Fork (Star) }\end{array}$ & $\begin{array}{l}\text { Wye, 6-phase, } \\
\text { Delta, Double } \\
\text { Way }\end{array}$ & $\begin{array}{l}\text { Wye, 6-phase, } \\
\text { Double Wye }\end{array}$ & $\begin{array}{l}\text { Wye, 12-phase, } \\
\text { Multiple Delta- } \\
\text { Wye Double Way }\end{array}$ & $\begin{array}{l}\text { Wye-Delta, 12- } \\
\text { phase, Quadruple } \\
\text { Wye }\end{array}$ \\
\hline \multicolumn{2}{|c|}{ NUMBER RECTIFIER PHASES } & 6 & 6 & 6 & 12 & 12 \\
\hline \multicolumn{7}{|c|}{ PHASOR DIAGRAMS } \\
\hline \multirow{4}{*}{$\begin{array}{l}\text { RECTIFIER } \\
\text { CURRENT }\end{array}$} & WAVE FORM & & & 9 & 9 & I \\
\hline & \begin{tabular}{|l} 
PEAK \\
\end{tabular} & $\mathrm{I}$ & I & $0.5 \mathrm{I}$ & 0.51 & $0.25 \mathrm{I}$ \\
\hline & AVERAGE & $0.167 \mathrm{I}$ & 0.3331 & $0.167 \mathrm{I}$ & $0.167 \mathrm{I}$ & $0.083 \mathrm{I}$ \\
\hline & RMS & $0.408 \mathrm{I}$ & $0.577 \mathrm{I}$ & $0.289 \mathrm{I}$ & 0.2891 & $0.144 \mathrm{I}$ \\
\hline \multirow{2}{*}{$\begin{array}{l}\text { D-C } \\
\text { WINDING } \\
\text { CURRENT }\end{array}$} & RMS & $\begin{array}{l}a=0.408 \mathrm{I} \\
b=0.577 \mathrm{I}\end{array}$ & 0.4711 & 0.2891 & $\begin{array}{l}\text { Delta }=0.235 \mathrm{I} \\
\text { Wye }=0.408 \mathrm{I}\end{array}$ & $0.144 \mathrm{I}$ \\
\hline & KVA RATING & $1.79 \mathrm{P}$ & $1.05 \mathrm{P}$ & $1.48 \mathrm{P}$ & $1.05 \mathrm{P}$ & $1.48 \mathrm{P}$ \\
\hline \multirow{3}{*}{$\begin{array}{l}\text { A-C } \\
\text { WINDING } \\
\text { CURRENT }\end{array}$} & WAVE FORM & & 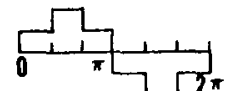 & $-\pi+2^{2 \pi}$ & 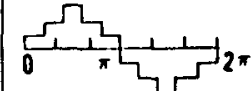 & \\
\hline & $\widehat{\text { RMS }}$ & $0.471 \mathrm{I}$ & $0.816 \mathrm{I}$ & $0.408 \mathrm{I}$ & 0.791 & $\begin{array}{l}\text { Wye }=0.204 \mathrm{I} \\
\text { Delta }=0.118 \mathrm{I}\end{array}$ \\
\hline & KVA RATING & $1.05 \mathrm{P}$ & $1.05 \mathrm{P}$ & $1.05 \mathrm{P}$ & $1.01 \mathrm{P}$ & $1.05 \mathrm{P}$ \\
\hline $\begin{array}{l}\text { THEORETICAL } \\
\text { \% RIPPLE = } \\
\text { AT N. L }\end{array}$ & $\begin{array}{l}\text { RMS } \\
\text { FUNDAMENTAL } \\
\text { AVG. DC }\end{array}$ & 4 & 4 & 4 & 1 & 1 \\
\hline \multicolumn{2}{|c|}{$\begin{array}{l}\text { PEAK INVERSE VOLTAGE } \\
\text { PER RECTIFIER LEG }\end{array}$} & $2.09 \mathrm{E}$ & $1.05 \mathrm{E}$ & $2.42 \mathrm{E}$ & $1.05 \mathrm{E}$ & $2.42 \mathrm{E}$ \\
\hline \multirow{3}{*}{$\begin{array}{l}\text { RECTIFIER } \\
\text { TRANS FORMER }\end{array}$} & NO. REQUIRED & 1 & 1 & 1 & 1 & 2 \\
\hline & $\begin{array}{l}\text { AVG. KVA } \\
\text { RATING } \\
\end{array}$ & $1.42 \mathrm{P}$ & $1.05 \mathrm{P}$ & $1.26 \mathrm{P}$ & $1.03 \mathrm{P}$ & $1.26 \mathrm{P}$ \\
\hline & $\begin{array}{l}\text { COIL } \\
\text { TERMINATIONS }\end{array}$ & 24 & 12 & 18 & 18 & 36 \\
\hline \multirow{2}{*}{$\begin{array}{l}\text { INTERPHASE } \\
\text { TRANS FORMER }\end{array}$} & NO. REQUIRED & 0 & 0 & 1 & 1 & 3 \\
\hline & KVA RATING & 0 & 0 & $0.071 \mathrm{P}$ & $0.013 \mathrm{P}$ & $\begin{array}{l}0.035 P(2 \text { Req'd) } \\
0.013 P(1 \text { Req'd) }\end{array}$ \\
\hline \multicolumn{2}{|l|}{ POWER FACTOR } & 0.855 & 0.855 & 0.055 & 0.988 & 0.988 \\
\hline
\end{tabular}


of the interphase transformer circuits. Disadvantages of this circuit are: (1) greater transformer size and weight; (2) relatively high peak-inverse voltage per rectifier leg; (3) relatively high rectifier loading; (4) increased transformer complexity compared to the other six-phase circuits.

b. Wye, Six-Phase, Delta, Double Way (Bridge)

In this circuit each junction of the transformer secondary winding is connected to the anode of one rectifying element and the cathode of another. The direct current load is connected between the cathodes of three rectifying elements and the anodes of the other three. Each rectifier carries the total value of the direct current (I) for 120 degrees, and each transformer secondary winding conducts current for 180 degrees.

The primary advantage of the double-way circuit is that the current in the transformer secondary windings flows in both directions; thus preventing transformer core saturation.

In addition to not having a no-load voltage rise, the bridge circuit has distinct advantage of minimum rectifier peak inverse voltages for a given direct-voltage output. The number of series rectifying elements required per rectifier leg is, therefore, held to a minimum. The transformer kva rating and therefore its size and weight is also less than any other six-phase circuits. The disadvantage of this circuit is the high rectifier loading.

c. Wye, Six-Phase, Double Wye

In this transformer rectifier circuit, the transformer secondary consists of two three-phase, wye-connected groups whose neutrals are interconnected with an interphase transformer. The secondary windings are so arranged that for each primary winding there is a winding in each secondary group. The secondary windings are displaced from each other by 180 degrees. The interphase transfor mer forces two rectifiers to operate in parallel (one from each secondary group) after the transition point. Each rectifier and secondary winding need carry only one-half of the full value of the direct current (I) for 120 degrees. The principal advantage of this circuit is the improved voltage regulation of the rectifiers and the reduction in amplitude of rectifier current. Except for the double-way bridge, the transformer in this circuit has the highest utilization factor of any six-phase circuit. The disadvantage of this circuit is the high peak inverse voltage per rectifier leg. 
d. Wye, Twelve-Phase, Multiple-Delta-Wye Double Way

This circuit combines two six-phase double-way (bridge) circuits. With one transformer secondary connected in wye and the other connected in delta, a 30 degree phase shift between secondary voltages is thus obtained. The use of an interphase transformer forces the two circuits to operate in parallel with 120 degree rectifier conduction resulting in twelve, rectifier-phase output characteristics. Each rectifier carries one-half of the total value of direct current (I) during the conducting period. As shown by the comparative values given in Table B.1, the overall electrical performance is better than any of the six-phase circuits. A particular advantage of the twelvephase circuit is the reduction of theoretical ripple voltage by a 4 to 1 ratio and generally a reduction in the rectifier loading.

e. Wye-Delta, Twelve-Phase, Quadruple Wye

This circuit combines two six-phase, double-wye circuits. A 30 degree phase shift between the secondary voltages of the two sixphase groups is obtained with two transformers: One transformer primary is connected in wye and the other is connected in delta. The use of an additional interphase transformer (a total of three), forces the two six-phase groups to operate in parallel with each rectifier and transformer secondary carrying current for 120 degrees. Each rectifier carries one-quarter of the total direct current (I) during the conducting period. Although each transformer required for this twelve-phase circuit is the same as for the six-phase double-wye circuit, the actual size and weight is larger because two separate transformers are required.

The quadruple-wye configuration is the most complex circuit of those presented. It requires the greatest number of transformer coil terminations and the greatest number of interphase transformers. With each rectifier carrying one-quarter of the total direct current (I) during their respective conducting periods the reduction in rectifier loading is the only advantage of this circuit.

\section{Conclusion}

The greatest improvement in electric performance of the twelve-phase circuits compared to similar six-phase circuits is reduced anode current per rectifying element. All of the twelve-phase circuits also provide a decrease in theoretical output voltage ripple. The gain in electrical performance of the twelve-phase circuits generally does not justify their use in space applications because: (1) increased circuit complexity; (2) reduced reliability; (3) increased weight and size. The justification for 
not using the comparatively complex twelve-phase circuits with attendant weight and size penalties is even more important in high temperature applications where problems of conductor joining and insulation requirements are greatly increased.

\section{B. Additional Design Considerations}

\section{Methods of Increasing Rectifier Rating}

Because the individual diode ratings are not compatible with system requirements, diodes must be connected in series and/or in parallel. The effect and limitations of these two arrangements are:

\section{a. Diodes in Series}

The use of diodes in some high-voltage, power-rectifier applications requires the use of rectifier elements (diodes) in series to form the equivalent of a single diode. The equivalent diode may then be used in any of the conventional converter circuits. To obtain the voltage capability to withstand the peak inverse voltage (PIV) of a system it is necessary to provide a positive means of uniform voltage distribution across the individual diodes. One approach is to match the reverse characteristics of each diode. Diodes, which have their reverse characteristics matched, have successfully operated in series without forced voltage balancing. Because the recovery time differs from diode to diode; there is some question, however, as to the transient-voltage division during load switching.

Another approach to forced voltage division is to shunt each diode with a capacitor and resistor network. This network compensates for the unmatched parameters which would otherwise destroy the rectifier assembly. The value of the resistors combined with the capacitive reactance of the shunting capacitors provide a shunting impedance to insure uniform voltage division under both steadystate and transient voltage conditions. The capacitors, which are primarily designed to off-set the effect of the distributed capacitance in the system, offer the additional effect of reducing uneven voltage distribution resulting from the differences in diode recovery time. Because diodes can withstand greater unbalance than capacitors, the steady-state voltage division across the capacitor must be controlled within closer limits for greatest reliability. The shunting resistors. used to force uniform voltage division across the basic diode of a rectifier assembly, also serves to keep uniform 
voltage across the shunting capacitors. Maintaining the peak recurrent voltage across the capacitors within a specified percentage of the capacitors d-c working voltage provides long capacitor life preventing catastrophic system failure.

b. Diodes in Parallel

To provide the required current capacity in some high power rectifier systems it is necessary to parallel diodes. The low regulation characteristics of rectifying elements require a positive means of current distribution to prevent overloading individual diodes. Proper current division can be obtained by matching the forward diode characteristics, by the addition of series resistance or reactance, by the use of balancing transformers, or by separate transformer windings. 